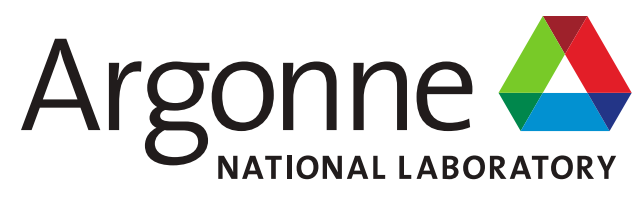

ANL/RTR/TM-21/3

\title{
MITR DDE End Fitting Structural Rigidity Analysis
}

Nuclear Science \& Engineering Division 


\title{
About Argonne National Laboratory
}

Argonne is a U.S. Department of Energy laboratory managed by UChicago Argonne, LLC under contract DE-AC02-06CH11357. The Laboratory's main facility is outside Chicago, at 9700 South Cass Avenue, Lemont, Illinois 60439. For information about Argonne and its pioneering science and technology programs, see www.anl.gov.

\section{DOCUMENT AVAILABILITY}

Online Access: U.S. Department of Energy (DOE) reports produced after 1991 and a growing number of pre-1991 documents are available free at OSTI.GOV (http://www.osti.gov/), a service of the U.S. Dept. of Energy's Office of Scientific and Technical Information.

\author{
Reports not in digital format may be purchased by the public from the \\ National Technical Information Service (NTIS): \\ U.S. Department of Commerce \\ National Technical Information Service \\ 5301 Shawnee Rd \\ Alexandria, VA 22312 \\ www.ntis.gov \\ Phone: (800) 553-NTIS (6847) or (703) \\ 605-6000 Fax: (703) 605-6900 \\ Email: orders@ntis.gov
}

\section{Reports not in digital format are available to DOE and DOE contractors from the Office of Scientific and Technical Information (OSTI):}

U.S. Department of Energy

Office of Scientific and Technical Information

P.O. Box 62

Oak Ridge, TN 37831-0062

www.osti.gov

Phone: (865) 576-8401

Fax: (865) 576-5728

Email: reports@osti.gov

Disclaimer

\section{Disclaimer}

This report was prepared as an account of work sponsored by an agency of the United States Government. Neither the United States Government nor any agency thereof, nor UChicago Argonne, LLC, nor any of their employees or officers, makes any warranty, express or implied, or assumes any legal liability or responsibility for the accuracy, completeness, or usefulness of any information, apparatus, product, or process disclosed, or represents that its use would not infringe privately owned rights. Reference herein to any specific commercial product, process, or service by trade name, trademark, manufacturer, or otherwise, does not necessarily constitute or imply its endorsement, recommendation, or favoring by the United States Government or any agency thereof. The views and opinions of document authors expressed herein do not necessarily state or reflect those of the United States Government or any agency thereof, Argonne National Laboratory, or UChicago Argonne, LLC. 
ANL/RTR/TM-21/3

\section{MITR DDE End Fitting Structural Rigidity Analysis}

prepared by

Cezary Bojanowski, David Jaluvka, and Erik Wilson

Nuclear Science \& Engineering Division, Argonne National Laboratory

October 2021 
(This page left intentionally blank) 


\section{Executive Summary}

As a part of the design of the MITR Design Demonstration Element (DDE), a new design for the end fittings must be considered to meet specific experiment needs, e.g., compatibility with the geometrical restrictions of the DDE testing location (BR2 test reactor located in Mol, Belgium), and to allow for proper inspection of these test elements during the experiments. The design of the MITR DDE end fittings is substantially different from the design of the end fittings of the MITR LEU fuel elements, with the DDE end fittings considerably smaller in overall size and weight. Consequently, the stiffness of the end fittings as well as of the entire fuel element is affected.

The end fittings in the MITR LEU fuel element are designed primarily for proper handling and flow distribution. The stiffness of the end fittings also constitutes a fraction of the total stiffness of the entire fuel element. It is debatable to what extent the end fittings provide the structural rigidity necessary for the fuel element to properly respond to potential loadings. It is presumed that the bulk of the overall stiffness of the element is derived from swaging multiple fuel plates into the side plates. However, the contribution of stiffness from various components of the MITR LEU fuel element and MITR DDE has not been determined so far.

The primary objective of the work presented in this report was to assess the extent to which the stiffness of the end fitting in the MITR DDE contributes to the stiffness of the entire fuel element, and how it compares to the equivalent stiffness of the end fitting in the MITR LEU fuel element. Several simplified load cases were analyzed for that purpose using the geometries of the MITR LEU fuel element, MITR DDE, as well as that of the MITR DDE without the top end fitting.

The numerical analysis, performed with COMSOL Multiphysics 5.3a commercial software, has shown that for distributed loads (thermal, surface, and line), most of the stiffness of both the MITR DDE and the MITR LEU element comes from the fuel plates swaged into the side plates. Although the MITR DDE end fitting has a significantly reduced mass and stiffness (because of the reduced volume and the removal of the handling cross bar) as compared to the MITR LEU element end fitting, this change in the design does not manifest in a significant loss of the stiffness of the entire element.

However, for point loads applied near the end fittings, the contribution of the end fitting's stiffness is larger than for the other analyzed types of loads. Under the selected lateral point load, equivalent to the weight of the MITR LEU element, the end fitting stiffness made the largest contribution to the stiffness of the entire fuel element. This load caused the maximum total displacements of 1.64 mil ( 1 mil $=0.001 \mathrm{inch}$ ), $1.26 \mathrm{mil}$, and $0.76 \mathrm{mil}$ in the elements without the top end fitting, with the MITR DDE end fittings, and with the MITR LEU end fittings, respectively. Thus, the MITR DDE end fitting reduced the maximum total displacements by $23 \%$, and the MITR LEU end fitting reduced them by $54 \%$, as compared to the element without the top end fitting. Nonetheless, these deflections remained very small in all cases for the range of the loads considered in this work.

The selected lateral line load applied along the length of the side plates, equivalent to 25 times the weight of the MITR LEU element, caused maximum total displacements of 8.65 mil, 7.70 mil, and 6.22 mil in the elements without the top end fitting, with the MITR DDE end fittings, and with the MITR LEU end fittings, respectively. Thus, the MITR DDE end fitting reduced the maximum total displacements by $11 \%$ and the MITR LEU end fitting reduced it by $28 \%$ as compared to the element without the top end fitting. 
The assumed surface load on the outermost fuel plate representing the hydraulic load due to the pressure differential resulting from channel gap thickness disparity caused the maximum total displacement of $2.45 \mathrm{mil}, 2.37 \mathrm{mil}$, and $2.23 \mathrm{mil}$ in the elements without the top end fitting, with the MITR DDE end fittings, and with the MITR LEU end fittings, respectively. Thus, the MITR DDE end fitting reduced the maximum total displacements by 3.1\%, and the MITR LEU end fitting reduced it by $8.8 \%$ as compared to the element without the top end fitting.

Thermal expansion based on the temperature field from the first element of the first cycle of the transition MITR LEU core has been analyzed for all geometries. Under this realistic thermal load, the maximum dimensional changes for all the models were predicted to be very similar. They were calculated at $4.76 \mathrm{mil}, 4.69 \mathrm{mil}$, and $4.65 \mathrm{mil}$ in the element without the top end fitting, with the MITR DDE end fittings, and with the MITR LEU end fittings, respectively.

The dimensional change of around 5.0 mil reduces the overall 42 mil gap around the MITR DDE end fitting in the irradiation basket by $11.9 \%$. However, this is not the total deformation expected in the element. Additional deformation due to irradiation effects must be estimated, but this is beyond the scope of the work presented in this report. Moreover, deformation of the basket due to thermal or irradiation effects was not considered.

In summary, it can be stated that the structural performance of MITR DDE end fittings is not substantially different from the MITR LEU end fittings and is adequate for the DDE irradiation experiment. 


\section{Table of Contents}

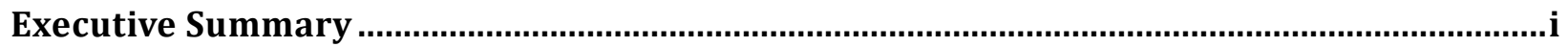

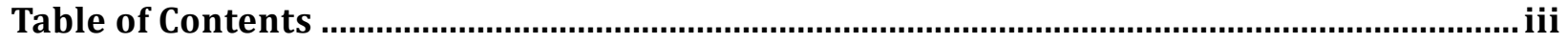

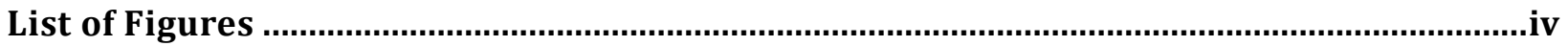

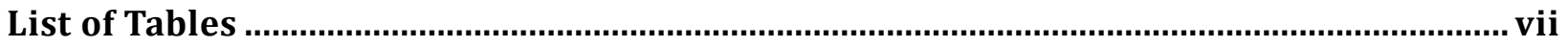

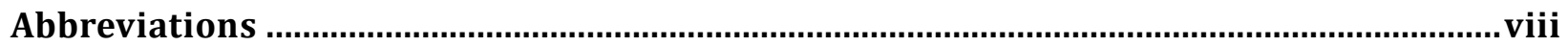

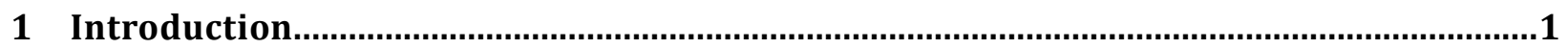

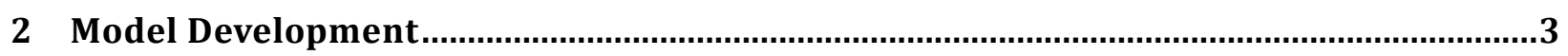

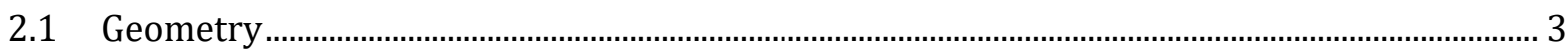

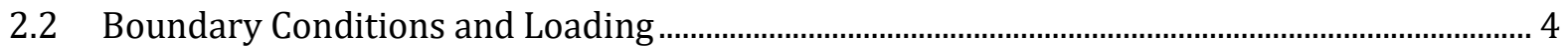

2.2.1 Lateral Point Load Only on End Fitting........................................................................................ 5

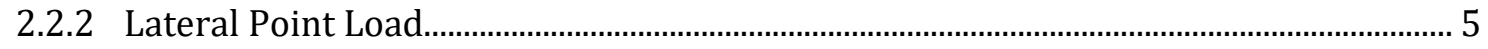

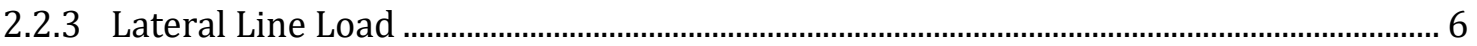

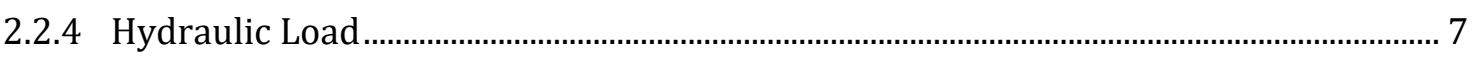

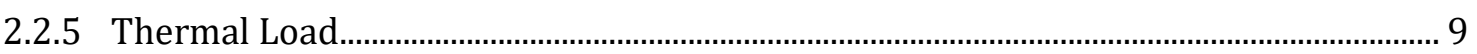

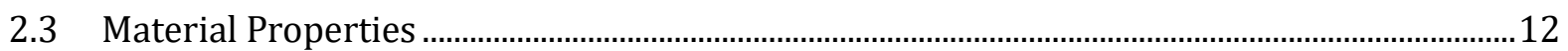

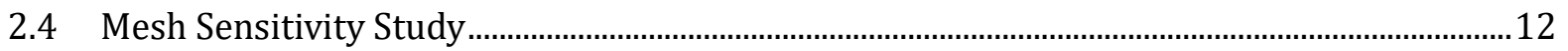

2.4.1 Number of Elements in the End Fitting …..........................................................................17

2.4.2 Number of Elements through the Thickness of the Plate.................................................17

2.4.3 Number of Elements through the Width of the Plate.........................................................20

2.4.4 Number of Elements through the Length of the Plate (Axial Direction) ......................21

2.4.5 Stresses in the Models...........................................................................................................21

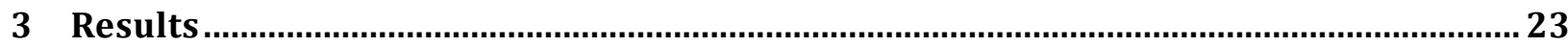

3.1 Lateral Point Load on End Fitting Only …..........................................................................................

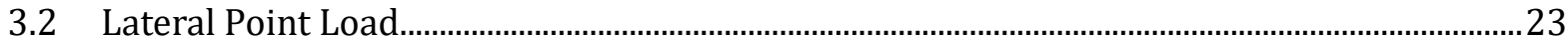

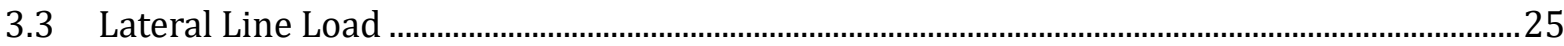

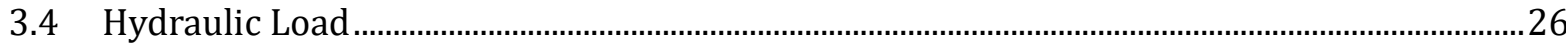

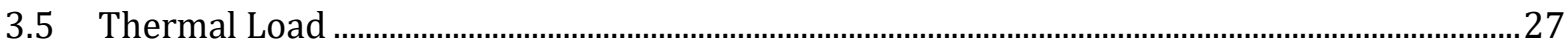

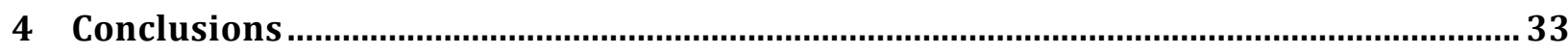

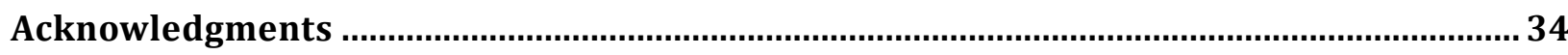

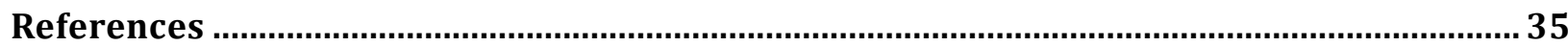

APPENDIX A: MITR LEU without top end fitting versus MITR DDE without top end fitting..

.

APPENDIX B: Average Temperature Distribution in the Plates of MITR LEU Transition Core

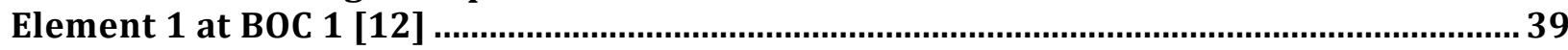

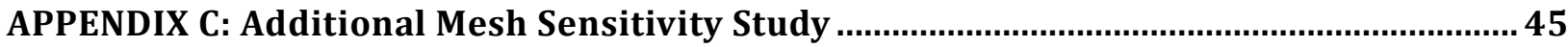




\section{List of Figures}

Figure 2.1. Details of end fittings: MITR LEU (left), MITR DDE (right).

Figure 2.2. Geometries of the models: with MITR LEU end fittings (left), with DDE end fittings (center), and with DDE bottom end fitting and no top end fitting (right).

Figure 2.3. Boundary conditions and the direction of load in the models with end fittings only: DDE (left), MITR LEU (right).

Figure 2.4. Boundary conditions (left) and the direction of point load in the models of three fuel elements: with no top end fitting (top right), with DDE end fitting (center right), and with MITR LEU

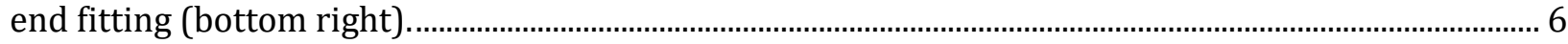

Figure 2.5. Area of load application for the "point load" case....................................................................... 6

Figure 2.6. Boundary conditions and the direction of line load in the models of three fuel elements: (left to right) with no top end fitting, with MITR DDE end fitting, and with MITR LEU end fitting, load application area on the opposite side of the constrained edge. 7

Figure 2.7 Pressure differential acting on the plate as a function of axial distance from its trailing edge for hydraulic load case analysis. 8

Figure 2.8. Boundary conditions in the cases with hydraulic load (top) MITR DDE (bottom) MITR LEU fuel element. . 8

Figure 2.9. Striping (discretization) in the thermal hydraulics models for MITR fuel elements........... 9

Figure 2.10. Temperature distribution in the MITR DDE at Cycle 1 BOC (left). Detail of the top end (right top) and bottom end (right bottom).

Figure 2.11. Boundary conditions in the cases with thermal load (top) MITR DDE (bottom) MITR LEU fuel element. .

Figure 2.12. Mesh in the DDE end fitting. From the top left: (a) coarser, (b) coarse, (c) normal, (d) fine, and (e) finer mesh densities.

Figure 2.13. Mesh in the MITR LEU end fitting. From the top left: (a) coarser, (b) coarse, (c) normal, (c) fine, and (d) finer mesh densities.

Figure 2.14. Mesh in the side and fuel plates. From the top left: (a) coarser, (b) coarse, (c) normal, and (d) fine mesh densities.

Figure 2.15. Assembly of the DDE end fitting with the side plates. .15

Figure 2.16. Assembly of the MITR LEU end fitting with the side plates. 16

Figure 2.17. Dependency of maximum displacements on number of DOFs in the model for point load cases with end fitting only: MITR DDE (left) and MITR LEU (right).

Figure 2.18. Mesh sensitivity study of the MITR LEU element, MITR DDE, and MITR DDE without top end fitting for the point load cases. 19

Figure 2.19. Mesh sensitivity study of the MITR DDE for the point load case............................................20

Figure 2.20. Mesh sensitivity study of the MITR DDE for the line load case..............................................21

Figure 2.21. Typical locations of the stress divergence (singularity) areas in the FE models...............22

Figure 2.22. Location of plate edge for von Mises stress comparison. ........................................................22

Figure 2.23. Von Mises stress along the top edge of the fuel plate in the line load case for the MITR DDE model... 
Figure 3.1. Total displacement in the end fittings under the point load: MITR DDE (left) and MITR LEU (right) (displacement scaling factor of 50 used for visualization purposes).

Figure 3.2. Total displacement under a point load of $79.0 \mathrm{~N}$ in the model without top end fitting; (left) top view (right) perspective view (displacement scaling factor of 100 used for visualization purposes).

Figure 3.3. Total displacement under a point load of $79.0 \mathrm{~N}$ in the model with MITR DDE end fitting (left) top view (right) perspective view (displacement scaling factor of 100 used for visualization purposes).

Figure 3.4. Total displacement under a point load of $79.0 \mathrm{~N}$ in the model with MITR LEU end fitting (left) top view (right) perspective view (displacement scaling factor of 100 used for visualization purposes)...

Figure 3.5. Total displacement under a line load of 2,000 $\mathrm{N}$ in the model with MITR DDE end fitting on the bottom (left) top view (right) perspective view (displacement scaling factor of 25 used for visualization purposes)...

Figure 3.6. Total displacement under a line load of 2,000 $\mathrm{N}$ in the model with MITR DDE end fittings (left) top view (right) perspective view (displacement scaling factor of 25 used for visualization purposes)...

Figure 3.7. Total displacement under a line load of 2,000 $\mathrm{N}$ in the model with MITR LEU end fittings (left) top view (right) perspective view (displacement scaling factor of 25 used for visualization purposes). .26

Figure 3.8. Total displacement under a surface load in the model without top end fitting (left) top view (right) perspective view (displacement scaling factor of 100 used for visualization purposes).

Figure 3.9. Total displacement under a surface load in the model with MITR DDE end fitting (left) top view (right) perspective view (displacement scaling factor of 100 used for visualization purposes).

Figure 3.10. Total displacement under a surface load in the model with MITR LEU end fitting (left) top view (right) perspective view (displacement scaling factor of 100 used for visualization purposes).

Figure 3.11. Measurement locations for thermal expansion at the top of the side plate.

Figure 3.12. $\mathrm{X}$ displacement field due to thermal load in MITR DDE without the top end fitting (displacement scaling factor of 50 used for visualization purposes). . .28

Figure 3.13. $\mathrm{X}$ displacement field at the top of the side plates due to thermal load in MITR DDE without the top end fitting.

Figure 3.14. X displacement field due to thermal load in MITR DDE (displacement scaling factor of 50

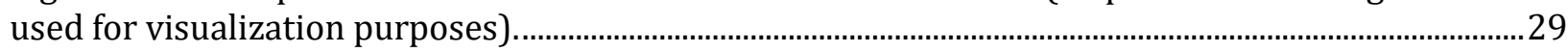

Figure 3.15. X displacement field at the top of the side plates due to thermal load in MITR DDE. ....29

Figure 3.16. X displacement field due to thermal load in MITR LEU fuel element (displacement scaling factor of 50 used for visualization purposes).

Figure 3.17. X component of displacement field at the top of the side plates due to thermal load in MITR LEU element.

Figure 3.18. Measurement locations for dimensional change caused by the thermal load at the top of the end fittings (left) MITR DDE (right) MITR LEU fuel element. 
Figure 3.19. X component of displacement field due to thermal load in MITR DDE (displacement scaling factor of 50 used for visualization purposes).

Figure 3.20. X component of displacement field at the level of the end fitting due to thermal load in MITR DDE.

Figure 3.21. X component of displacement field due to thermal load in MITR LEU fuel element (displacement scaling factor of 50 used for visualization purposes).

Figure 3.22. X component of displacement field at the level of the end fitting due to thermal load in MITR LEU fuel element. 


\section{List of Tables}

Table 2.1. Average bulk coolant temperature distribution (for stripes 1 and 4) in Cycle 1 BOC for MITR

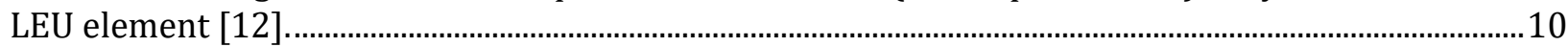

Table 2.2. Temperature distribution in plate 15 of Cycle 1 BOC for MITR LEU element [12]..............10

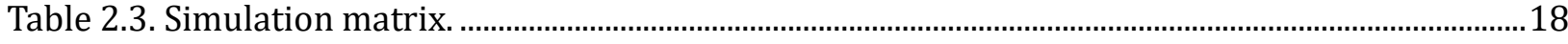

Table 2.4. Element and DOF count in the models.................................................................................................18 


\section{Abbreviations}

$\begin{array}{ll}\text { BOC } & \text { beginning of cycle } \\ \text { CFD } & \begin{array}{l}\text { computational fluid dynamics } \\ \text { CSM }\end{array} \\ \text { DDE } & \begin{array}{l}\text { design demonstration element } \\ \text { degree of freedom }\end{array} \\ \text { DOF } & \text { finite element } \\ \text { FE } & \text { finite element analysis } \\ \text { FEA } & \text { fuel fabrication } \\ \text { FF } & \text { fuel qualification } \\ \text { FQ } & \text { fluid-structure interaction } \\ \text { FSI } & \text { highly enriched uranium with } \geq 20 \text { wt } \% \text { enrichment } \\ \text { HEU } & \text { low-enriched uranium with < 20 wt } \% \text { enrichment } \\ \text { LEU } & \text { NNSA Office of Material Management and Minimization } \\ \text { M } & \text { Massachusetts Institute of Technology Reactor } \\ \text { MITR } & \text { U.S. National Nuclear Security Administration } \\ \text { NNSA } & \text { thermal hydraulics } \\ \text { TH } & \text { uranium-10 wt } \% \text { molybdenum } \\ \text { U-10Mo } & \text { U.S. high-Performance research reactor } \\ \text { USHPRR } & \end{array}$




\section{Introduction}

As part of the U.S. National Nuclear Security Administration's (NNSA's) mission to eliminate or minimize the civilian use of weapon-grade highly enriched uranium (HEU) fuels, the NNSA Office of Material Management and Minimization ( $\mathrm{M}^{3}$ ) Conversion Program is collaborating with six U.S. high-performance research reactors (USHPRR), including one critical facility, to convert from the use of HEU to low-enriched uranium (LEU) fuel. The $\mathrm{M}^{3}$ conversion objectives for the USHPRR are to develop LEU fuel element designs that will ensure safe reactor operations, as well as maintain the existing experimental performance of each facility. The work is being conducted through many interrelated activities that are being completed by stakeholders across multiple organizations.

Four of the USHPRR, including the Massachusetts Institute of Technology Reactor (MITR-II, also referred to as MITR), have progressed through preliminary element design using the proposed monolithic alloy of uranium-10 wt $\%$ molybdenum (U-10Mo). The U-10Mo monolithic plate design consists of U-10Mo fuel core sandwiched between $\mathrm{Zr}$ diffusion barriers and encapsulated in Al-based AA6061 cladding.

The efforts toward converting the MIT Research Reactor (MITR) from highly enriched uranium (HEU) to low-enriched uranium (LEU) are ongoing. On the reactor side, the preliminary Safety Analysis Report (SAR) was initially submitted to the U.S. Nuclear Regulatory Commission in December 2017, and a revision was submitted and accepted for review in October 2018 [1]. On the LEU U-10Mo fuel qualification side, mini-plate and large-plate irradiations have been successfully performed, and more experiments are either ongoing or planned. One essential experimental campaign focuses on a full prototypic MITR element serving as the Design Demonstration Element (DDE) will be irradiated in the BR2 test reactor in Belgium.

As a part of the design of the MITR DDE, a new design for the end fittings must be considered to meet specific experiment needs, e.g., compatibility with the geometrical restrictions of the DDE testing locations (BR2 located in Mol, Belgium), and to allow for proper inspection of these test elements during the experiments. The design of the MITR DDE end fittings is substantially different from that of the end fittings in the LEU fuel elements, with the DDE end fittings considerably smaller in overall size and weight. Consequently, the stiffness of the end fittings as well as of the entire element is affected.

The end fittings in the MITR LEU fuel element are designed primarily for proper handling and flow distribution. The stiffness of the end fittings also constitutes a fraction of the total stiffness of the entire fuel element. It is debatable to what extent the end fittings provide the structural rigidity necessary for the element to properly respond to potential loadings. It is presumed that the bulk of the overall stiffness of the element is derived from swaging multiple plates into an element. However, the distribution of stiffness within different components of the MITR DDE has not been characterized.

The primary objective of this work is to assess the extent to which the stiffness of the end fitting in the MITR DDE contributes to the stiffness of the entire element, and how it compares to the equivalent stiffness of the end fitting in the MITR LEU element.

It is expected that the primary sources of structural loads on the fuel elements will come from the following: 
- Irradiation and thermal effects (expansion caused by swelling of plates or uneven temperature distribution);

- Fluid-structure interaction (FSI) effects (pressure differential between components of the element as well as vibrations or motion of the element in the flow loop or reactor core); and - Handling accidents (i.e., dropping of the elements).

Proper characterization of the above-listed loadings and the deformations they cause would require a significant effort in the form of complex multiphysics analyses or experimental testing. However, to assess the relative stiffness between the MITR LEU and MITR DDE, a simplified approach can be taken by assuming small deformations and linear elastic properties of the materials. The consequence of these assumptions is the proportionality of the deformations to the magnitude of the load. That is, doubling the load causes doubling of the deflection. Additionally, the stiffness of the element is inversely proportional to the magnitude of the deflection. Also, the magnitude of the load is not essential for assessing the relative stiffness of two structures. Identical loads can be applied to the components of the MITR LEU fuel element, the MITR DDE, and the MITR DDE with no top end fitting. The comparison of deflections reported for these elements can be used to estimate the differences in the stiffness and hence, the consequences of replacing the MITR LEU end fitting with the MITR DDE end fitting. In this work, simplified cases of structural and thermal loads will be analyzed. 


\section{Model Development}

\subsection{Geometry}

Three Finite Element models have been initially developed in COMSOL Multiphysics 5.3a software [2] for this comparative study to represent MITR LEU fuel element, MITR DDE, as well as MITR DDE without the top end fitting. The geometry of the MITR LEU fuel element and MITR DDE is identical in the plated region. Their common parts, the side plates and the fuel plates, have been created using the technical drawings of the fuel plates [3], [4], [5], side plate [6], and the assembly drawings [7]. The geometry of the MITR LEU end fitting was developed previously, with the design drawings shown in [8], [9]. The current 3D model of the DDE end fitting is based on the most recent design drawings [10]. Figure 2.1 shows close-up views of the end fitting 3D models. Figure 2.2 presents perspective views of all three models used in this study: MITR LEU fuel element, MITR DDE, and MITR DDE without the top end fitting. The bottom end fitting in that last model was retained to allow for application of equivalent boundary conditions among the models.

Additional simulations for MITR LEU fuel element without the top end fitting have been performed for converged meshes. The results from that case were compared to the results from the simulations with the MITR DDE model without the top end fitting and are listed in APPENDIX A. For all but the case with the line load, the differences in the predicted maximum displacement were below $1 \%$. For the case with the line load, the difference in the maximum deflection was about $8 \%$. Thus, it is reasonable to present the results from one of these two cases without the top end fitting.
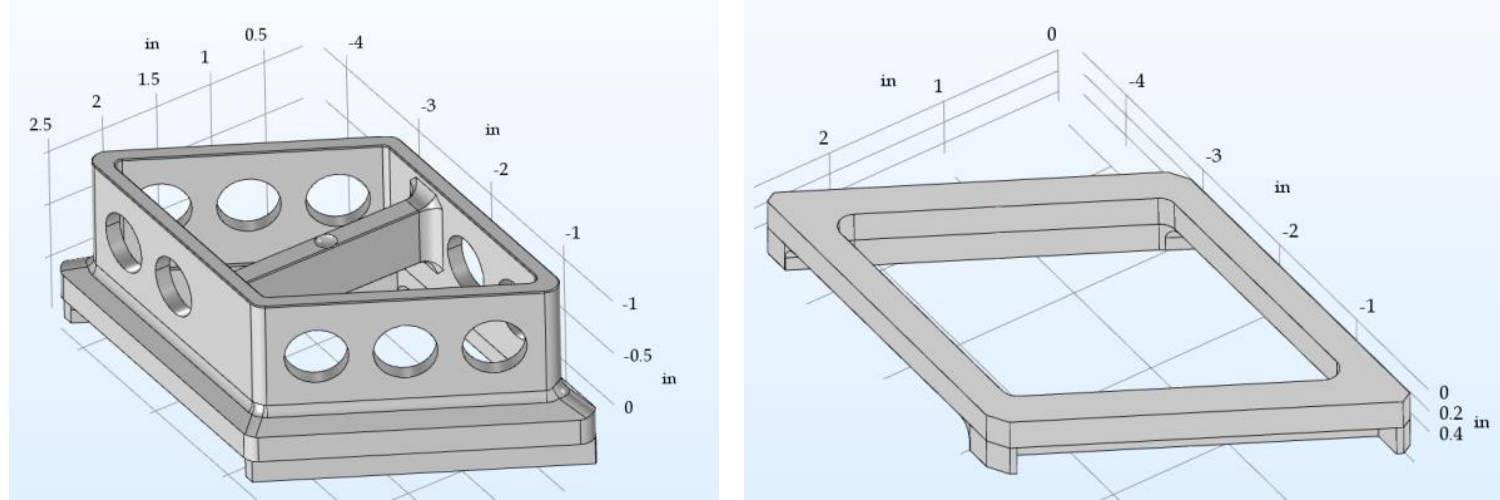

Figure 2.1. Details of end fittings: MITR LEU (left), MITR DDE (right). 
in

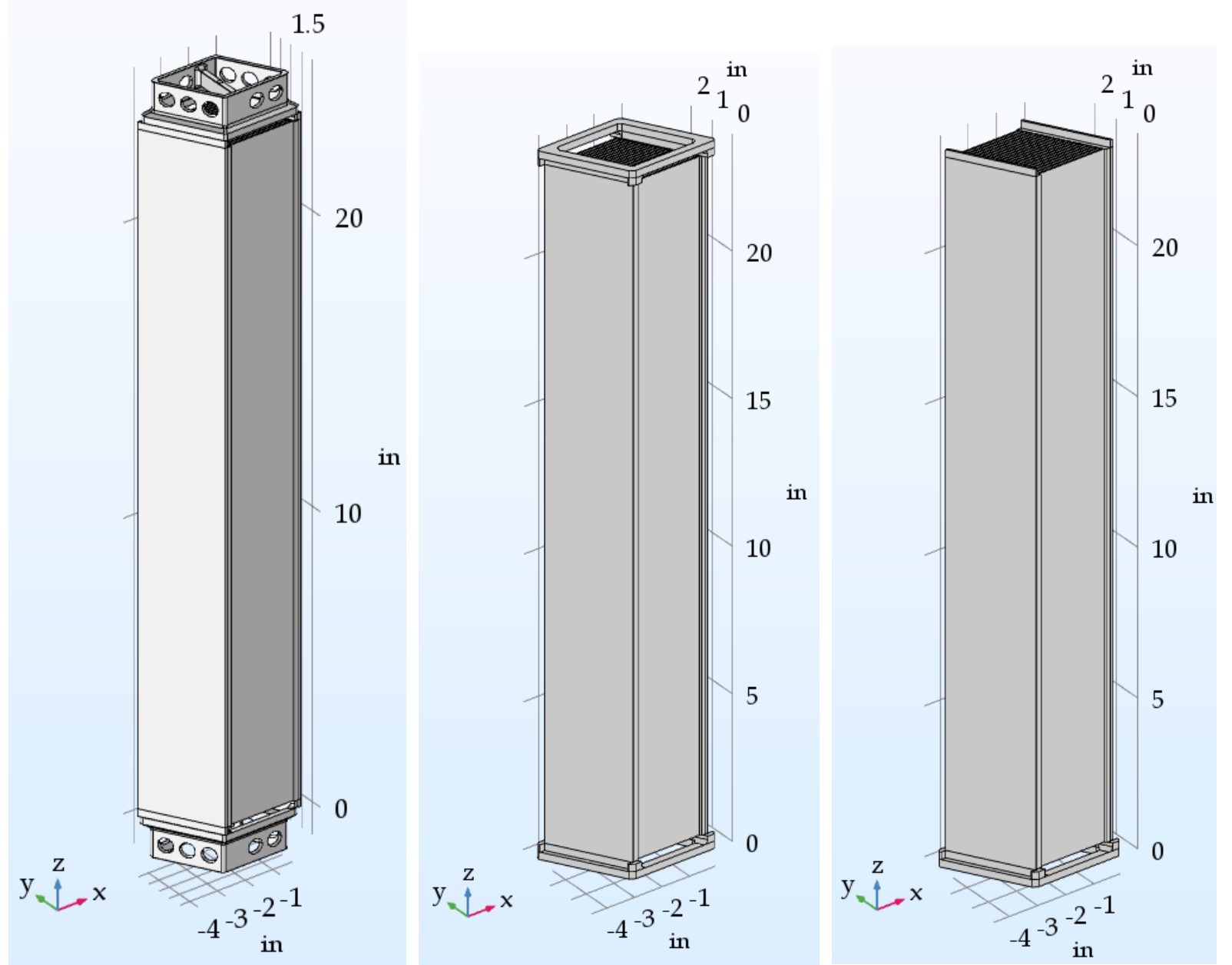

Figure 2.2. Geometries of the models: with MITR LEU end fittings (left), with DDE end fittings (center), and with DDE bottom end fitting and no top end fitting (right).

\subsection{Boundary Conditions and Loading}

Five different loading sets with specific boundary conditions were considered in this study:

1. Lateral point load only on the top end fitting,

2. Lateral point load on the element,

3. Lateral line load on the side of the element,

4. Hydraulic load on a single plate, and

5. Thermal load on the entire element.

Since the loads resulting from the hydraulic loads and the motion of the elements in the basket are not needed for the estimation of the relative stiffness of the elements, the magnitudes of the mechanical point load and line load are not based on the magnitudes of these hydraulic loads. Instead, they were compared to the weight of the MITR LEU elements to provide a reference.

The MITR LEU fuel element and the MITR DDE are not fully constrained in the MITR reactor and irradiation basket, respectively. Instead, the elements can move within the small gaps around them in their respective locations. Thus, the true boundary conditions are applied to contact points or surfaces and may change in time due to the motion of the elements. For these reasons, the selected 
boundary conditions used in the simulations are meant to prevent the models from rigid body motions and facilitate the comparison of the relative stiffnesses of the elements under specific load types.

\subsubsection{Lateral Point Load Only on End Fitting}

This set of simulations was run to develop meshes for the end fittings, which were subsequently used in the models of the full elements. In the simulations, one corner of the end fitting was constrained at a small patch, marked in Figure 2.3 with yellow color. On the opposite side of the end fitting, a load of $79.0 \mathrm{~N}$ was applied along the shorter diagonal to an equally small area. This load is equivalent to the weight of the entire MITR LEU element. For the MITR LEU end fitting (Figure 2.3, right), this load direction meets a large resistance because of the presence of the handling bar. Other load directions were tested as well. However, the direction selected for the current study exposes the influence of the largest difference between the two designs of the end fittings, which is the cross bar present in the design of the MITR LEU end fitting.

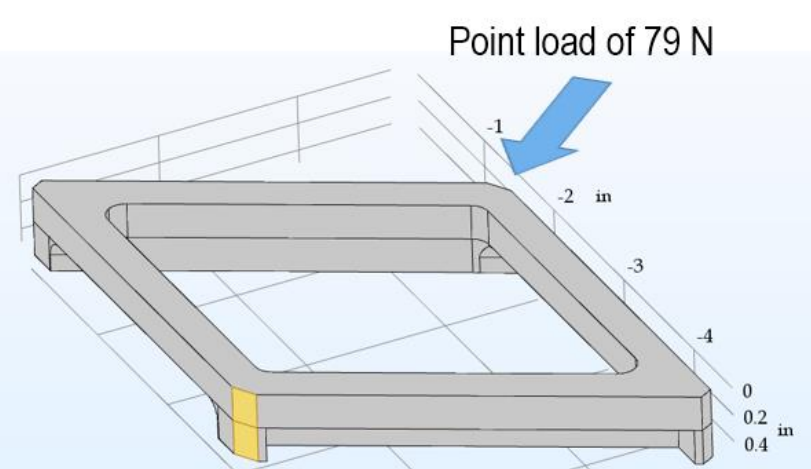

Fixed BC

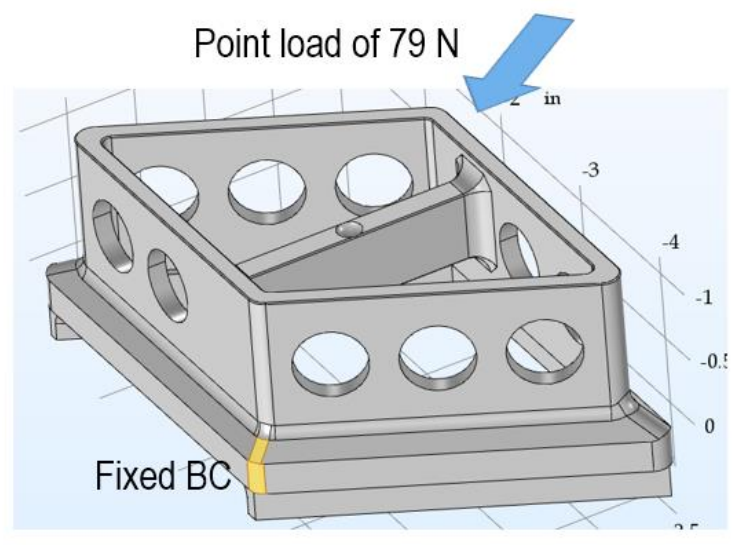

Figure 2.3. Boundary conditions and the direction of load in the models with end fittings only: DDE (left), MITR LEU (right).

\subsubsection{Lateral Point Load}

In the first case of the full element analysis, a point load of $79.0 \mathrm{~N}$ was applied, as in the previous case analyzed for the end fittings only. The direction of the load also matched the one from the previous case with load acting along the shorter diagonal of the element. In this case, for all three elements, i.e., MITR LEU, DDE, and DDE without the top end fitting, the edge on the opposite side from the load was constrained. Figure 2.4 shows the entire DDE and the constrained narrow area marked with yellow color. On the right, close-up views for all three elements are shown. Each of the elements had the same constrained area. Also, the load of $79.0 \mathrm{~N}$ was applied to the same small area for all three models. To avoid singularities in the model caused by the application of forces to a vertex, the load was applied to a finite small patch, marked with purple color in Figure 2.5. 


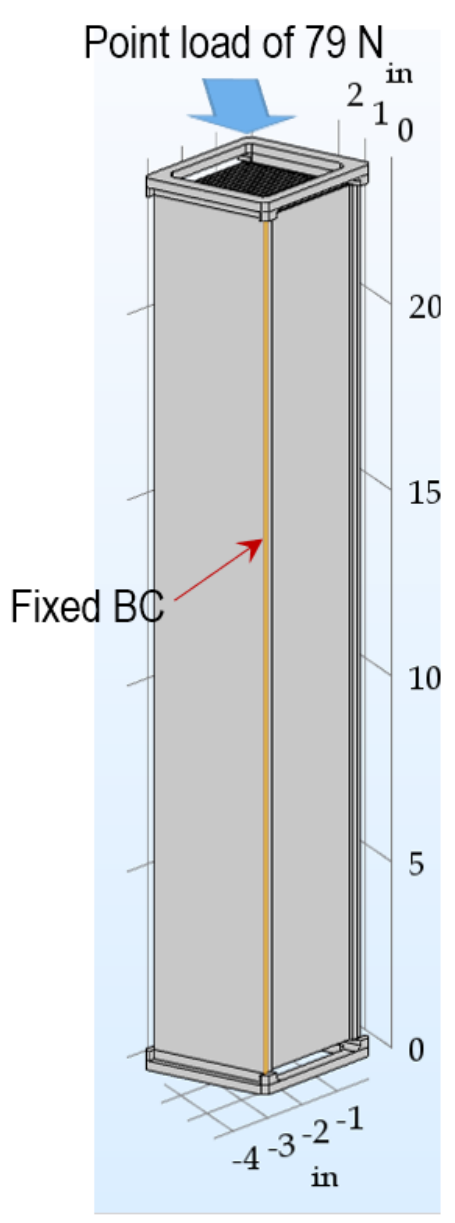

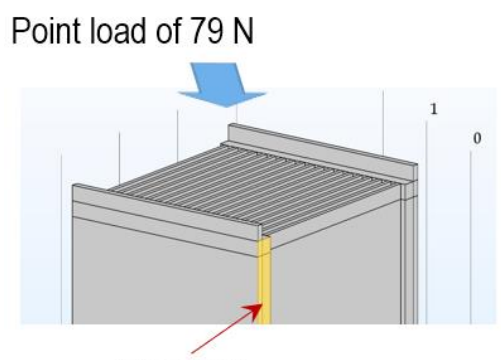

Fixed BC

Point load of $79 \mathrm{~N}$

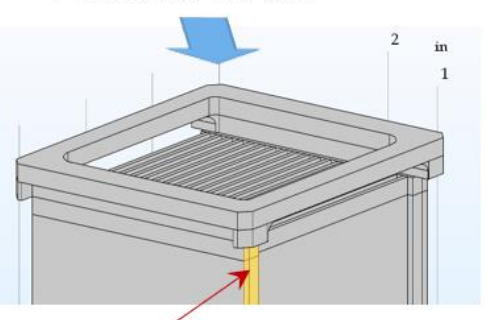

Fixed BC

Point load of $79 \mathrm{~N}$

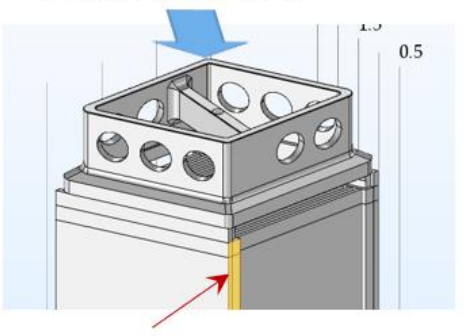

Fixed BC

Figure 2.4. Boundary conditions (left) and the direction of point load in the models of three fuel elements: with no top end fitting (top right), with DDE end fitting (center right), and with MITR LEU end fitting (bottom right).

Area of load

application

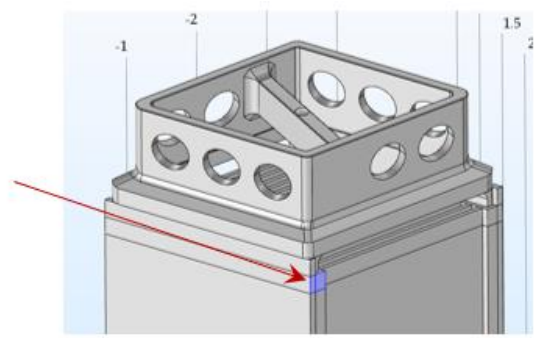

Figure 2.5. Area of load application for the "point load" case.

\subsubsection{Lateral Line Load}

In the second case of the full-element analysis, a line load of 2,000 $\mathrm{N}$ was applied to a narrow surface on the opposite side from the constrained surface (marked in yellow color in Figure 2.6), in a similar fashion to the previous case. The load is equivalent to $\sim 25$ times the weight of the LEU element. Its direction is, again, along the shorter diagonal of the element's rhomboid cross section, as shown in Figure 2.6. 

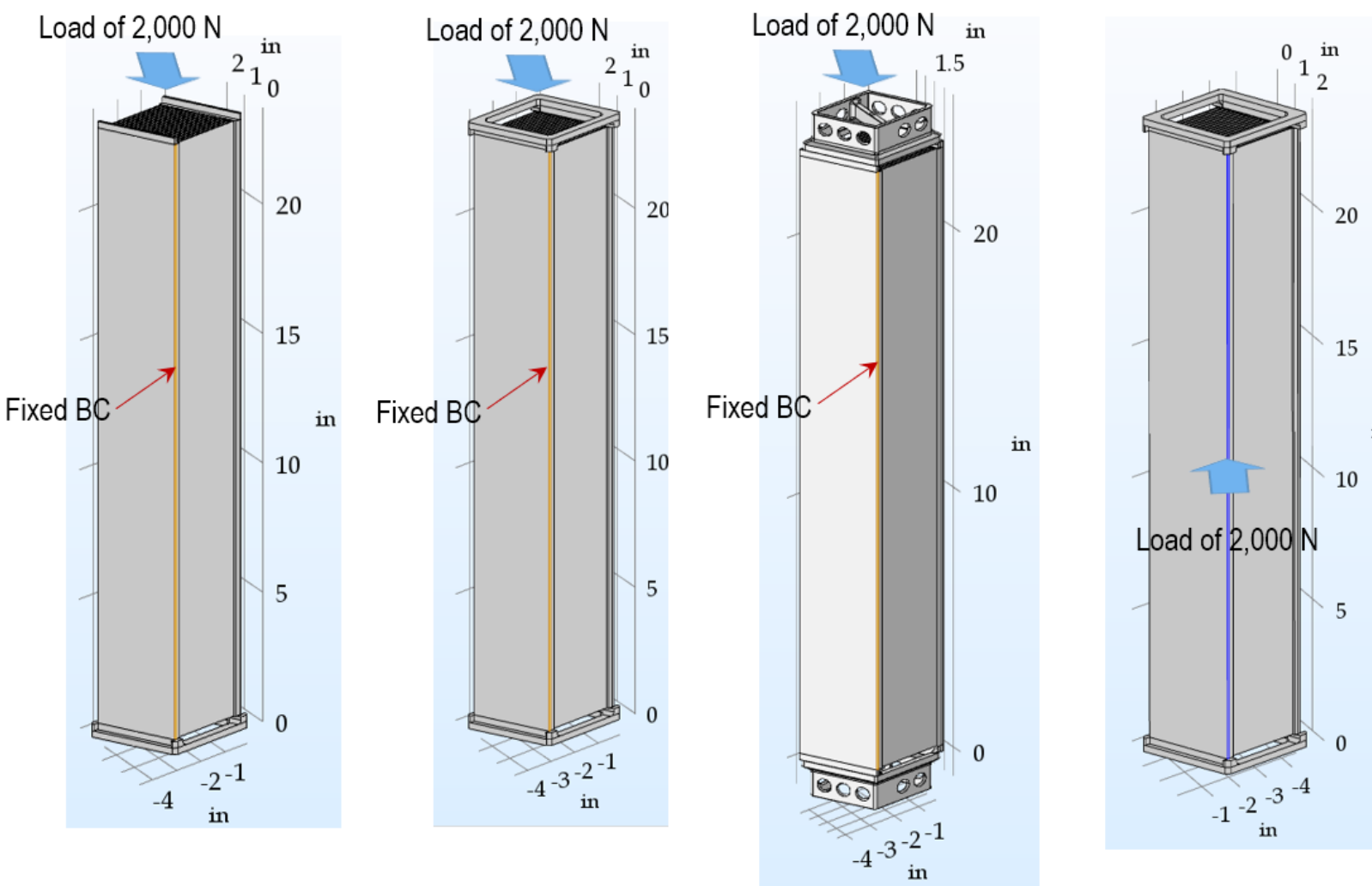

Figure 2.6. Boundary conditions and the direction of line load in the models of three fuel elements: (left to right) with no top end fitting, with MITR DDE end fitting, and with MITR LEU end fitting, load application area on the opposite side of the constrained edge.

\subsubsection{Hydraulic Load}

Variations in the channel gap thickness on both sides of a fuel plate lead to disparities in the coolant velocity which cause pressure differential acting on that plate. That pressure differential leads to plate deflections. At the time of writing this report, neither the full element FSI nor CFD analyses have been performed for the MITR LEU element. Thus, the hydraulic load acting on all the components of the fuel element is not known. However, the FSI analysis for the most limiting plate within the MITR LEU element (with the largest possible channel gap thickness disparities) has been recently analyzed, and the representative loads acting on that plate are available [11]. The largest disparities in the channel gap thickness will occur in the MITR LEU fuel elements that face each other with their outer channel gaps combined into one double size channel gap. In the previously performed analysis [11], the hydraulic load has been estimated for the outermost plate in the MITR LEU element (plate 1 or 19) for such configuration of the fuel elements in the core. The hydraulic load for the current analysis is assumed based on that prior analysis with the nominal flow and geometry conditions. The distribution of the assumed pressure differential on the outermost plate as a function of the axial position is presented in Figure 2.7. The load is applied in the direction forcing the plate to deflect outwards. The same load was applied for the three models considered in this study: MITR LEU fuel element, MITR DDE, and MITR DDE without the top end fitting. Figure 2.8 shows the boundary conditions applied to the models used in this load case scenario. 


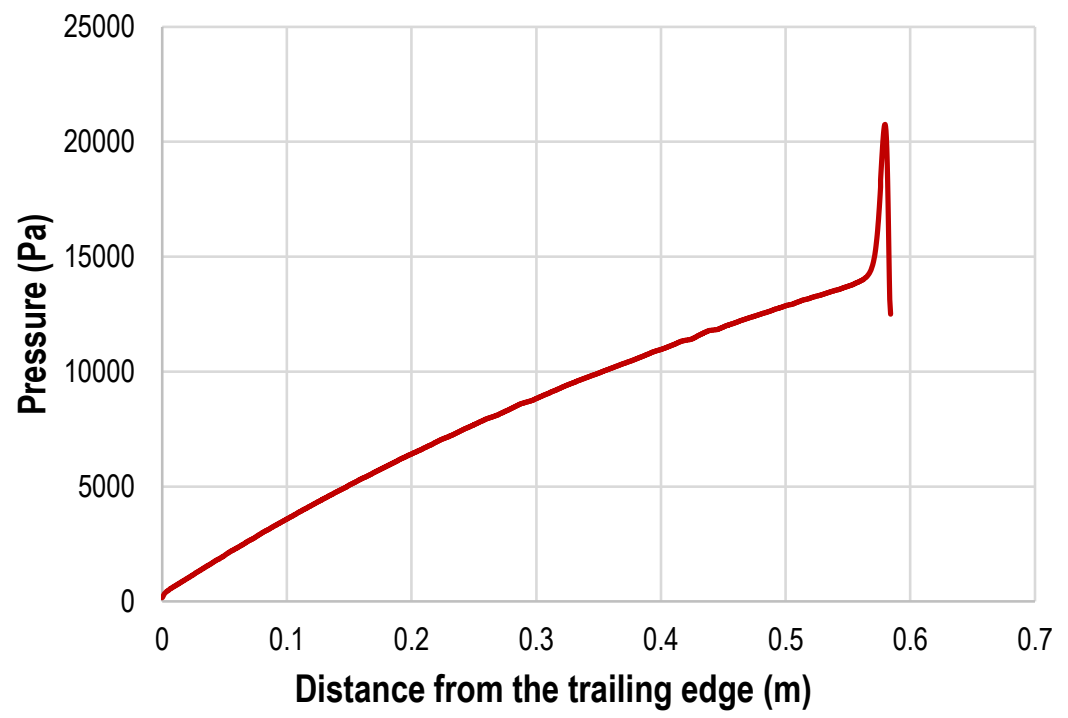

Figure 2.7 Pressure differential acting on the plate as a function of axial distance from its trailing edge for hydraulic load case analysis.
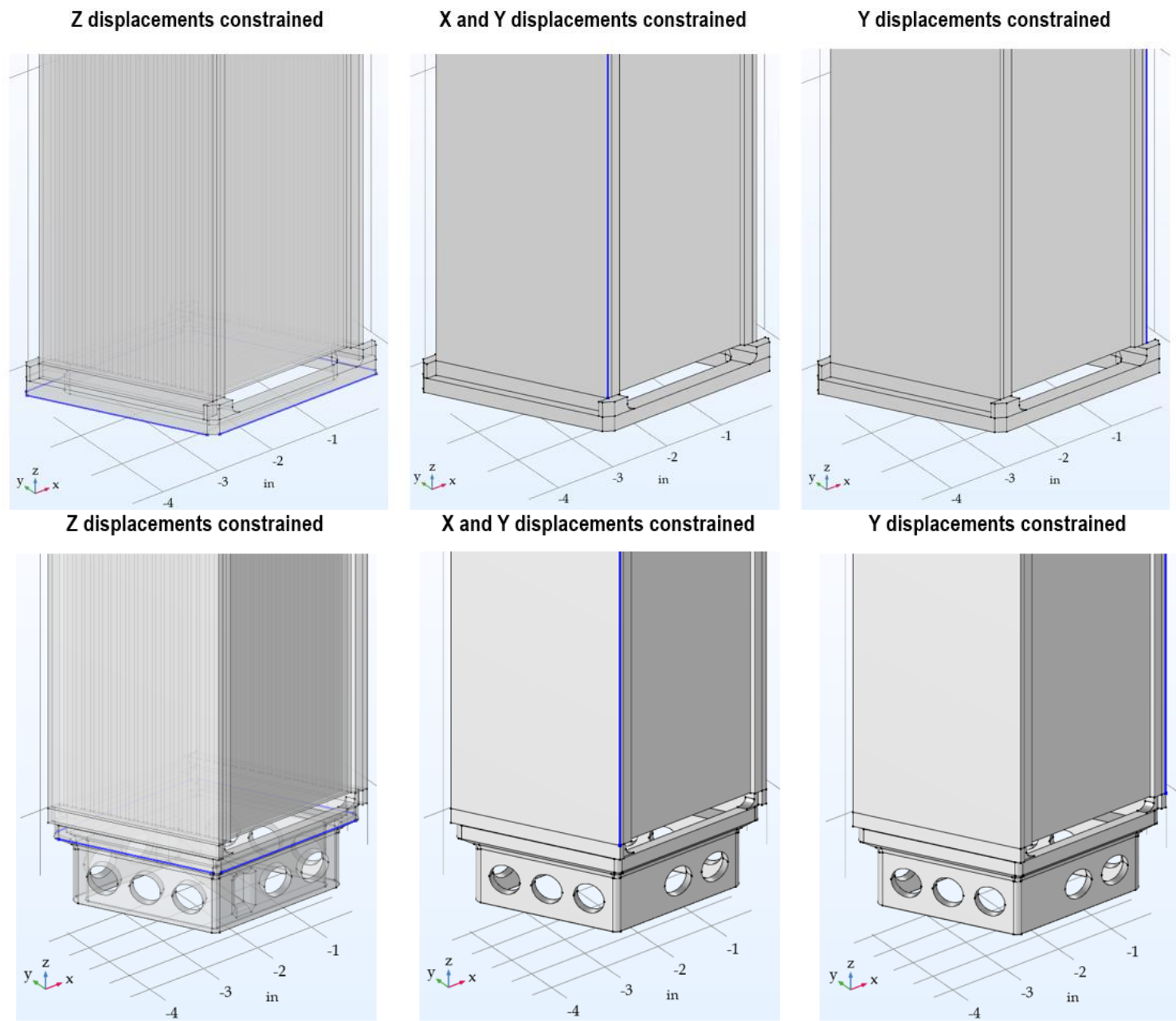

Figure 2.8. Boundary conditions in the cases with hydraulic load (top) MITR DDE (bottom) MITR LEU fuel element. 


\subsubsection{Thermal Load}

Temperatures in the fuel core and on the cladding surface on both sides of the fuel plates were available from the prior MITR LEU transition core analysis [12]. While the analyzed cases do not exactly match the conditions that the MITR DDE will experience during irradiation in the BR2 reactor, they are representative enough to be used for the purposes of this work [13]. A thermal hydraulics $(\mathrm{TH})$ analysis of the MITR DDE is planned and will be available in later stages of the experiment.

The temperature field in the TH analysis of the MITR fuel elements is usually determined numerically, after the division of the fueled portions of the plates into four equally wide stripes in the lateral (width) direction and sixteen nodes in the axial direction. See Figure 2.9 for the striping of the MITR fuel element model. Based on this discretization, 192 (16 in axial direction $\times 3$ in thickness direction $\times 4$ number of stripes) data points are identified per plate.

The temperature of the unfueled stripes on the edges of the plate (portions on the left and right without the fuel, shown in Figure 2.9), the side plates, and the end fittings was assumed based on the distribution of the coolant bulk temperature. The axial distribution of that temperature is presented in Table 2.1.

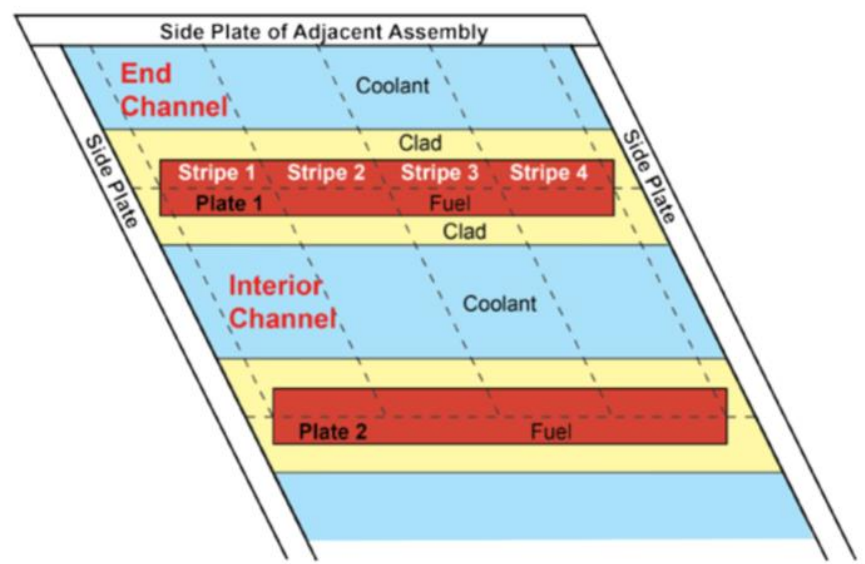

Figure 2.9. Striping (discretization) in the thermal hydraulics models for MITR fuel elements.

Since the variation of the temperature across the thickness of the plate was smaller than $5{ }^{\circ} \mathrm{C}$, it was assumed that it does not affect the overall behavior of the expanding element. For that reason, the temperature input was averaged in the thickness direction. This simplification reduced the number of distinct input data points per plate to $64(16 \times 4)$. Table 2.2 shows the temperature distribution in plate 15 of Cycle 1 BOC for the MITR DDE, which had the highest temperature in the analyzed fuel element. The temperature field used as an input for the remaining plates is listed in APPENDIX B: . Table 2.1 lists the average bulk coolant temperature distribution for stripes 1 and 4 in Cycle 1 BOC for the MITR DDE. The average coolant temperature for stripes 1 and 4 was $45.1{ }^{\circ} \mathrm{C}$ at the inlet and $71.9^{\circ} \mathrm{C}$ at the outlet. Figure 2.10 shows the temperature distribution, as imported to the COMSOL model of the MITR DDE. 
Table 2.1. Average bulk coolant temperature distribution (for stripes 1 and 4) in Cycle 1 BOC for MITR LEU element [12].

$\begin{array}{cc}\begin{array}{c}\text { axial } \\ \text { location } \\ (\mathrm{m})\end{array} & \begin{array}{c}\text { temp } \\ \left({ }^{\circ} \mathrm{C}\right)\end{array} \\ 0.579 & 45.1 \\ 0.542 & 47.1 \\ 0.506 & 48.9 \\ 0.469 & 50.8 \\ 0.433 & 52.7 \\ 0.396 & 54.7 \\ 0.360 & 56.7 \\ 0.323 & 58.7 \\ 0.287 & 60.7 \\ 0.250 & 62.6 \\ 0.214 & 64.5 \\ 0.177 & 66.3 \\ 0.140 & 67.9 \\ 0.104 & 69.3 \\ 0.067 & 70.6 \\ 0.031 & 71.9\end{array}$

Table 2.2. Temperature distribution in plate 15 of Cycle 1 BOC for MITR LEU element [12].

$\begin{array}{ccccc}\begin{array}{c}\text { axial } \\ \text { location } \\ (\mathrm{m})\end{array} & \begin{array}{c}\text { stripe 1 } \\ \text { avg } \\ \text { temp } \\ \left({ }^{\circ} \mathrm{C}\right)\end{array} & \begin{array}{c}\text { stripe 2 } \\ \text { avg } \\ \text { temp } \\ \left({ }^{\circ} \mathrm{C}\right)\end{array} & \begin{array}{c}\text { stripe 3 } \\ \text { avg } \\ \text { temp } \\ \left({ }^{\circ} \mathrm{C}\right)\end{array} & \begin{array}{c}\text { stripe 4 } \\ \text { avg } \\ \text { temp } \\ \left({ }^{\circ} \mathrm{C}\right)\end{array} \\ 0.579 & 91.23 & 79.12 & 80.09 & 95.60 \\ 0.542 & 84.02 & 74.75 & 75.16 & 88.05 \\ 0.506 & 87.38 & 78.64 & 78.95 & 91.66 \\ 0.469 & 90.25 & 82.16 & 82.98 & 95.62 \\ 0.433 & 93.91 & 84.72 & 85.39 & 98.10 \\ 0.396 & 94.98 & 86.35 & 87.76 & 100.65 \\ 0.360 & 97.50 & 88.17 & 89.09 & 101.48 \\ 0.323 & 97.26 & 88.55 & 89.63 & 103.42 \\ 0.287 & 98.95 & 89.57 & 91.26 & 104.95 \\ 0.250 & 100.75 & 90.46 & 91.62 & 105.55 \\ 0.214 & 99.51 & 89.77 & 90.75 & 105.09 \\ 0.177 & 97.55 & 88.26 & 89.62 & 103.87 \\ 0.140 & 95.72 & 86.55 & 87.87 & 102.20 \\ 0.104 & 93.50 & 84.65 & 85.62 & 99.97 \\ 0.067 & 91.43 & 82.31 & 83.96 & 98.08 \\ 0.031 & 94.74 & 85.31 & 86.61 & 102.22\end{array}$


Surface: Temperature $(\mathrm{K})$

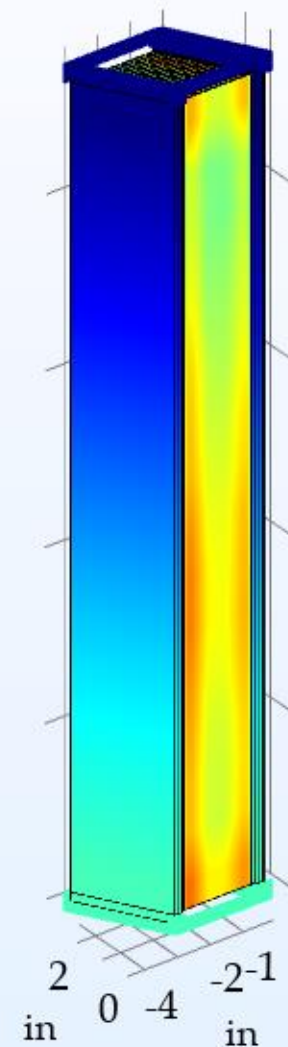

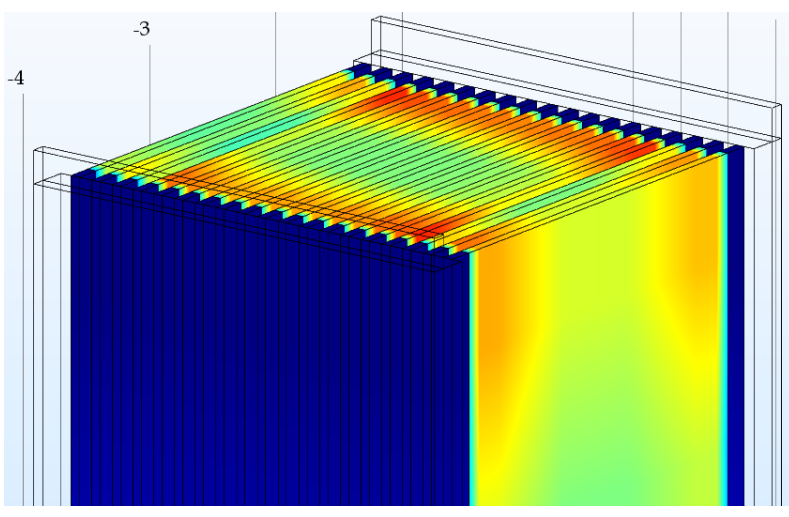

350

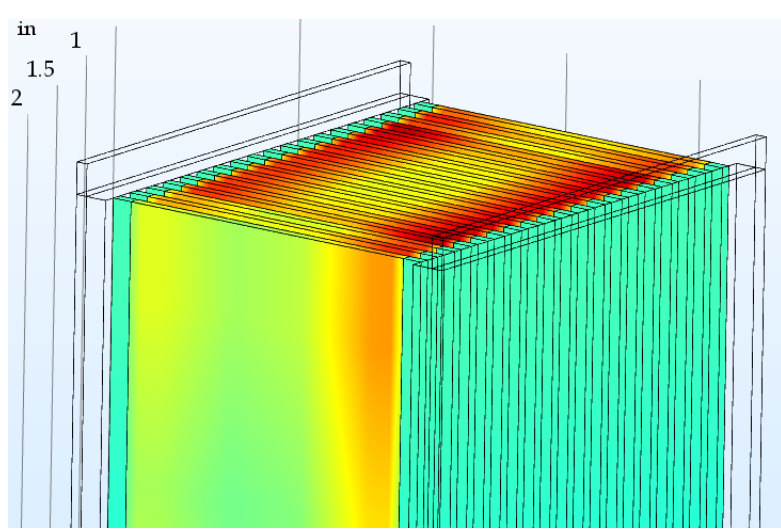

Figure 2.10. Temperature distribution in the MITR DDE at Cycle 1 BOC (left). Detail of the top end (right top) and bottom end (right bottom).

Boundary conditions for that case are only applied to prevent rigid body motions and otherwise allow for an unconstrained expansion of the element under the thermal load. Figure 2.11 shows the boundary conditions in the models.

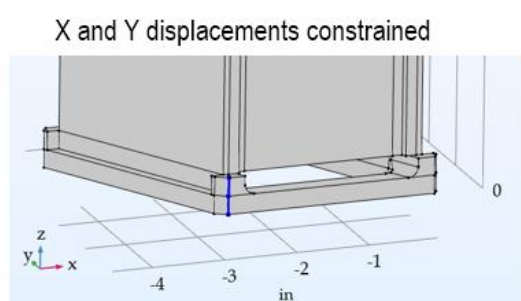

$X$ and $Y$ displacements constrained

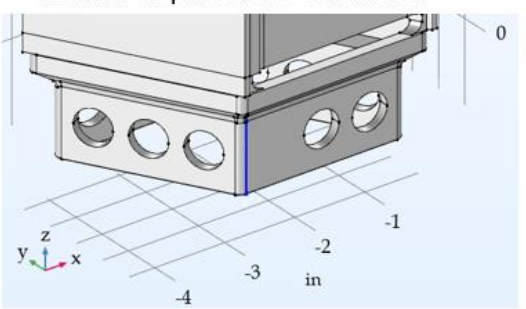

$Z$ displacements constrained

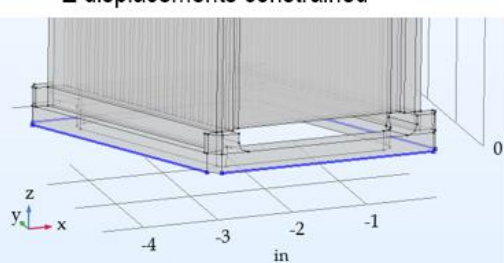

Z displacements constrained

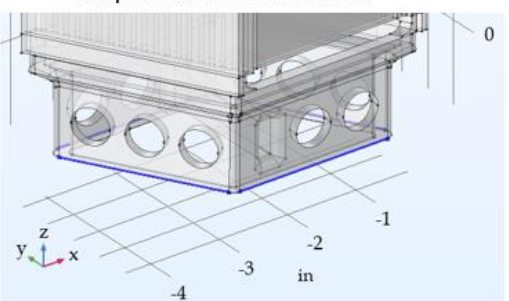

Y displacements constrained

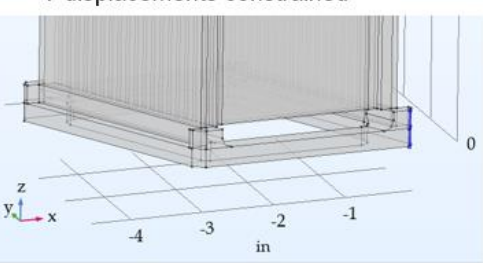

Y displacements constrained

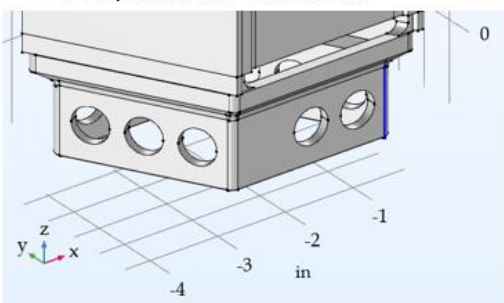

Figure 2.11. Boundary conditions in the cases with thermal load (top) MITR DDE (bottom) MITR LEU fuel element. 


\subsection{Material Properties}

When the reactor starts its operation, raising the temperature in the fuel core causes thermal strain. Elastic, unirradiated properties govern the behavior of the fuel elements at that stage. Thermal and mechanical properties of the fuel core and cladding are known to vary with temperature and irradiation conditions [14], [15]. Modeling changes and degradation in the fuel and cladding thermomechanical properties with irradiation conditions and temperature is beyond the scope of this work but performed under other activities within the USHPPR Project [16], [17].

The present work focuses on the relative rigidity of the fuel elements, encompassing the linear elastic effects only. The only material properties governing the response of the element to the considered here loads in elastic range are the Young's modulus, the Poisson's ratio, and the coefficient of thermal expansion. For simplicity, the entire elements were modeled as homogenous with the material properties of the cladding made of AA6061. These were assumed as constant at $70 \mathrm{GPa}, 0.33$, and 23e-6 $[1 / \mathrm{K}]$, respectively. Since the focus of this study is the relative stiffness of the fuel elements in the elastic range, it is noted that any deviations in Young's modulus due to presence of the stiffer fuel core inside of the fuel plates, and irradiation effects, would affect the stiffness of both the MITR DDE and the MITR LEU elements in the same way.

\subsection{Mesh Sensitivity Study}

The end fittings of the MITR element are welded to the side plates on the outside along a single line [7]. This feature has an impact on the way computational models in COMSOL are built. In the case where a perfect bond between touching parts is to be preserved, the so-called "union approach" to managing the model can be used. The mesh in that case is built across the touching parts, without preservation of the interfaces. In the opposite case, when not all touching parts are bonded, the socalled "assembly approach" should be used. In that case, separate meshing of subcomponents is preserved, and additional forms of connection between these parts in the assembly must be defined. The assembly approach may be used even if all the surfaces are bonded, but there is a need for separate mesh settings for its components.

In the current models, the assembly approach is preferred because of the presence of a single line weld despite a larger contact area between the side plates and the end fittings. The fuel plates and the side plates can be meshed using hexahedral mesh through extrusion of a rectangular mesh on the surface of a cross section perpendicular to the axial direction of the element. This is a preferred meshing technique over free tetrahedral meshing. The total count of the hexahedral elements can be kept lower than that of tetrahedral elements, and the quality of the mesh in that portion of the model can be controlled more tightly. For such an extrusion-based mesh in the plated region, the number of elements along each edge must be defined by the user.

Due to the complex 3D shape of the end fittings, the tetrahedral elements are the only viable option for their discretization. Figure 2.12 shows a perspective view of five DDE end fitting models with different mesh density levels from coarser through coarse, normal, fine, and finer. These are COMSOL designations for default settings that are populated automatically based on selected physics and the size of the discretized object. Features, like sharp corners and large curvatures, are automatically detected and are meshed with smaller elements to represent the geometry better. The total number of degrees of freedom (DOFs) in the coarser mesh of the DDE end fitting was around 77,000. The normal mesh contained over 420,000 DOFs, while the finer mesh had almost 6 million DOFs. For the final models that were used to report the results, the normal mesh was used. 
(a)

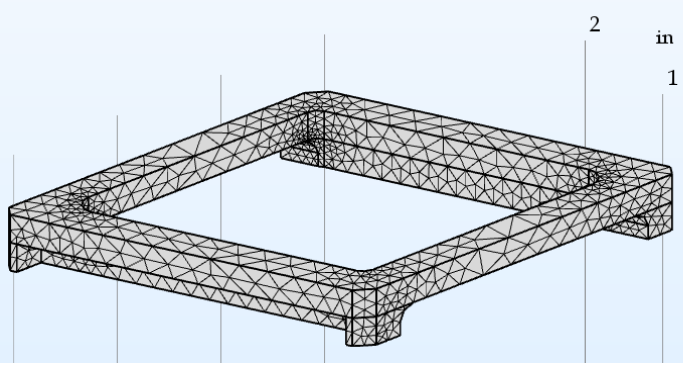

(c)

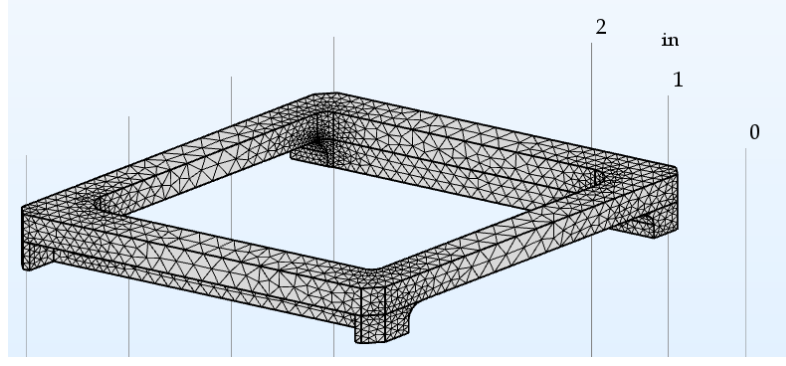

(b)

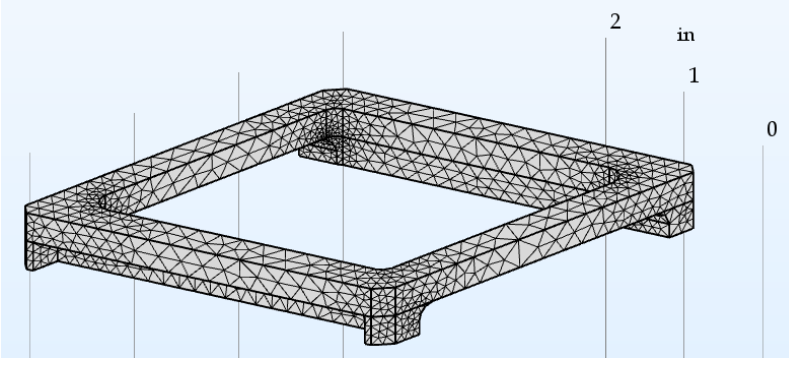

(d)

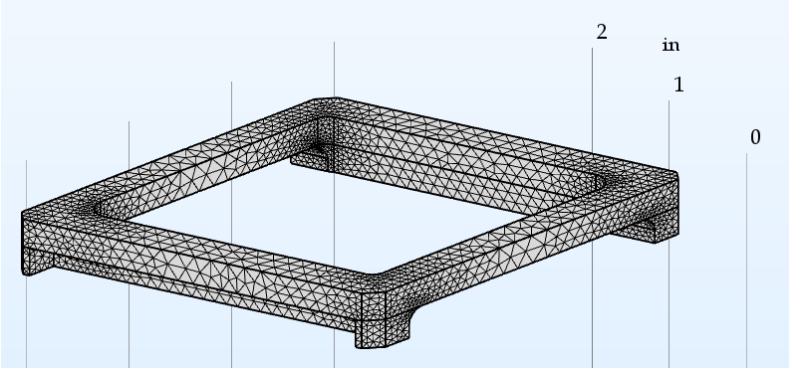

(e)

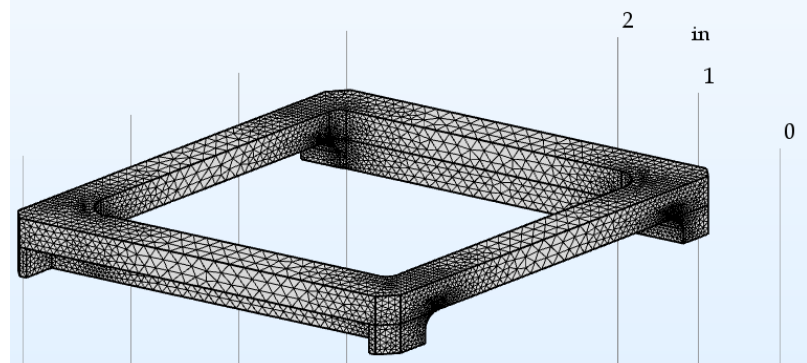

Figure 2.12. Mesh in the DDE end fitting. From the top left: (a) coarser, (b) coarse, (c) normal, (d) fine, and (e) finer mesh densities.

Figure 2.13 presents various mesh densities in the MITR LEU end fitting model, using again from coarser to finer mesh settings. The total number of DOFs in the coarser model of the MITR LEU end fitting was around 174,000. The normal mesh contained over 635,000 DOFs, while the finer mesh had over 3 million DOFs. Again, the normal mesh was used for the final models for which the results are reported in this report. 
(a)

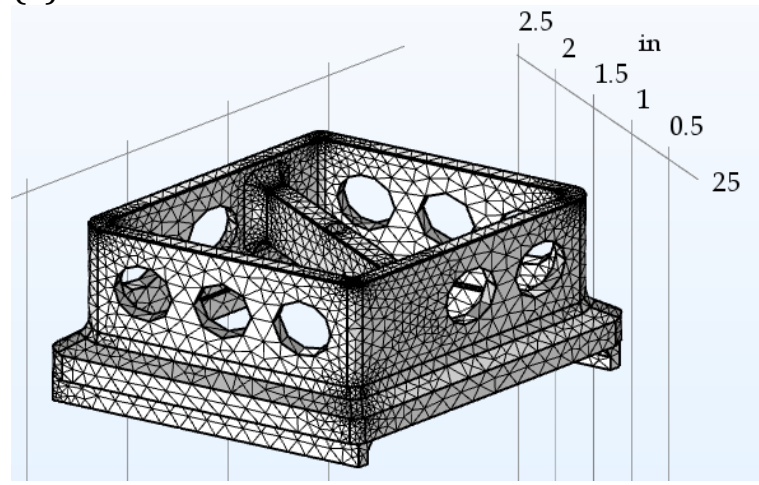

(c)

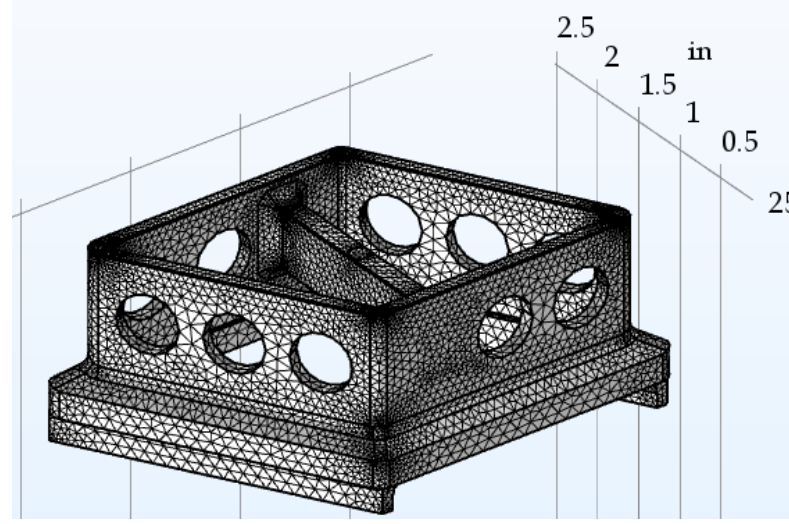

(b)

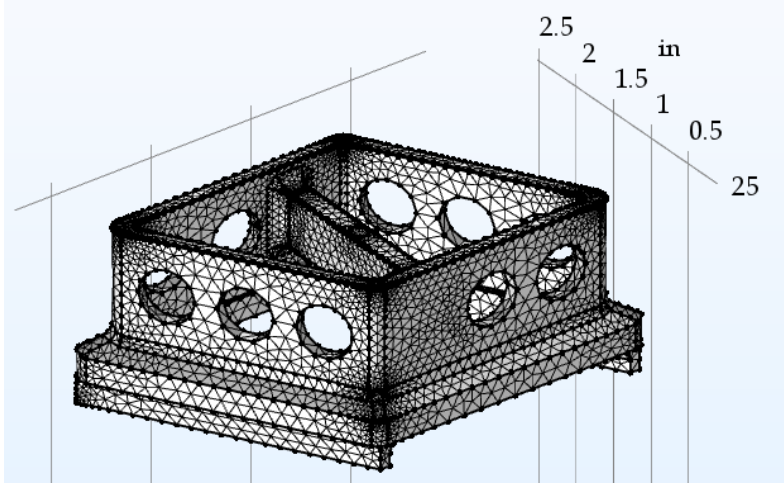

(d)

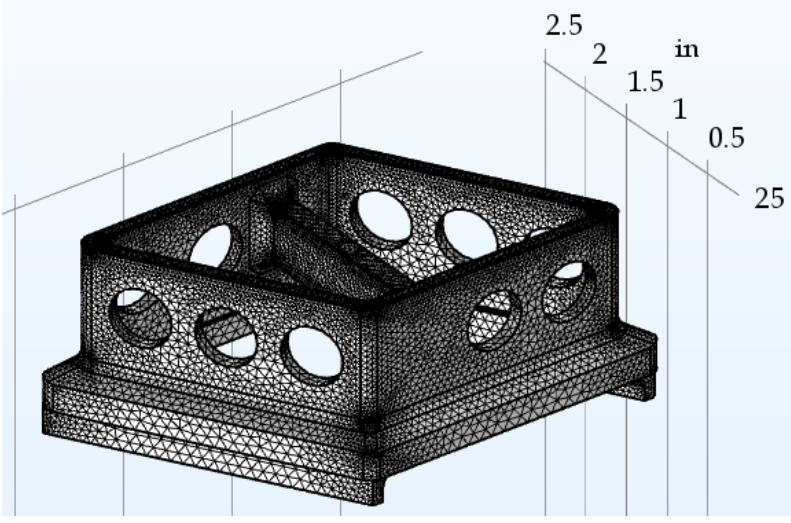

(e)

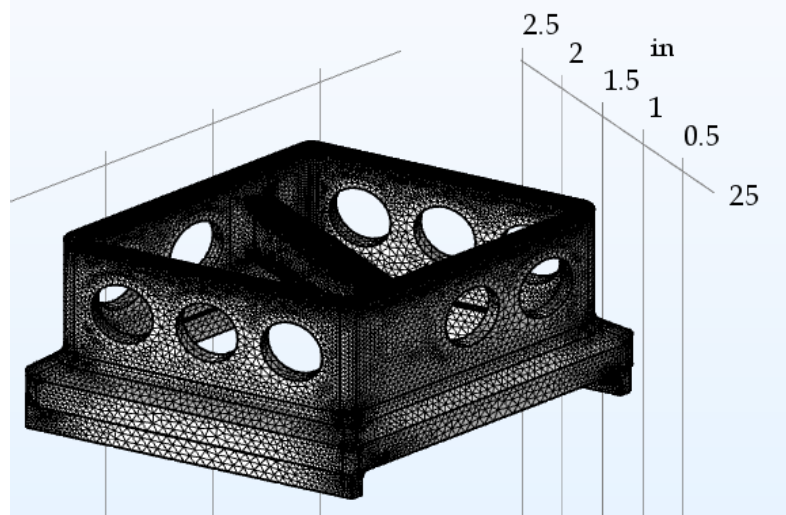

Figure 2.13. Mesh in the MITR LEU end fitting. From the top left: (a) coarser, (b) coarse, (c) normal, (c) fine, and (d) finer mesh densities.

As mentioned earlier, an extrusion-type mesh has been used for meshing the side and fuel plates. Figure 2.14 shows perspective views of models with five different mesh densities in the side and fuel plates. The coarser mesh contained only one quadratic element (using quadratic shape functions for interpolation of field variables) through the thickness of the plates. The coarse model had two, normal had three, and the fine model had four quadratic elements through the thickness of the plate. Twice as many elements were used to model the thickness of the side plate as were used to model the thickness of the fuel plate. These models with various mesh densities were used in an extensive mesh sensitivity study, the results of which are presented in this section as well as in APPENDIX C. 
(a)

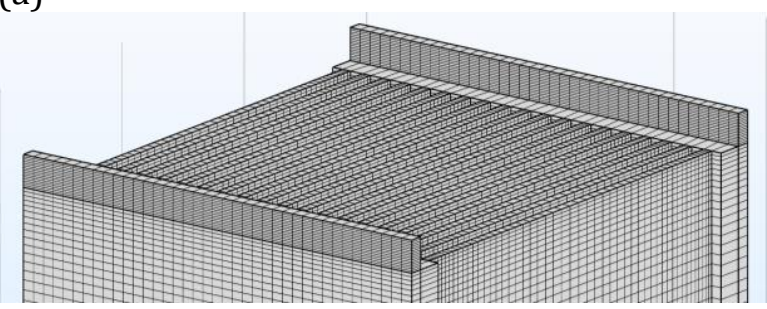

(c)

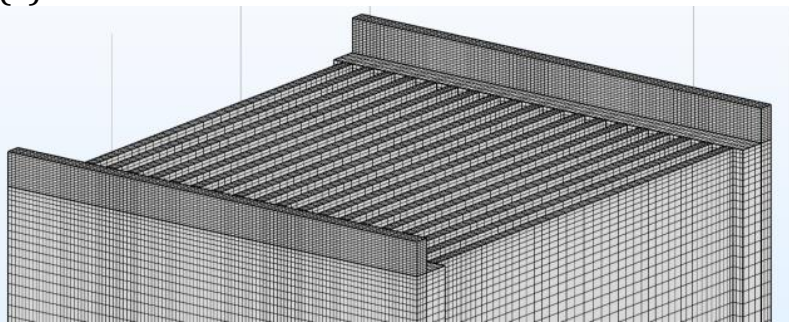

(b)

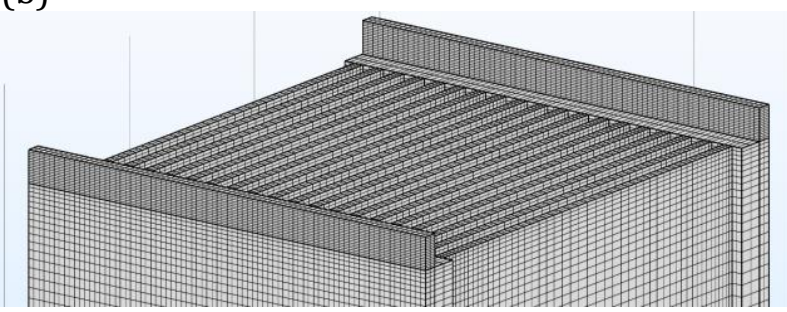

(d)

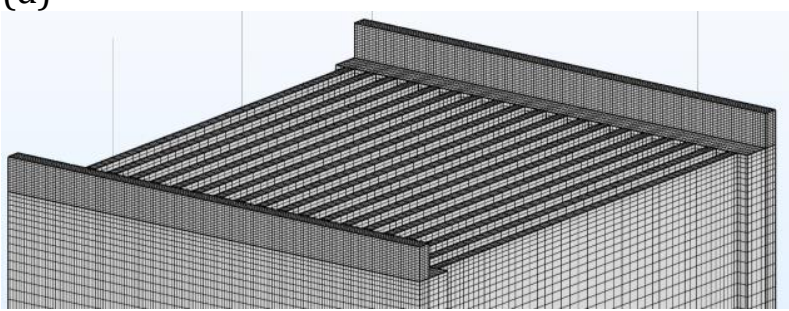

Figure 2.14. Mesh in the side and fuel plates. From the top left: (a) coarser, (b) coarse, (c) normal, and (d) fine mesh densities.

Figure 2.15 and Figure 2.16 show how the models of the fuel elements are assembled. In the models, the top surface of the side plate lip (marked with pink color) is bonded with the horizontal surface on the bottom of the end fitting (marked with yellow color). Using the so-called continuity feature in COMSOL, a perfect bond is created between common parts of the surfaces highlighted in yellow and pink colors in Figure 2.15. This feature ensures continuity of displacements across the interface of the subassemblies (side plates and end fittings). The strength of the welds was not a subject of this study; instead, it is assumed that the bond created in the model between the end fittings and side plates cannot be broken by application of an external force. The contact between the other neighboring surfaces of the side plates and the end fittings was not defined. The lack of contact means that deforming parts of the side plate may intersect the surfaces of the end fitting without exerting forces. Adding contact feature would change the model from a linear to a highly nonlinear one, in which contact points may change depending on the direction, magnitude, and evolution of the load. The computation cost of these simulations would increase significantly. It was decided that the added complexity of the model would not change the conclusions of this comparative study, because the simplifications used in the analysis affect the models of the MITR LEU element and MITR DDE in a similar fashion.
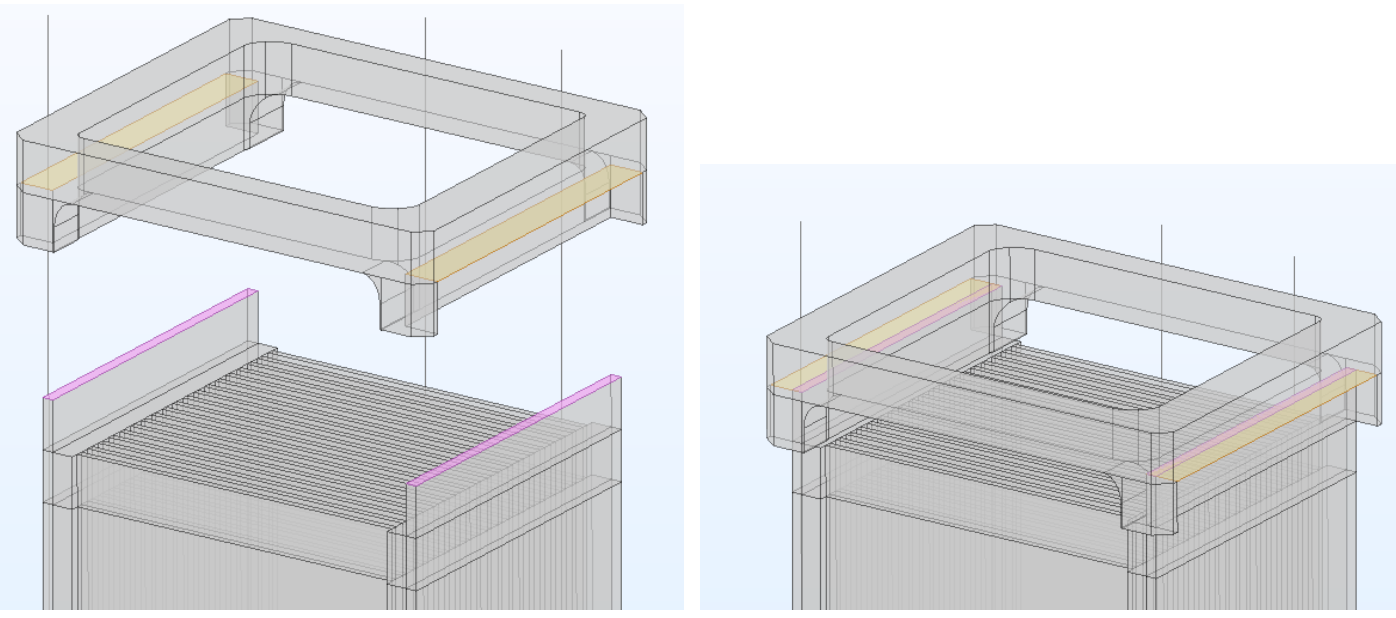

Figure 2.15. Assembly of the DDE end fitting with the side plates. 


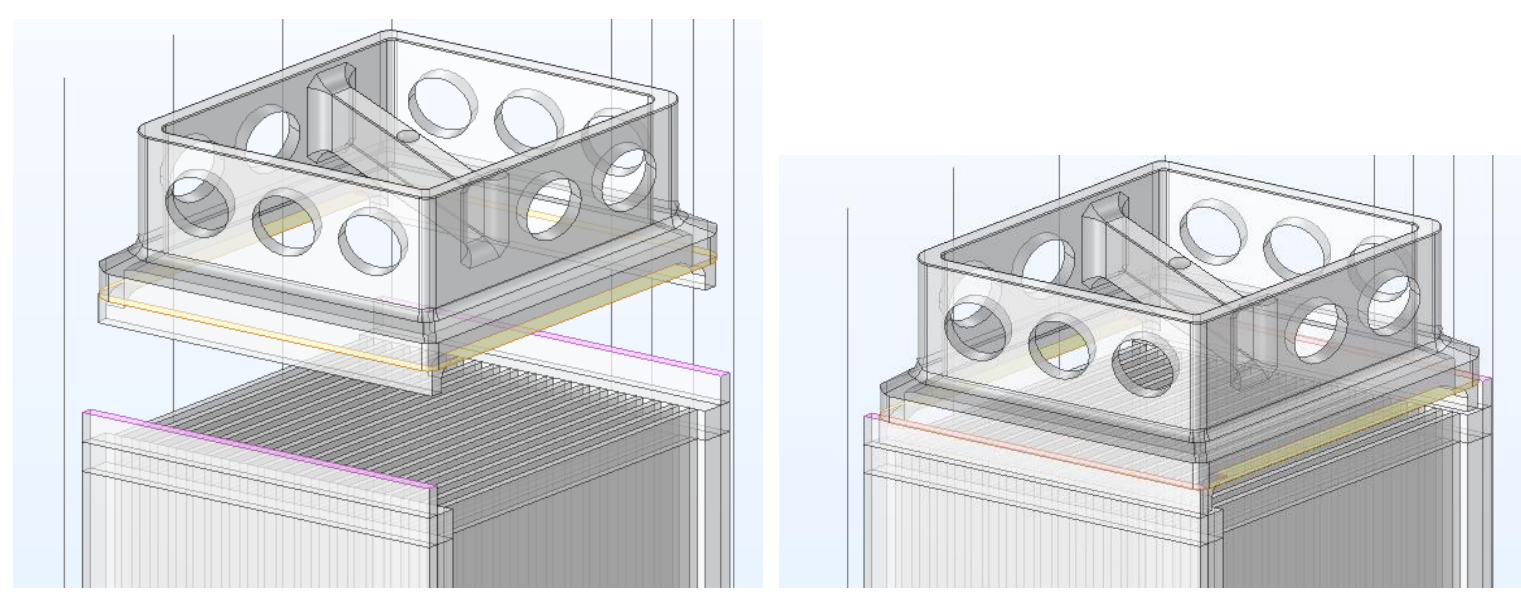

Figure 2.16. Assembly of the MITR LEU end fitting with the side plates.

The primary quantity of interest in this study is the displacement caused by each of the considered loads. Since an elastic material and the theory of small displacements were used, the displacements are a surrogate for the relative stiffness of the structure. If a deflection in one model is $10 \%$ larger than a deflection in another one under the same load, for such elastic material, the stiffness of that model must have been $10 \%$ smaller than the stiffness of the structure that deflected less. Thus, the sensitivity study was aimed at achieving the mesh size that will display convergence for the maximum deflection in the model as the quantity of most interest.

The models developed in this work have simplified geometries and connections between different parts of the models. Sharp corners created in the geometry defeaturing process, perfect bonds between subcomponents, and the elasticity of the modeled material are some of the assumed simplifications. These assumptions should be inconsequential in predicting maximum deflections, assuming that these deformations are small and do not lead to reaching the yield strength of the material. Relative stiffness between the models with various end fittings should also not be affected by these assumptions. However, in certain cases, such models can predict inaccurate stresses in the fuel elements. In Finite Element Analysis (FEA), the modeling assumptions mentioned above frequently lead to stress singularities in sharp re-entrant corners. With increasing mesh density, the stresses at these locations continue increasing and convergence cannot be achieved. This does not mean that these stresses are real. To avoid stress singularities in the corners, all fillets in the geometry would have to be preserved and finely meshed in the FE representation. Additionally, activating contact and plasticity models could allow for small local plastic zones to form in small contact areas and limit further growth of stresses. Both remedies would significantly increase the computation time for all the simulations. Singularities in the FEA are well known, and the FE analysts accept these results with the following remarks [18], [19]:

- The mesh sensitivity study needs to be performed to identify all the affected zones,

- Displacements in the model must be converged even near the singularity area, and

- Although stresses at the singularity are inaccurate, the stresses away from it are correct, thanks to St. Venant's principle, which states that the difference between the effects caused by two equivalent loads (for example, a point load and a distributed load with the same integral magnitude) is negligible at sufficiently large distances from the area of load application. 
For these reasons, the current modeling methodology was assumed to be valid, but an extensive mesh sensitivity analysis has been performed for each model and loading scenario to identify the singularities and ensure convergence in the predicted displacement field regardless of the lack of convergence in the stresses at the location of singularities.

\subsubsection{Number of Elements in the End Fitting}

Figure 2.17 shows the dependency of the maximum displacements on the number of DOFs in the models for point load cases involving the end fitting only. For both models (MITR DDE and MITR LEU end fittings), five different meshes were used. The difference in the maximum displacements between the "normal" mesh, marked with the white circle, and the finer mesh for both cases is below $0.3 \%$. This result was the basis for the selection of the mesh density for which comparative results are reported on full models.
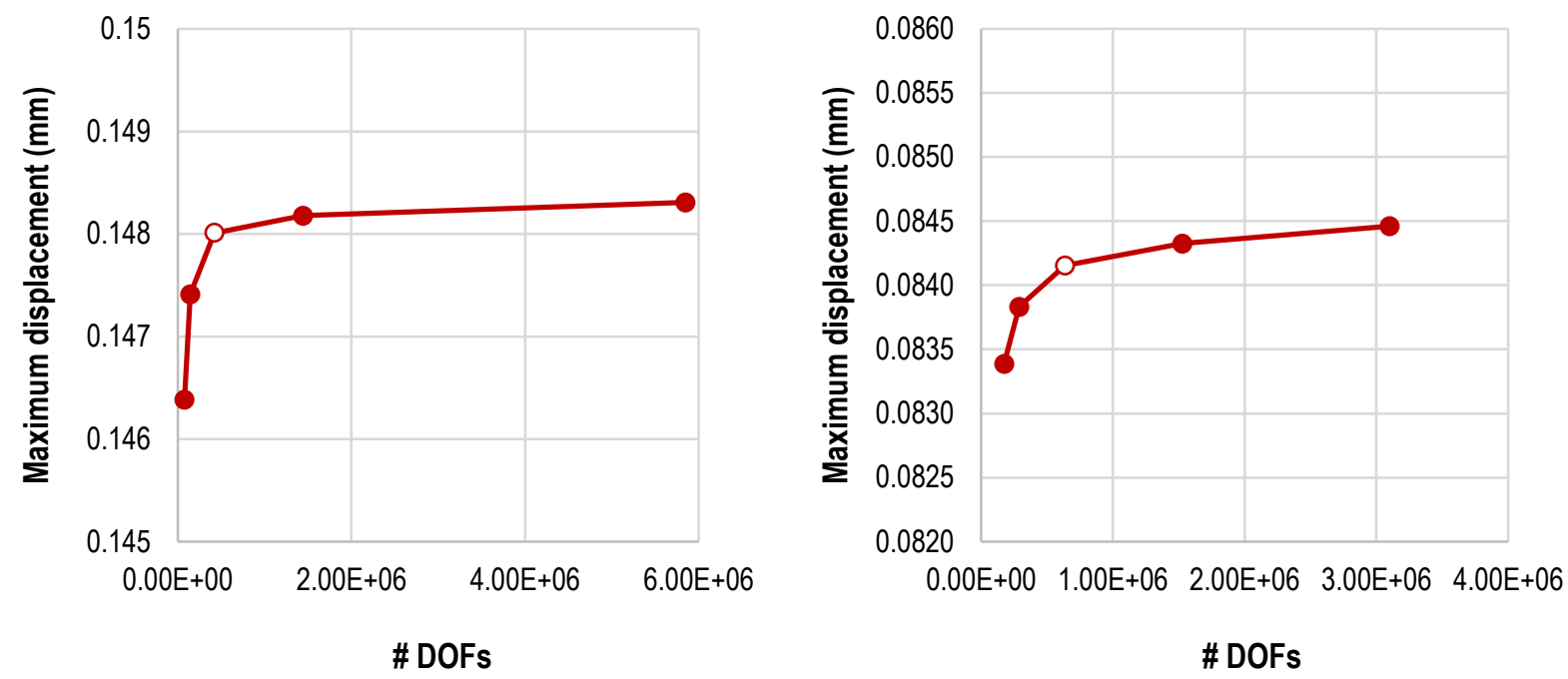

Figure 2.17. Dependency of maximum displacements on number of DOFs in the model for point load cases with end fitting only: MITR DDE (left) and MITR LEU (right).

\subsubsection{Number of Elements through the Thickness of the Plate}

Table 2.3 shows the matrix of runs conducted for the sensitivity study. Five different loading scenarios and, for most of them, three different mesh densities across the thickness of the plate were considered. Table 2.4 lists the number of elements and DOFs in each mesh for the three geometry types considered here. The number of DOF is about an order of magnitude higher than the number of finite elements since the quadratic elements have been used for all simulations. The mesh in the fuel plates and the side plates was the same, regardless of the end fitting attached to the plated portion of the fuel element. The difference in the FE (and the DOF) count between the models with the MITR DDE and the MITR LEU end fittings comes from the difference in the meshes of the end fittings only. The number of DOFs in the models of full fuel elements varies from 3.5 million for the coarser mesh to almost 10 million for the normal mesh.

Figure 2.18 shows six plots presenting the dependency of the maximum deflection and maximum von Mises stress in the three models under the point load. The displacement increases, on average, by about $1.0 \%$ for the coarse meshes as compared to the coarser meshes. Any further change of the mesh from the coarse to the normal settings causes the maximum displacement to increase, on average, by 
an additional $0.4 \%$. This is a very small variation, and it can be assumed that the normal mesh provides converged results for the prediction of the displacements. For the model without end fittings, an additional simulation with the fine mesh was run, providing a fourth data point on the convergence plots. This model had 13.6 million DOFs. The maximum displacement for that case increased by $0.17 \%$ as compared to the normal mesh, confirming that convergence has indeed been achieved.

However, in all plots on the right side of Figure 2.18, presenting the dependency of the maximum von Mises stresses in the models as a function of the DOFs, the convergence has not been achieved The maximum stresses are reported near the areas of load application and in sharp corners in the connection between the fuel plates and the side plates. The stresses in these "hot spots" are not realistic and, as explained earlier, are a consequence of the underlying FEA methodology and modeling simplifications. Nonetheless, for the purpose of the relative stiffness calculations, the developed models are deemed sufficient. The dependency of the results on the number of elements through the thickness of the plate for other load cases is presented in APPENDIX C.

Table 2.3. Simulation matrix.

\begin{tabular}{|c|c|c|c|c|c|c|c|c|c|c|c|c|c|c|}
\hline \multirow[t]{2}{*}{ ID } & \multirow[t]{2}{*}{ loading cases } & \multicolumn{5}{|c|}{ MITR LEU end fitting } & \multicolumn{4}{|c|}{ MITR DDE end fitting } & \multicolumn{4}{|c|}{ no top end fitting } \\
\hline & & coarser & coarse & normal & fine & finer & coarser & coarse & normal & fine & coarser & coarse & normal & fine \\
\hline 1 & lateral end fitting only & $\checkmark$ & $\checkmark$ & $\checkmark$ & $\checkmark$ & $\checkmark$ & $\checkmark$ & $\checkmark$ & $\checkmark$ & $\checkmark$ & $x$ & $x$ & $x$ & $x$ \\
\hline 2 & lateral point load & $\checkmark$ & $\checkmark$ & $\checkmark$ & $x$ & $x$ & $\checkmark$ & $\checkmark$ & $\checkmark$ & $x$ & $\checkmark$ & $\checkmark$ & $\checkmark$ & $\checkmark$ \\
\hline 3 & lateral line load & $\checkmark$ & $\checkmark$ & $\checkmark$ & $\checkmark$ & $x$ & $\checkmark$ & $\checkmark$ & $\checkmark$ & $x$ & $\checkmark$ & $\checkmark$ & $\checkmark$ & $x$ \\
\hline 4 & hydraulic load & $\checkmark$ & $\checkmark$ & $\checkmark$ & $x$ & $x$ & $\checkmark$ & $\checkmark$ & $\checkmark$ & $x$ & $\checkmark$ & $\checkmark$ & $\checkmark$ & $x$ \\
\hline 5 & thermal load & $\checkmark$ & $\checkmark$ & $\checkmark$ & $x$ & $x$ & $\checkmark$ & $\checkmark$ & $\checkmark$ & $x$ & $\checkmark$ & $\checkmark$ & $\checkmark$ & $x$ \\
\hline
\end{tabular}

Table 2.4. Element and DOF count in the models.

\begin{tabular}{|c|c|c|c|c|c|c|}
\hline \multirow{2}{*}{ mesh density } & \multicolumn{2}{|c|}{ MITR LEU end fitting } & \multicolumn{2}{c|}{ MITR DDE end fitting } & \multicolumn{2}{c|}{ no top end fitting } \\
\hline & \# elements & \# dos & \# elements & \# dofs & \# elements & \# dofs \\
\hline coarser & 224,283 & $3,550,399$ & 185,224 & $3,497,287$ & 175,676 & $3,447,733$ \\
\hline coarse & 481,949 & $6,392,014$ & 416,836 & $6,308,383$ & 400,211 & $6,226,711$ \\
\hline normal & 856,859 & $9,993,574$ & 717,388 & $9,815,806$ & 684,751 & $9,663,061$ \\
\hline fine & $1,402,053$ & $15,432,169$ & $1,077,490$ & $13,969,828$ & 994,234 & $13,601,815$ \\
\hline
\end{tabular}



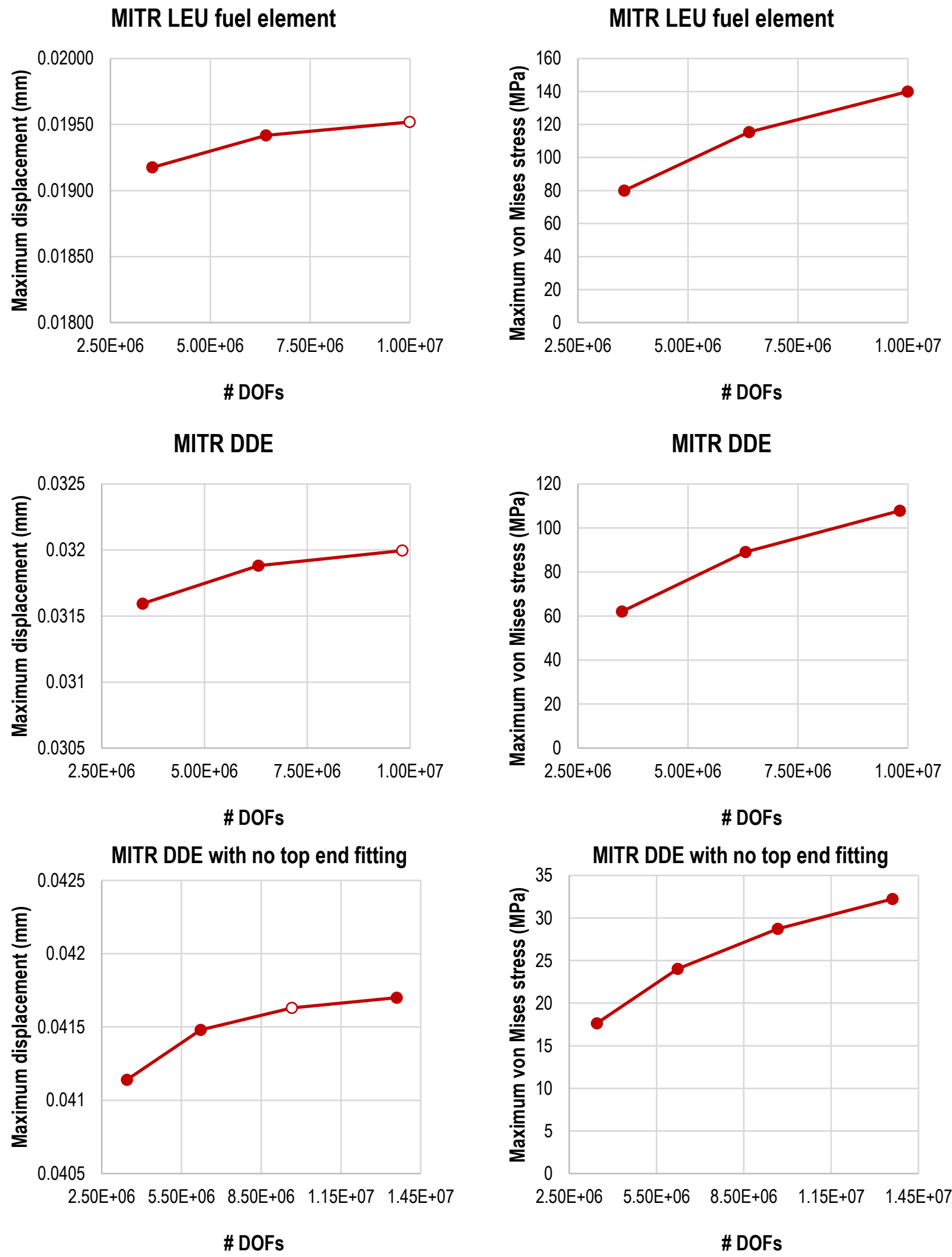

Figure 2.18. Mesh sensitivity study of the MITR LEU element, MITR DDE, and MITR DDE without top end fitting for the point load cases. 


\subsubsection{Number of Elements through the Width of the Plate}

The results presented in the previous sections were all obtained with the models that had 50 elements across the width (span or transverse direction) of the plate. The mesh in that direction was built with a variable element size. The elements near the side plates were three times smaller than the elements in the middle of the span to capture higher gradients of stresses and strains in the areas where the fuel plates connect with the side plates.

The mesh sensitivity study for the plate's width (span) direction was performed for the point load with normal mesh settings and the line load with the coarser mesh settings as described in the previous section. For both loading cases, the MITR DDE without top end fitting model was used to illustrate the convergence of the results.

Figure 2.19 presents the mesh sensitivity study for the case with point load. The "normal" mesh with 50 elements in the direction of the plate's span predicted maximum displacement of $0.04163 \mathrm{~mm}$. Increasing the mesh density to 100 elements in the width direction caused the displacement to increase by only $0.11 \%$ to $0.04168 \mathrm{~mm}$.

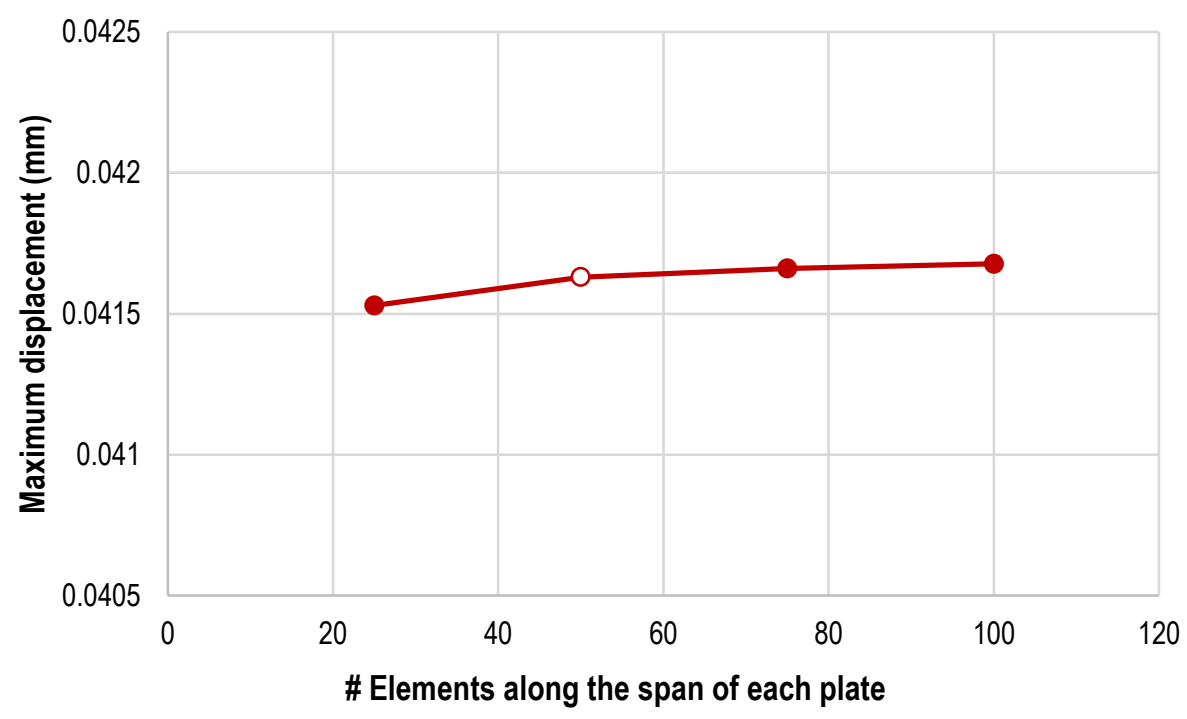

Figure 2.19. Mesh sensitivity study of the MITR DDE for the point load case.

Figure 2.20 presents the mesh sensitivity study for the case with the line load. The maximum displacement predicted by the model with 100 elements along the width of the plate increases by $0.2 \%$ as compared to the displacement predicted by the "normal" model with 50 elements in that direction. Based on these two verification cases, it can be concluded that the model with 50 elements across the width of the plate produces converged results and no further refinement of the mesh in this direction is required. 


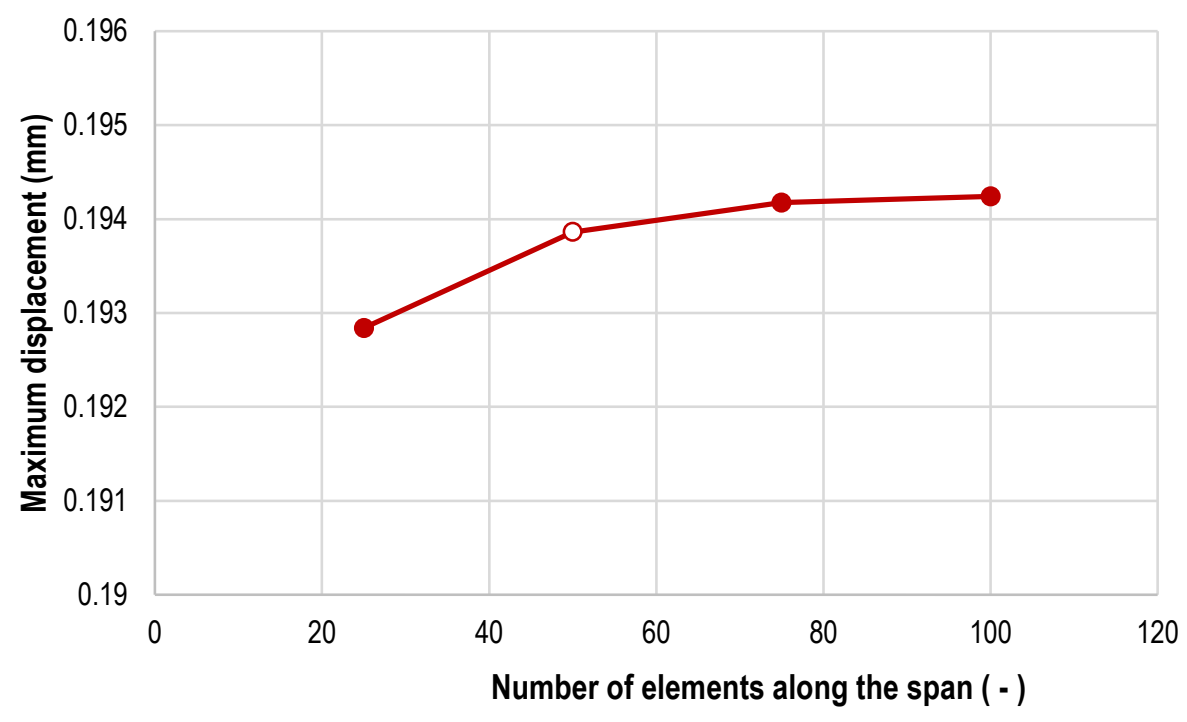

Figure 2.20. Mesh sensitivity study of the MITR DDE for the line load case.

\subsubsection{Number of Elements through the Length of the Plate (Axial Direction)}

The simulations performed in the previous sections were all done with the model that had 150 elements along the length (axial direction) of the plate. The mesh in that direction was also built with a variable element size. The elements near the leading and trailing edges of the plate were ten times smaller than the elements in the middle of the length to capture higher gradients of deformations resulting from point and surface loads present at these locations. The effects of the line and thermal loads are distributed along the length of the plate and are less affected by the size of the elements in the axial direction.

The mesh sensitivity study for the plate's length (axial) direction was performed for the surface load with normal mesh settings for through thickness and across the width of the plates as described in the previous section. Mesh with 75 and 300 elements in the axial direction were built in addition to the normal mesh with 150 elements. The change of the maximum total displacements from the mesh with 75 to the mesh with 150 elements is equal to only $0.04 \%$. Further doubling of elements in the axial direction from 150 to 300 provides almost identical result. Thus, the mesh with 150 elements in the axial direction and non-uniform distribution of element size explained previously was deemed sufficient for the reminder of the work.

\subsubsection{Stresses in the Models}

Figure 2.21 shows typical von Mises stress distribution in the models under the line load. The highest stresses are reported in the corners of the fins on the ends of the side plates. Sharp corners in the connections between the fuel plates and the side plate cause stress singularities (red areas in Figure 2.21). Figure 2.23 shows von Mises stress along the top edge of the fuel plate, with the origin of the $x$ axis (distance along the span of the plate) denoting the location of the stress singularity. This edge is highlighted in blue color in Figure 2.22. The coarser model, with one quadratic element across the thickness of the plate, and the normal model, with three quadratic elements across the thickness of the plate, were studied here in detail. Along the width of the plate, 50, 75, and 100 elements of nonuniform width were used, providing various sizes of the smallest elements in the stress singularity 
areas. It can be noted that even the coarsest mesh gave good predictions of the stresses along the plate as compared to the finest mesh, except for that stress singularity zone. When the size of the elements decreases, the predicted stresses in that area increase. Stresses from these locations cannot be used for any predictive purposes. Nonetheless, they do not affect the primary quantity of interest, which are the displacements.
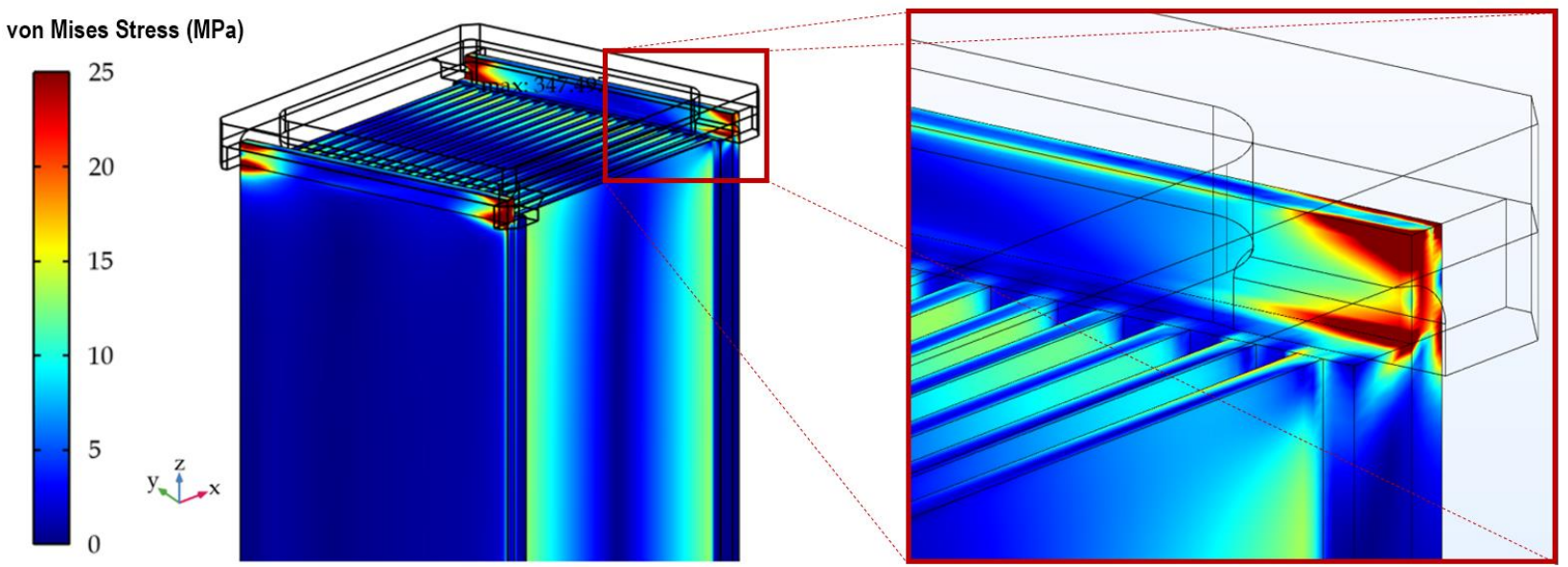

Figure 2.21. Typical locations of the stress divergence (singularity) areas in the FE models.

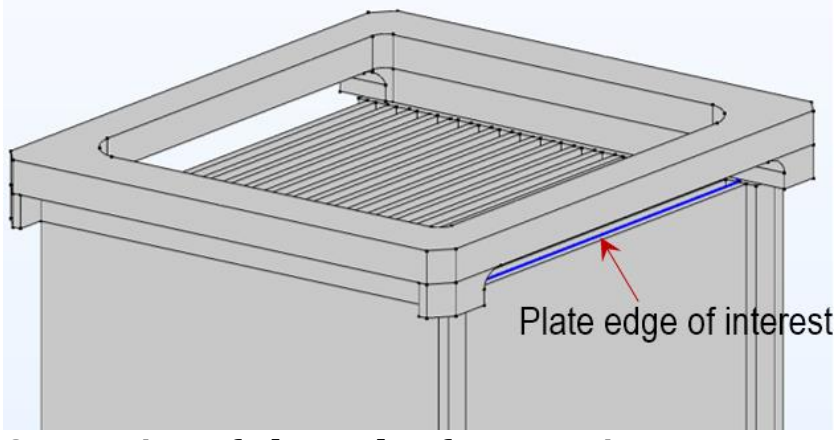

Figure 2.22. Location of plate edge for von Mises stress comparison.

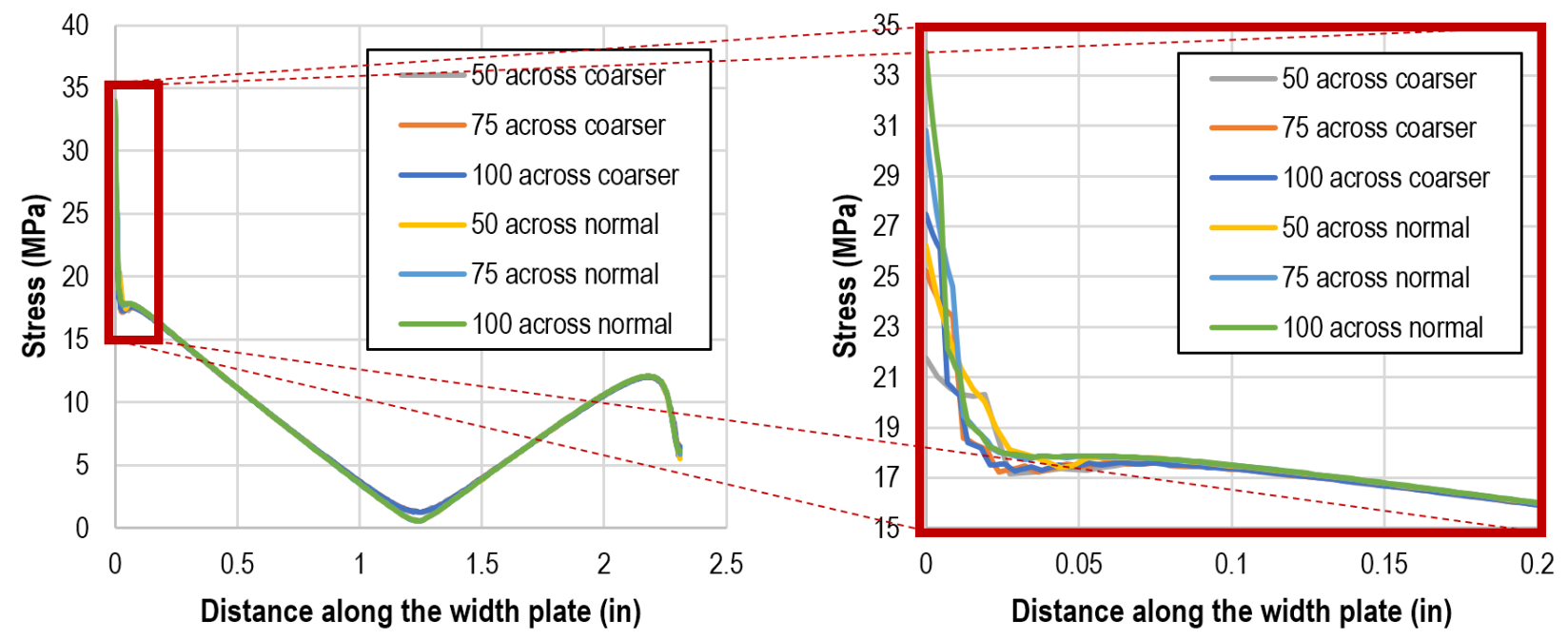

Figure 2.23. Von Mises stress along the top edge of the fuel plate in the line load case for the MITR DDE model. 


\section{Results}

\subsection{Lateral Point Load on End Fitting Only}

Figure 3.1 presents total displacement in the MITR DDE and MITR LEU end fittings under the point loading of $79.0 \mathrm{~N}$ (which is equivalent to the weight of the MITR LEU element) applied along the diagonal. In the MITR LEU end fitting, the cross bar, which is designed for handling purposes, increases the stiffness significantly. The maximum total displacement in the MITR LEU end fitting in the case analyzed here was $0.084 \mathrm{~mm}$ (3.31 mil), while the maximum total displacement of the MITR DDE end fitting was $0.148 \mathrm{~mm}$ (5.83 mil). Thus, the stiffness of the MITR LEU end fitting for that specific load was $76 \%$ higher than that of the MITR DDE end fitting.. For the assessment of the importance of this difference, the full element loading cases were subsequently analyzed.
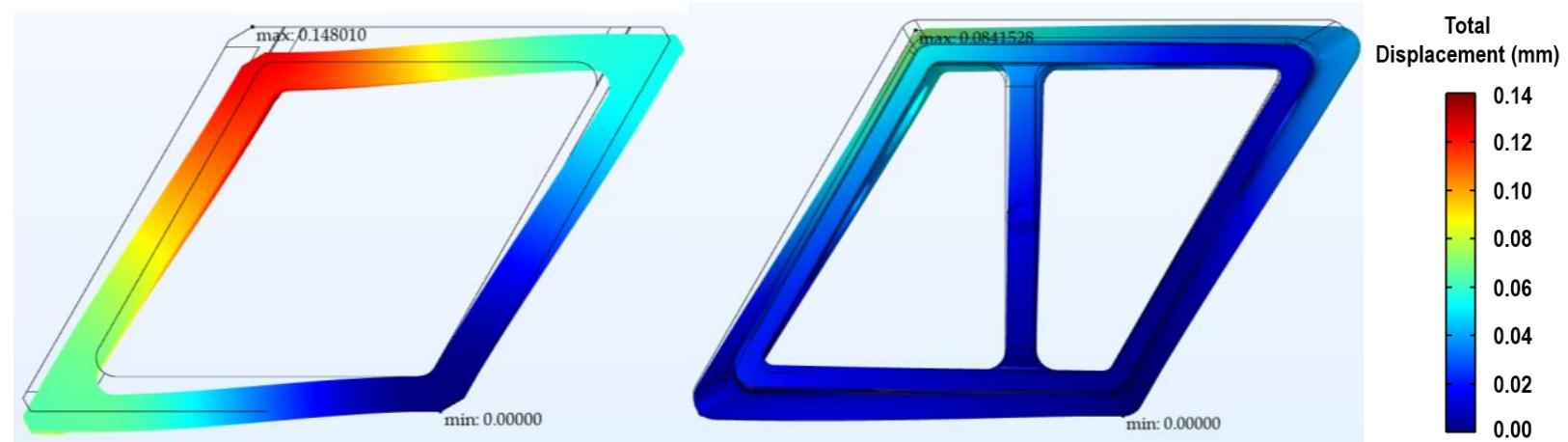

Figure 3.1. Total displacement in the end fittings under the point load: MITR DDE (left) and MITR LEU (right) (displacement scaling factor of 50 used for visualization purposes).

\subsection{Lateral Point Load}

Figure 3.2, Figure 3.3, and Figure 3.4 show deformations in the models without the top end fitting, with the MITR DDE end fitting, and with the MITR LEU end fitting, respectively, under a point load of $79.0 \mathrm{~N}$.

For the case without the top end fitting, the maximum calculated displacement was $0.0416 \mathrm{~mm}$ (1.64 mil), which is used as a reference value for the other two geometries. In the model with the MITR DDE end fitting, the total displacement was reduced to $0.0320 \mathrm{~mm}(1.26 \mathrm{mil})$, or by $23 \%$. In the model with the MITR LEU fuel element end fitting, the maximum total displacement was reduced to 0.0193 $\mathrm{mm}(0.76 \mathrm{mil})$, or by $54 \%$ compared to the case without the end fitting. While for such a concentrated load with a magnitude equal to the weight of the MITR LEU element, the MITR LEU end fitting provided greater resistance than the DDE LEU end fitting, the overall magnitude of the total displacement remained very small.

The dependence of the results on the mesh density for this load case has already been presented in Section 2.4.2. 

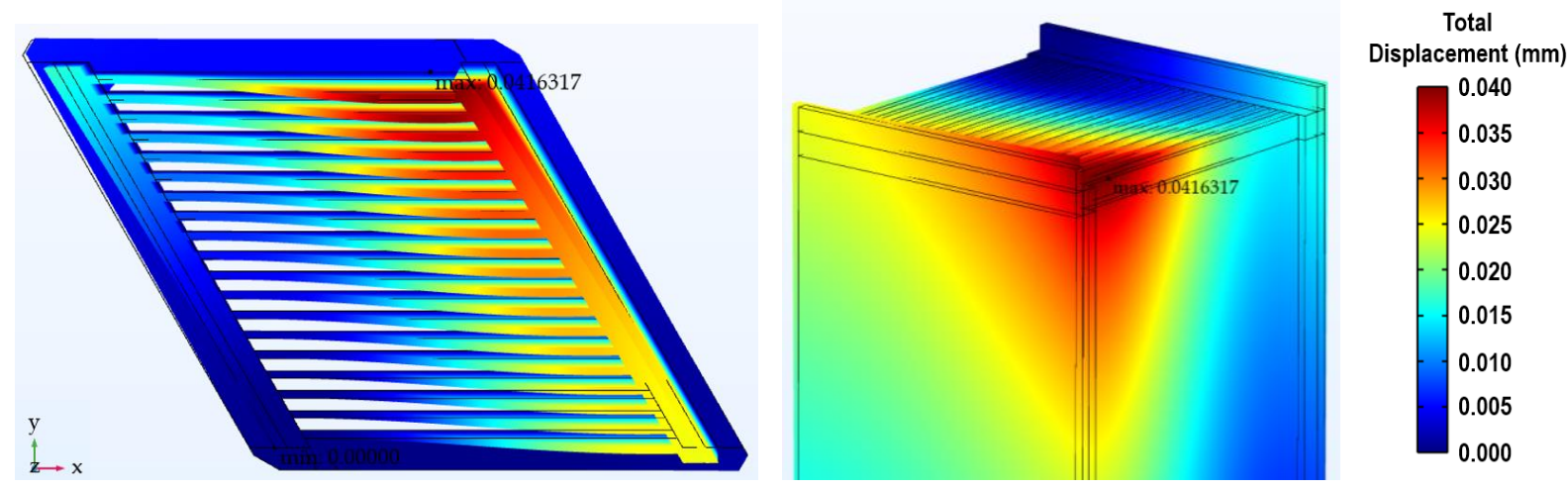

Figure 3.2. Total displacement under a point load of $79.0 \mathrm{~N}$ in the model without top end fitting; (left) top view (right) perspective view (displacement scaling factor of 100 used for visualization purposes).

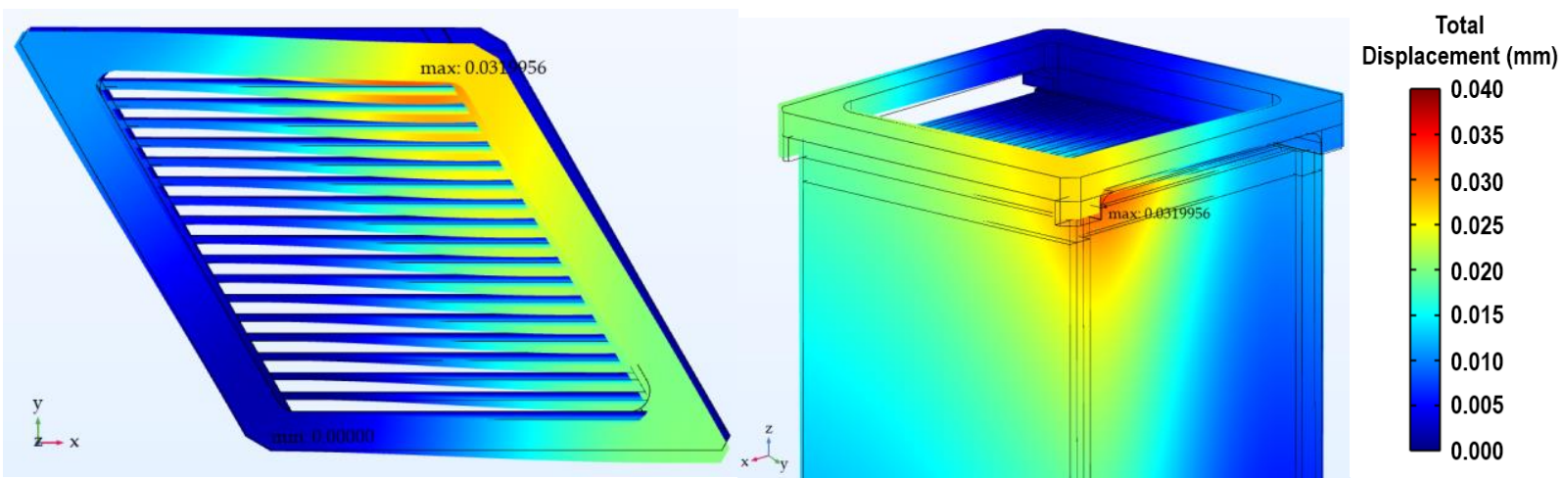

Figure 3.3. Total displacement under a point load of 79.0 $\mathrm{N}$ in the model with MITR DDE end fitting (left) top view (right) perspective view (displacement scaling factor of 100 used for visualization purposes).
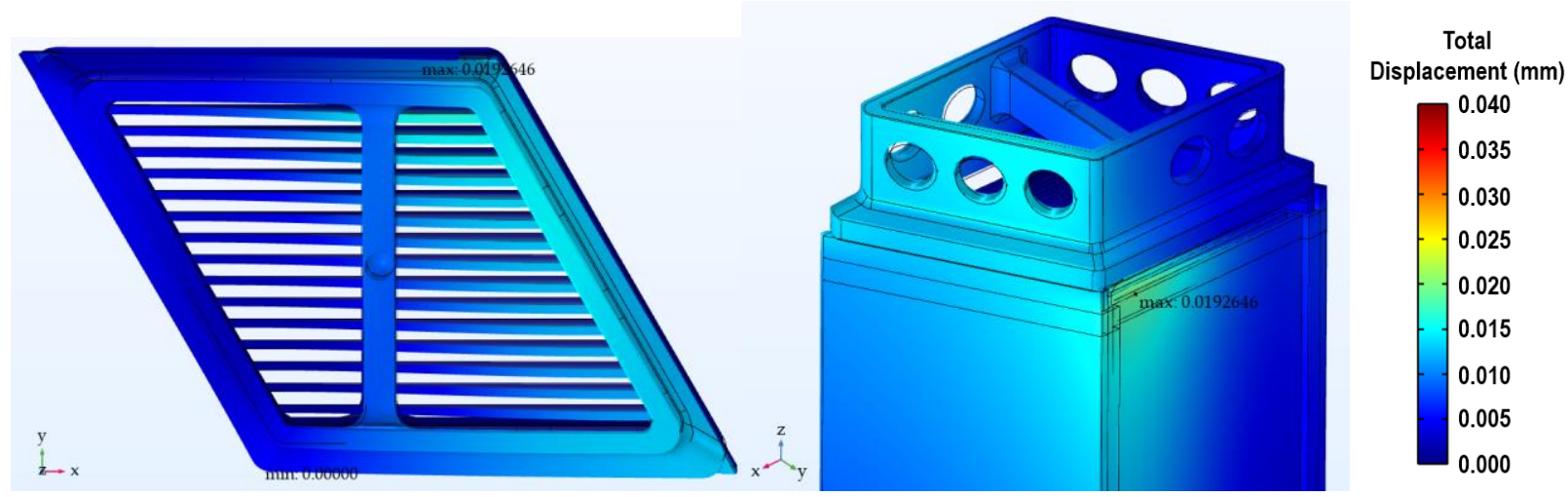

Figure 3.4. Total displacement under a point load of $79.0 \mathrm{~N}$ in the model with MITR LEU end fitting (left) top view (right) perspective view (displacement scaling factor of 100 used for visualization purposes). 


\subsection{Lateral Line Load}

Figure 3.5, Figure 3.6, and Figure 3.7 show deformations in the models without the top end fitting, with the MITR DDE end fittings, and with the MITR LEU end fittings, respectively, under a line load of $2000 \mathrm{~N}$. In these figures, a scaling factor of 25 was applied to the displacement field for visualization purposes. The character of the deformations among the deflections in the three analyzed cases is similar. The line load of 2,000 N, which is equivalent to about 25 times the weight of the MITR LEU fuel element, caused a maximum total displacement of $0.220 \mathrm{~mm}$ ( $8.65 \mathrm{mil})$ in the model without the top end fitting. The maximum total displacement in the model with the MITR DDE end fittings was $11 \%$ lower, at $0.196 \mathrm{~mm}(7.70 \mathrm{mil})$. The maximum total displacement in the model with the MITR LEU end fittings was $28 \%$ lower than in the model without the top end fitting, at $0.158 \mathrm{~mm}(6.22 \mathrm{mil})$.
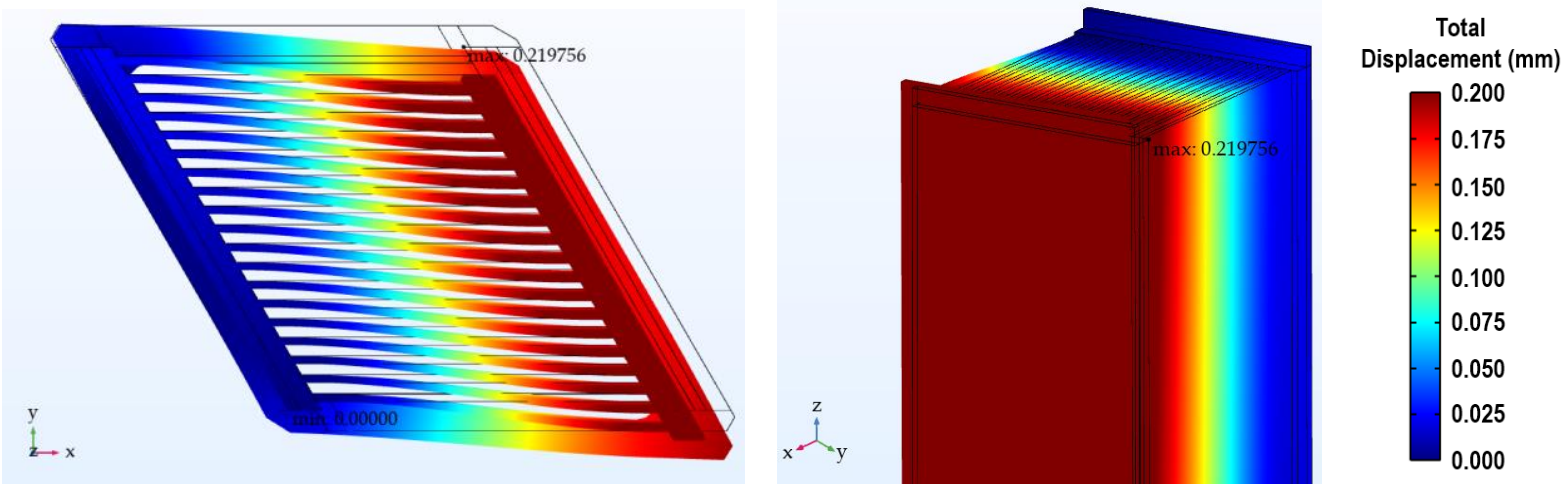

Figure 3.5. Total displacement under a line load of 2,000 $\mathrm{N}$ in the model with MITR DDE end fitting on the bottom (left) top view (right) perspective view (displacement scaling factor of 25 used for visualization purposes).
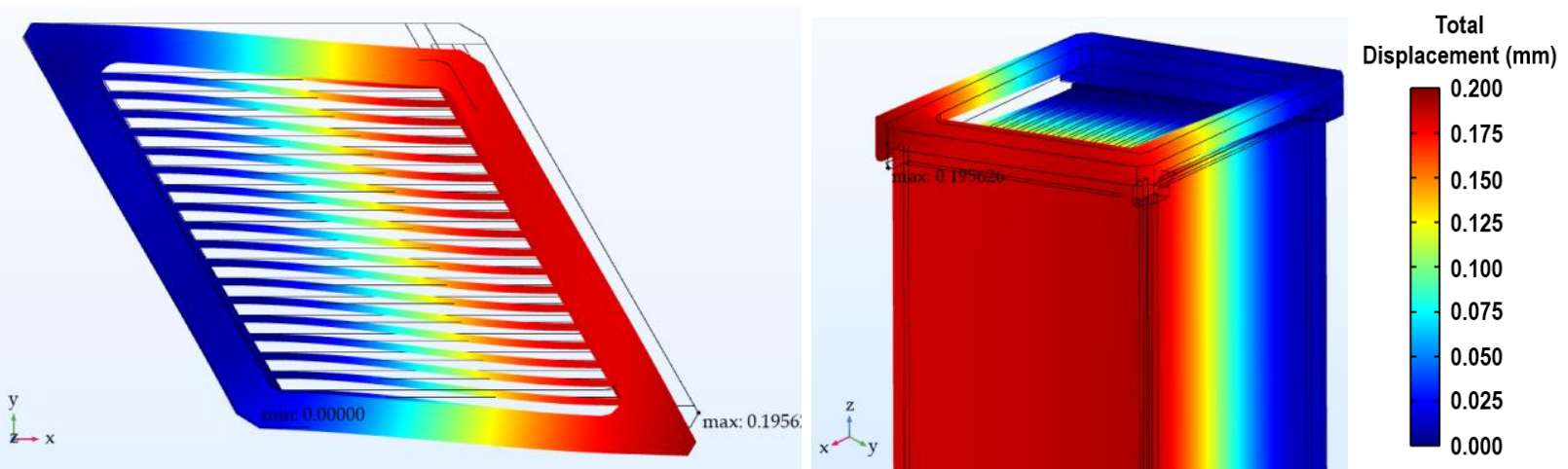

Figure 3.6. Total displacement under a line load of 2,000 $\mathrm{N}$ in the model with MITR DDE end fittings (left) top view (right) perspective view (displacement scaling factor of 25 used for visualization purposes). 

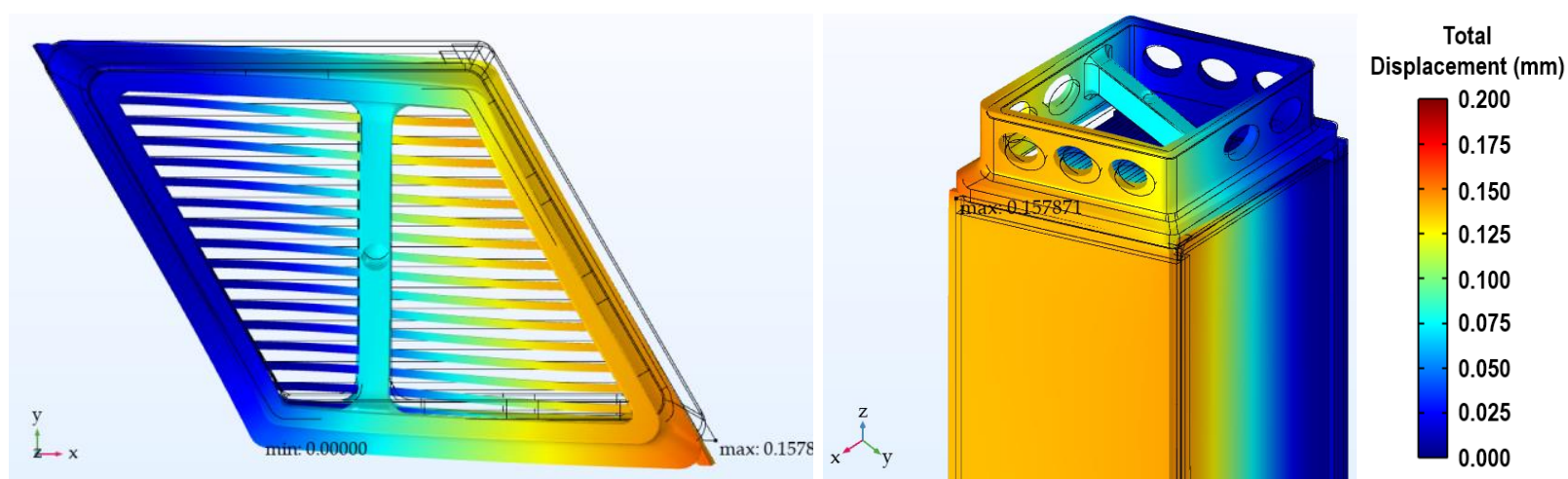

Figure 3.7. Total displacement under a line load of 2,000 $\mathrm{N}$ in the model with MITR LEU end fittings (left) top view (right) perspective view (displacement scaling factor of 25 used for visualization purposes).

The dependence of the results on the mesh density for this load case has been presented in APPENDIX C.

\subsection{Hydraulic Load}

Figure 3.8, Figure 3.9, and Figure 3.10 show deformations in the models without the top end fitting, with the MITR DDE end fittings, and with the MITR LEU end fittings, respectively, under a surface load applied to the outermost plate. In these figures, a scaling factor of 100 was applied to the displacement field for visualization purposes. The assumed surface load caused a maximum total displacement of $0.0622 \mathrm{~mm}$ ( $2.45 \mathrm{mil})$ in the model without the top end fitting. The maximum total displacement in the model with the MITR DDE end fittings was 3.1\% lower, at $0.0602 \mathrm{~mm}$ (2.37 mil). The maximum total displacement in the model with the MITR LEU end fittings was $8.8 \%$ lower than in the model without the top end fitting, at $0.0568 \mathrm{~mm}$ (2.23 mil).

The dependence of the results on the mesh density for this load case has been presented in APPENDIX C.

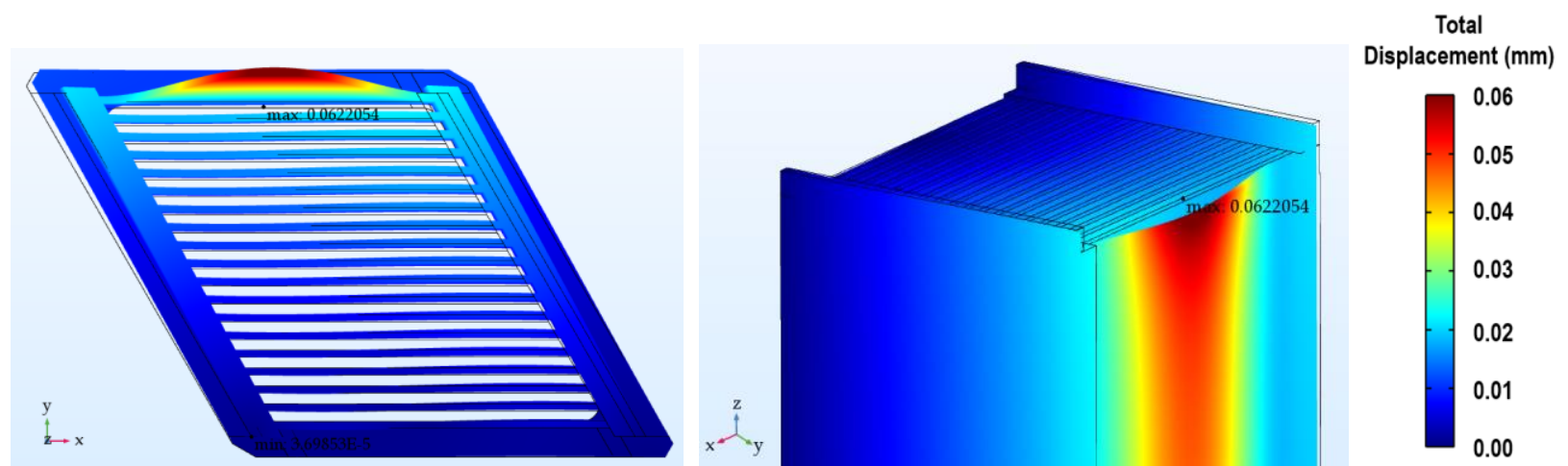

Figure 3.8. Total displacement under a surface load in the model without top end fitting (left) top view (right) perspective view (displacement scaling factor of 100 used for visualization purposes). 

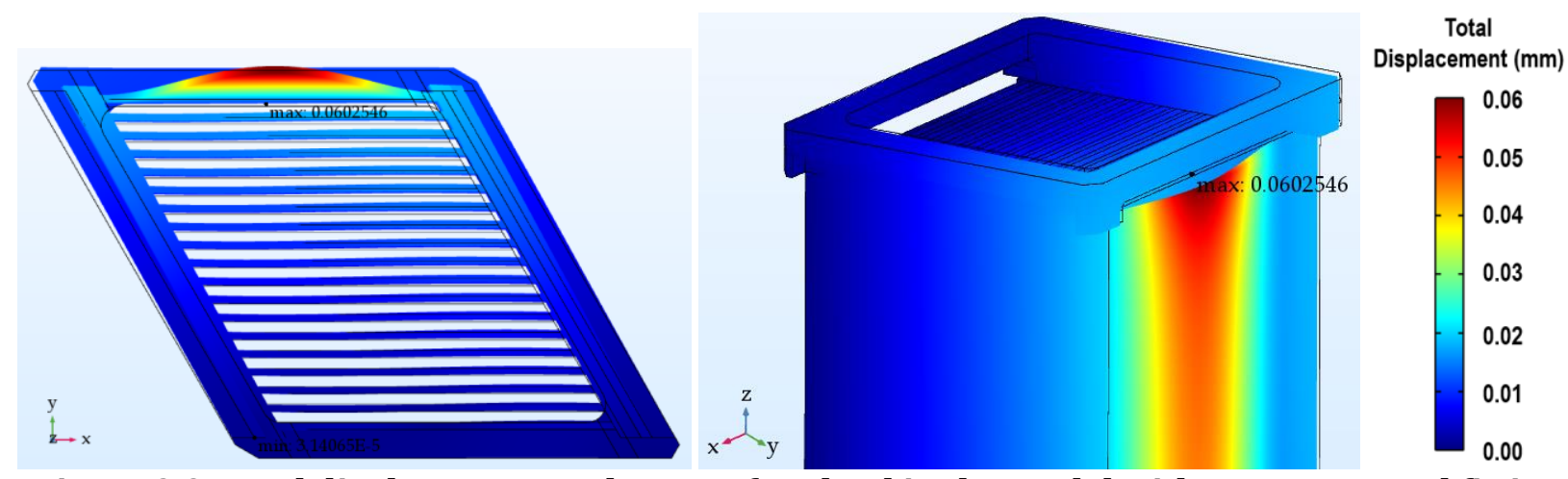

Figure 3.9. Total displacement under a surface load in the model with MITR DDE end fitting (left) top view (right) perspective view (displacement scaling factor of 100 used for visualization purposes).
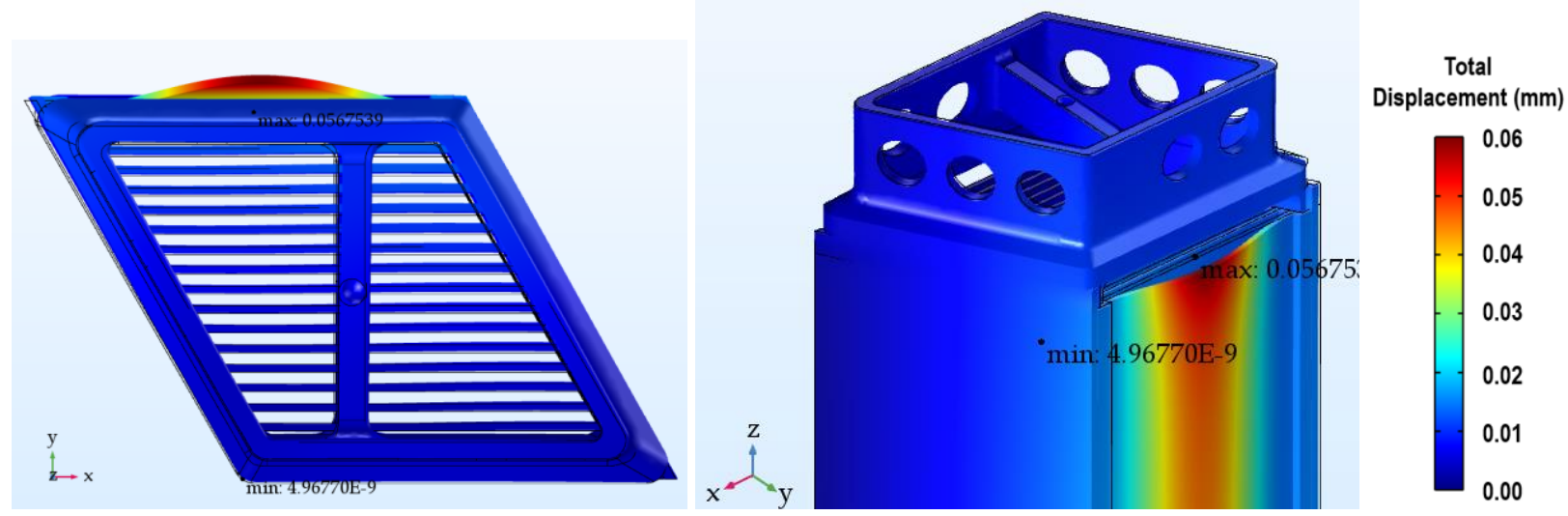

Figure 3.10. Total displacement under a surface load in the model with MITR LEU end fitting (left) top view (right) perspective view (displacement scaling factor of 100 used for visualization purposes).

\subsection{Thermal Load}

The displacements due to the thermal load were calculated along the outer edges on the top of the side plates, as shown in Figure 3.11. X component of the displacement field (called "X displacement" for brevity) along these two edges was of most interest as it represents the change in the shape of the element in the plate width (span) direction due to the thermal load.

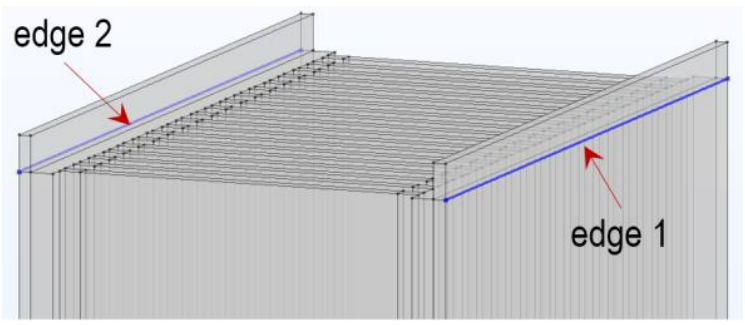

Figure 3.11. Measurement locations for thermal expansion at the top of the side plate.

Figure 3.12 shows the top view of the element without the top end fitting after deformation due to the thermal load. The plot in Figure 3.13 presents the X displacement of two edges at the top of the 
side plates and a subtraction of the two curves representing the lateral change in the shape of the element. The maximum dimensional change of the fuel element in the width direction (X direction in Figure 3.12) was $0.121 \mathrm{~mm}$ ( $4.76 \mathrm{mil}$ ). Figure 3.14 and Figure 3.15 show equivalent plots for the MITR element with DDE end fittings. The maximum dimensional change of the fuel element in the width direction reported at the top of the side plate was $0.119 \mathrm{~mm}$ (4.69 mil) and was $1.9 \%$ lower than in the element without the top end fitting. Figure 3.16 and Figure 3.16 show the same set of results for the element with MITR LEU end fittings. The maximum dimensional change of the fuel element in the width direction due to the same thermal load was $0.118 \mathrm{~mm}$ (4.65 mil) or $2.4 \%$ lower than in the element without the top end fitting. From this load case analysis, it can be concluded that the geometry of the end fittings does not substantially impact the amount of dimensional change of the fuel element due to the thermal load.

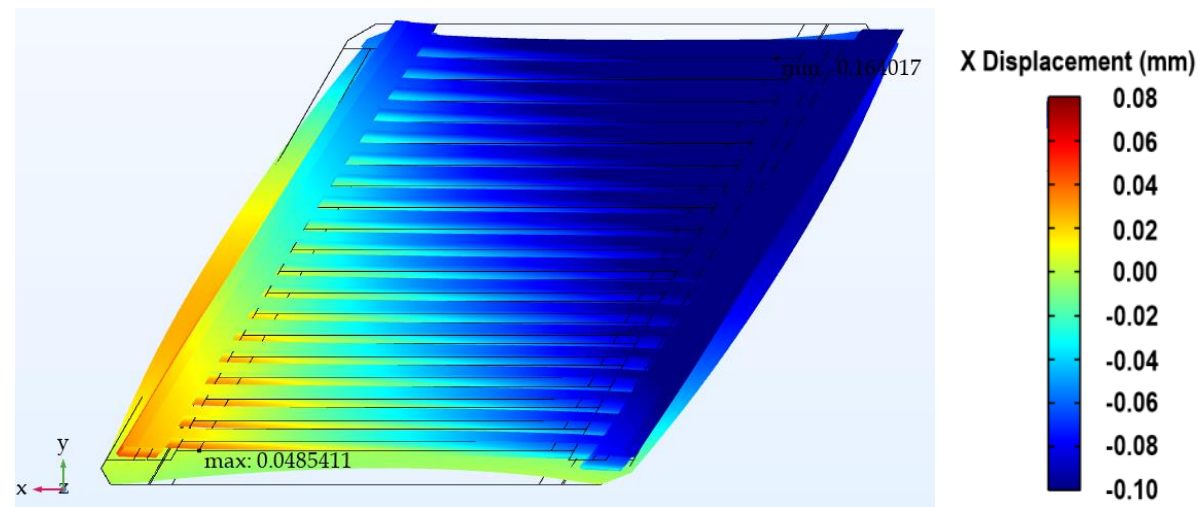

Figure 3.12. $X$ displacement field due to thermal load in MITR DDE without the top end fitting (displacement scaling factor of 50 used for visualization purposes).

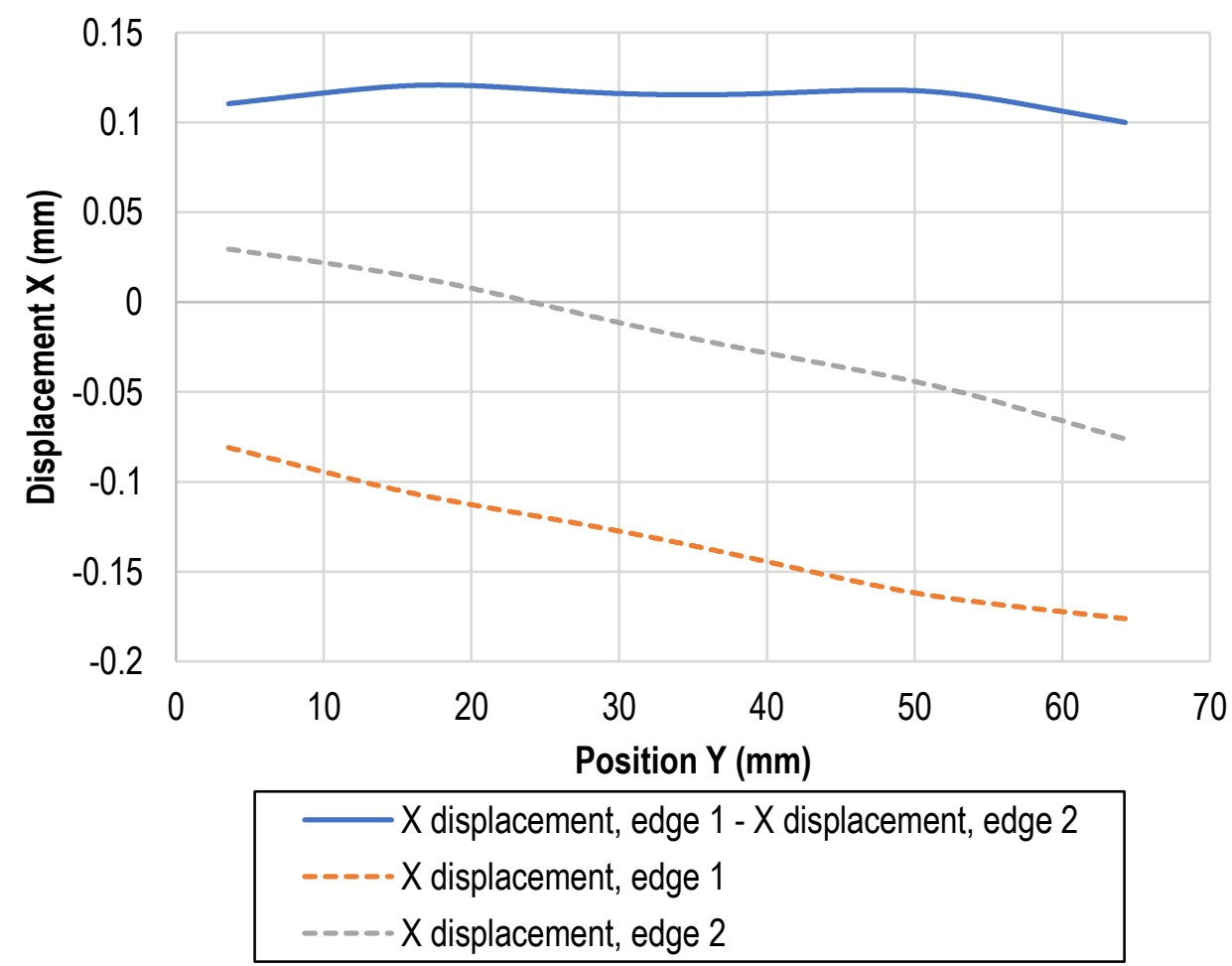

Figure 3.13. $X$ displacement field at the top of the side plates due to thermal load in MITR DDE without the top end fitting. 


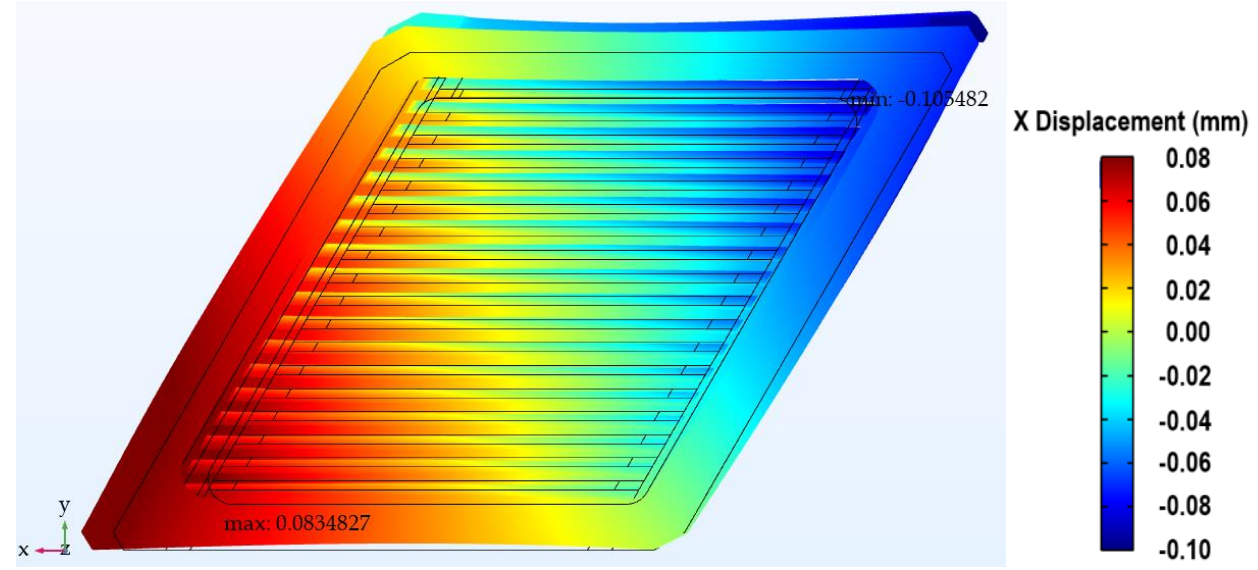

Figure 3.14. $X$ displacement field due to thermal load in MITR DDE (displacement scaling factor of 50 used for visualization purposes).

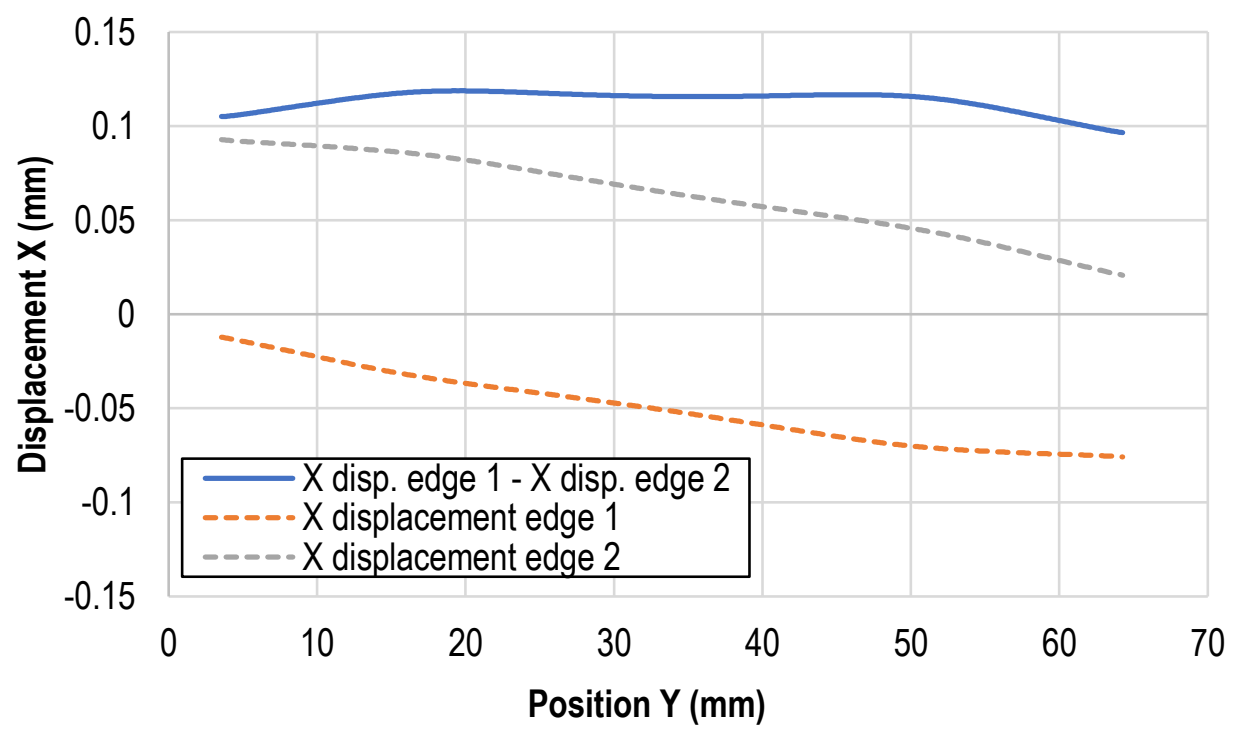

Figure 3.15. $X$ displacement field at the top of the side plates due to thermal load in MITR DDE.

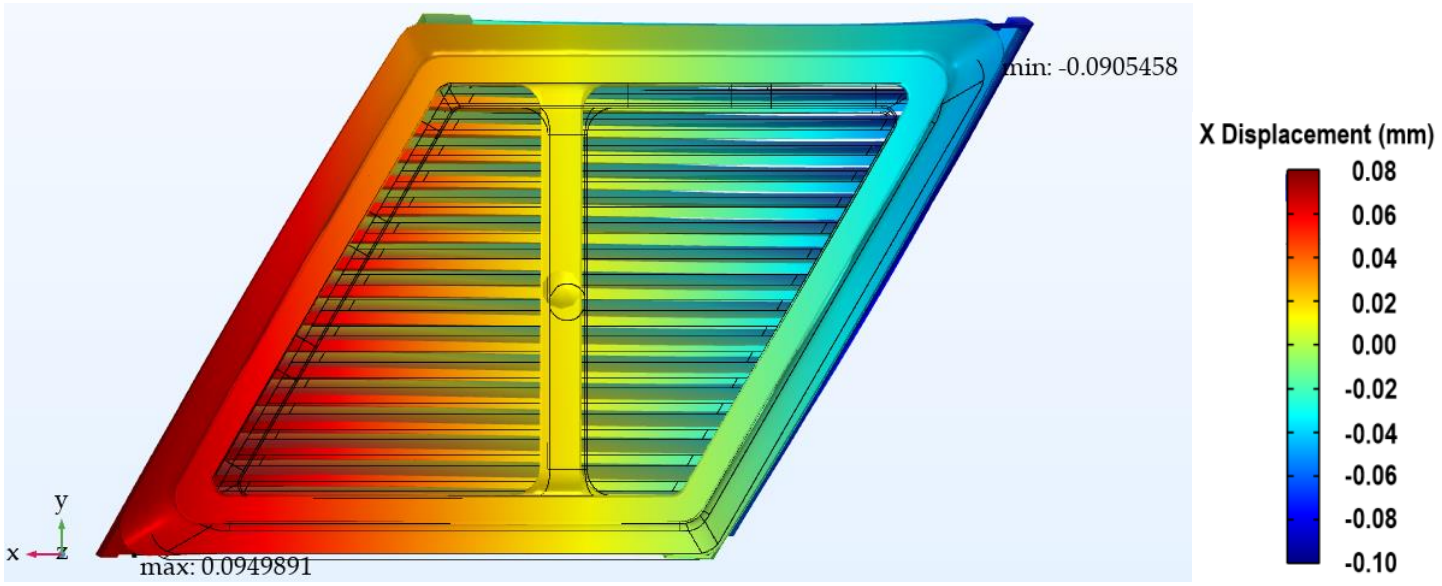

Figure 3.16. $X$ displacement field due to thermal load in MITR LEU fuel element (displacement scaling factor of 50 used for visualization purposes). 


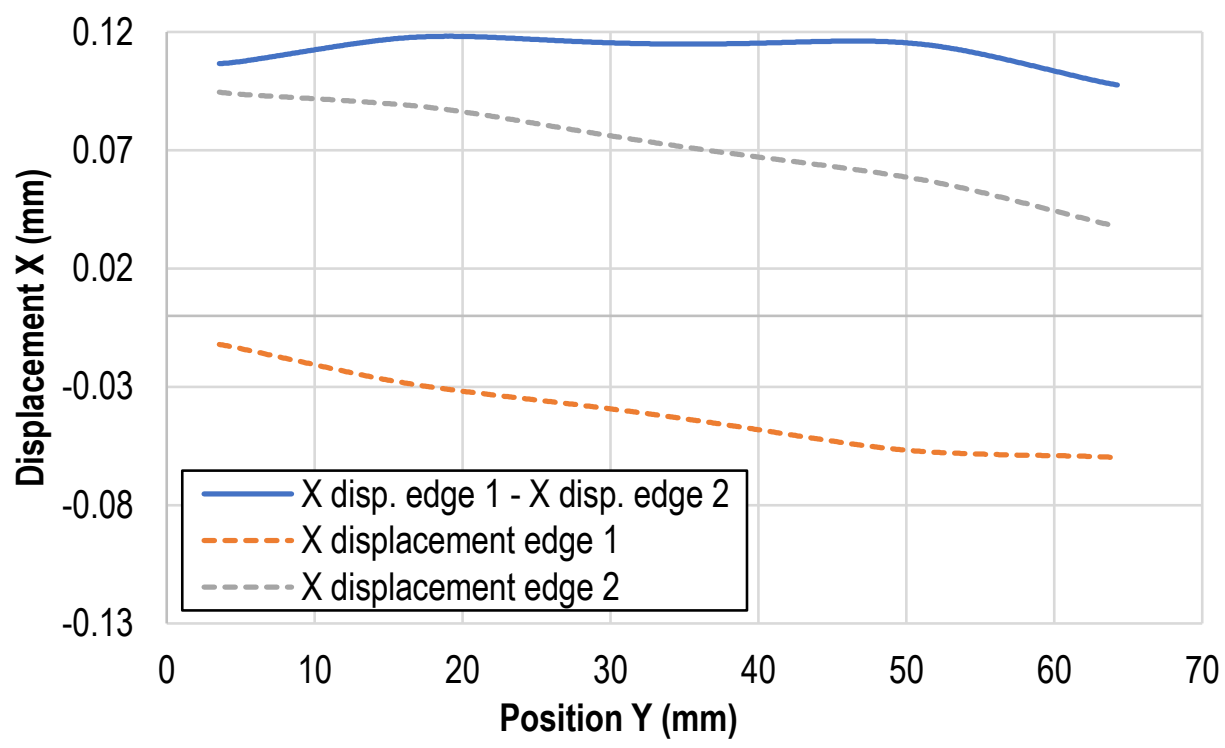

Figure 3.17. $X$ component of displacement field at the top of the side plates due to thermal load in MITR LEU element.

In order to estimate the total change in shape in the end fittings due to the thermal load, which is needed for the estimation of the clearances in the testing basket, an additional set of results has been extracted along the external edges of the end fittings as shown in Figure 3.18.
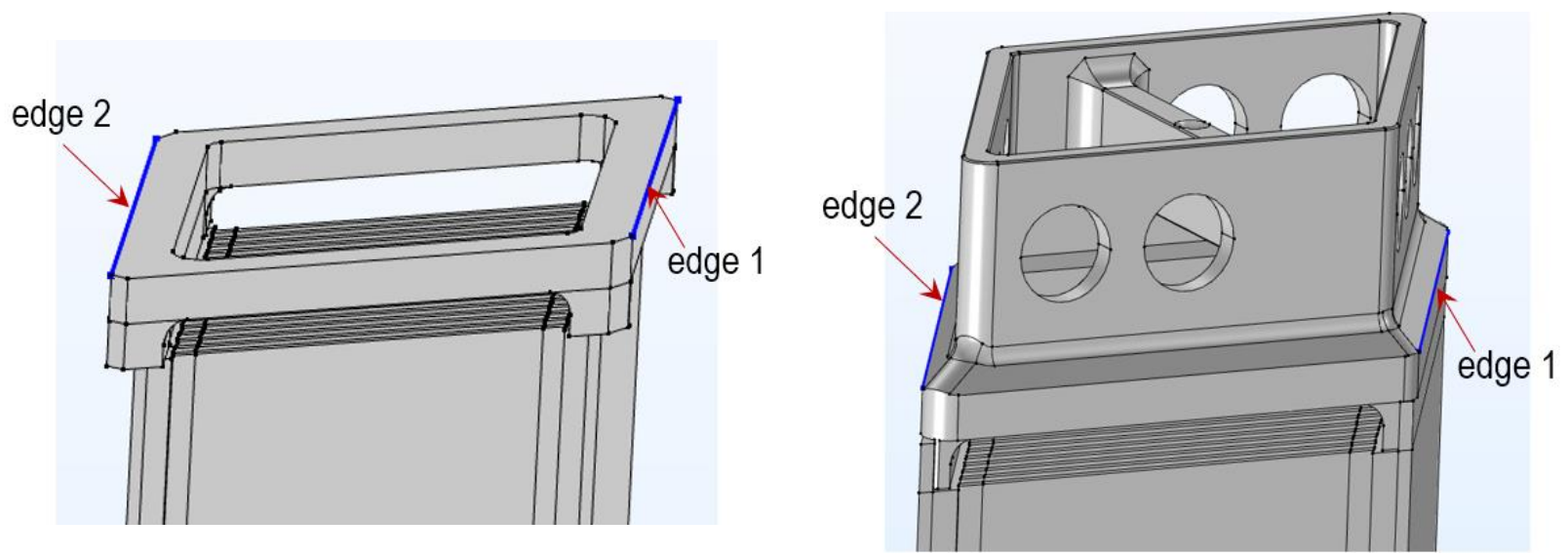

Figure 3.18. Measurement locations for dimensional change caused by the thermal load at the top of the end fittings (left) MITR DDE (right) MITR LEU fuel element.

Figure 3.19 shows the $\mathrm{X}$ component of the total displacements due to the thermal load in the end fitting of the MITR DDE(The X component of the total displacement is parallel to the plates as shown in Figure 3.12, Figure 3.14, and Figure 3.16). Figure 3.20 presents the $\mathrm{X}$ component of the displacement field at the level of the end fitting. The maximum change in shape along the blue line shown in the plot was $0.0128 \mathrm{~mm}$ (5.0 mil). 


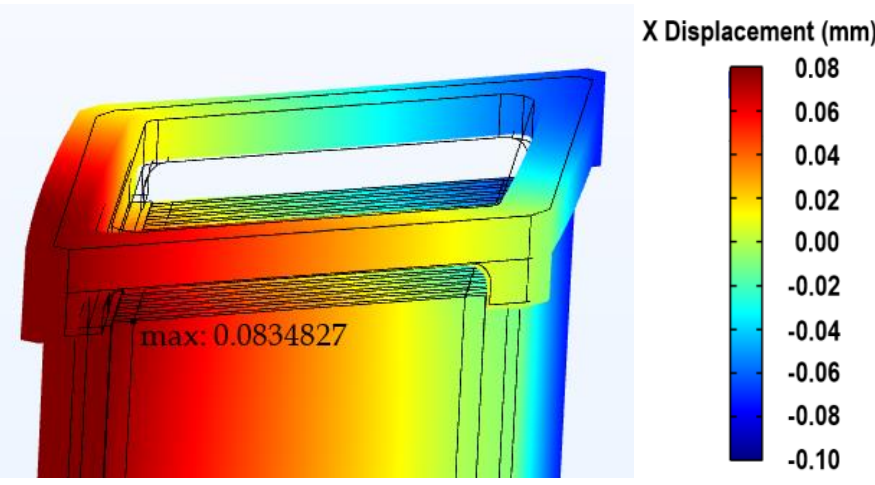

Figure 3.19. $X$ component of displacement field due to thermal load in MITR DDE (displacement scaling factor of 50 used for visualization purposes).

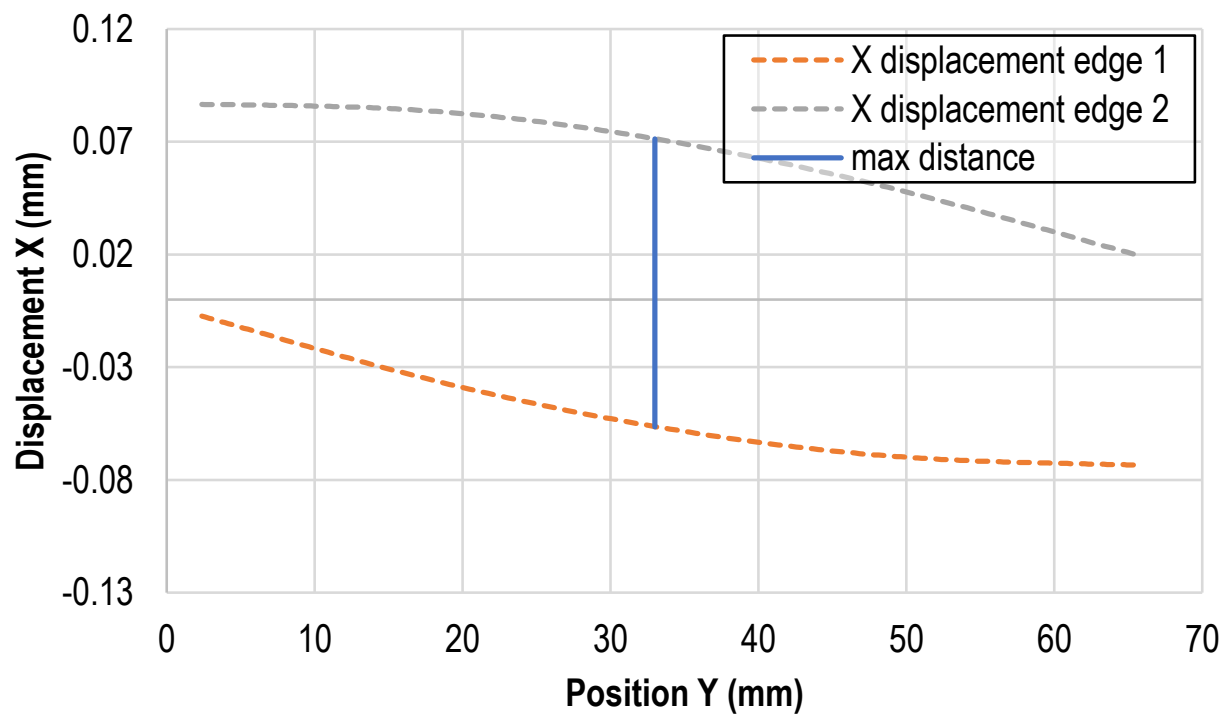

Figure 3.20. X component of displacement field at the level of the end fitting due to thermal load in MITR DDE.

Figure 3.21 shows the $\mathrm{X}$ component of the total displacements due to the thermal load in the end fitting of the MITR LEU fuel element. Figure 3.22 presents the X component of the displacement field at the level of the end fitting. The maximum change in shape along the blue line shown in the plot was $0.0106 \mathrm{~mm}$ (4.2 mil).

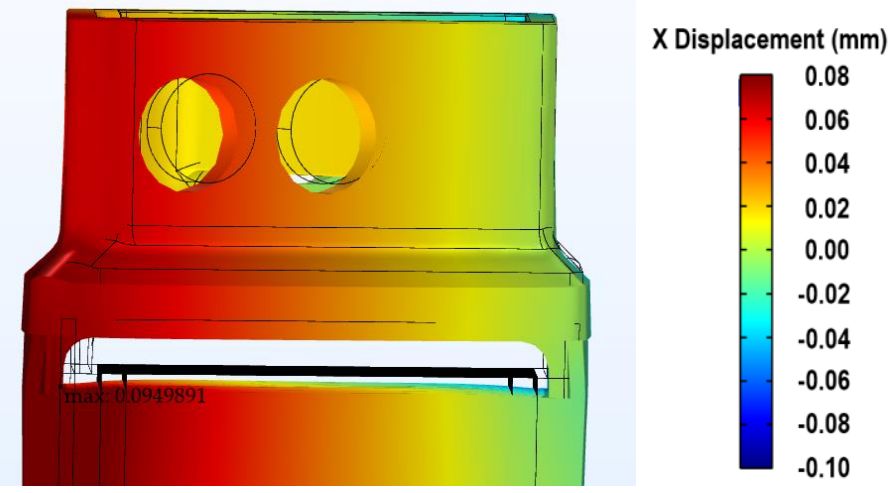

Figure 3.21. X component of displacement field due to thermal load in MITR LEU fuel element (displacement scaling factor of $\mathbf{5 0}$ used for visualization purposes). 


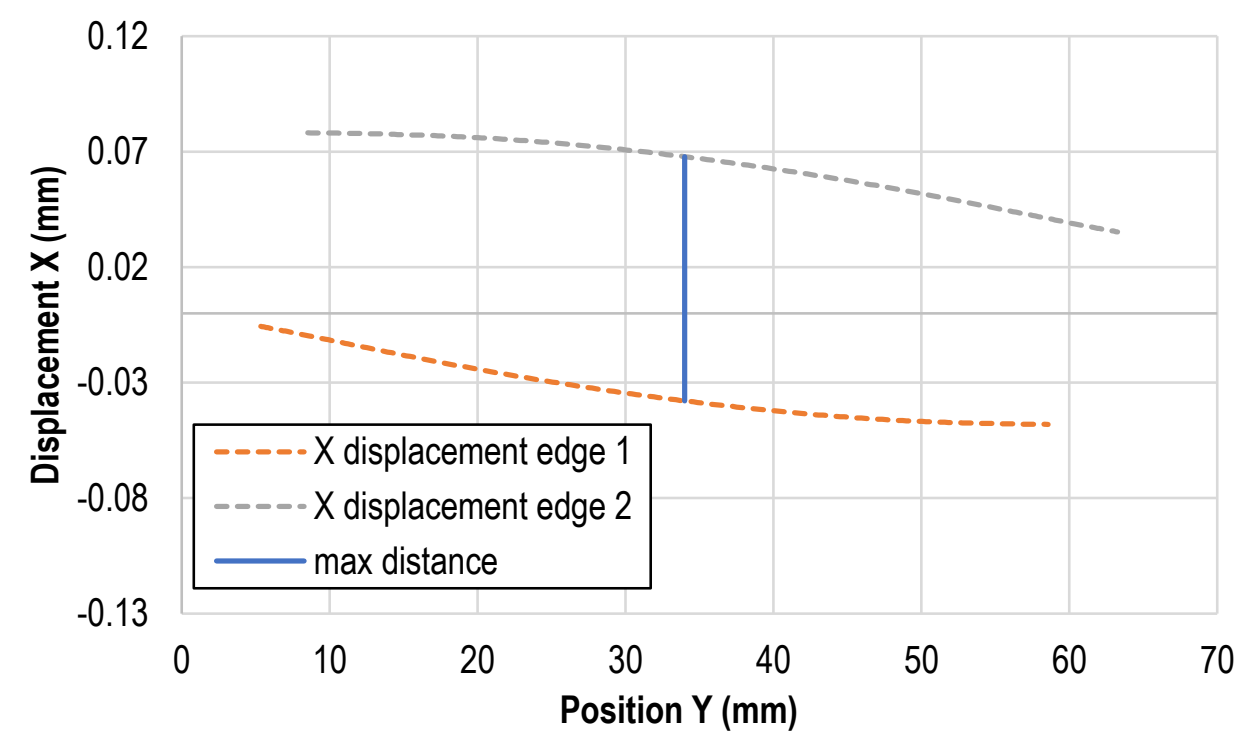

Figure 3.22. $\mathrm{X}$ component of displacement field at the level of the end fitting due to thermal load in MITR LEU fuel element.

It is worth recalling that this analysis only covers the expansion due to the thermal load and contribution from other factors such as fuel swelling and irradiation induced creep to the overall deformation of the displacement is not considered in this work. In the design of the basket, the clearance between the end fitting and the basket caps is 21 mil on both sides of the end fitting, 42 mil in total. Owing to the thermal expansion, this clearance will be reduced to 37.0 mil. No significant differences are expected with regard to the clearance between the test article and the irradiation basket if the MITR LEU end fittings are used instead. 


\section{Conclusions}

The following conclusions can be drawn from the results presented in this report:

1. Although the MITR DDE end fitting (with reduced volume and no cross bar) has a significantly reduced mass and stiffness as compared to the MITR LEU element end fitting, this change in the design does not manifest in a significant loss of the stiffness of the entire element, especially for distributed loads.

2. Under the selected lateral point load, equivalent to the weight of the MITR LEU element, the end fitting stiffness made the largest contribution to the stiffness of the entire fuel element. This load caused the maximum total displacements of $1.64 \mathrm{mil}, 1.26 \mathrm{mil}$, and $0.76 \mathrm{mil}$ in the element without the top end fitting, with the MITR DDE end fittings, and with the MITR LEU end fittings, respectively. Thus, the MITR DDE end fitting reduced the maximum total displacement by $23 \%$, and the MITR LEU end fitting reduced that quantity by $54 \%$ as compared to the element without the top end fitting. Nonetheless, these displacements remained very small in all cases for the range of the loads considered in this work.

3. The selected lateral line load, equivalent to 25 times the weight of the MITR LEU element, caused the maximum total displacement of $8.65 \mathrm{mil}, 7.70 \mathrm{mil}$, and $6.22 \mathrm{mil}$ in the elements without the top end fitting, with the MITR DDE end fittings, and with the MITR LEU end fittings, respectively. Thus, the MITR DDE end fitting reduced the maximum total displacements by $11 \%$ and the MITR LEU end fitting reduced it by $28 \%$ as compared to the element without the top end fitting.

4. The assumed surface load on the outermost fuel plate representing the hydraulic load due to the pressure differential caused the maximum total displacement of $2.45 \mathrm{mil}, 2.37 \mathrm{mil}$, and 2.23 mil in the elements without the top end fitting, with the MITR DDE end fittings, and with the MITR LEU end fittings, respectively. Thus, the MITR DDE end fitting reduced the maximum total displacements by $3.1 \%$ and the MITR LEU end fitting reduced it by $8.8 \%$ as compared to the element without the top end fitting.

5. Thermal expansion based on the temperature field from element 1 at the beginning of cycle 1 of the transition MITR LEU core has been analyzed for all three geometries. Under this realistic thermal load, the maximum dimensional changes for all the elements were predicted to be very similar. They were calculated at $4.76 \mathrm{mil}, 4.69 \mathrm{mil}$, and $4.65 \mathrm{mil}$ in the element without the top end fitting, with the MITR DDE end fittings, and with the MITR LEU end fittings, respectively.

6. The dimensional change of around 5.0 mil reduces the overall 42 mil gap around the MITR DDE end fitting in the irradiation basket by $11.9 \%$. However, this is not the total deformation expected in the element. Additional deformation due to irradiation effects must be estimated. Also, deformation of the basket due to thermal or irradiation effects was not considered.

7. In summary, it can be stated that the structural performance of MITR DDE end fittings is not substantially different from that of the MITR LEU end fitting and is adequate for the DDE irradiation experiment. 


\section{Acknowledgments}

Dr. Lin-wen $\mathrm{Hu}$, and many staff and students, of the Massachusetts Institute of Technology Nuclear Reactor Laboratory are gratefully acknowledged for contributions to reactor conversion, including in the formation of the works referenced. The authors would like to thank Dr. Pham Son of Argonne National Laboratory for his valuable comments.

This work was sponsored by the U.S. Department of Energy, Office of Material Management and Minimization in the U.S. National Nuclear Security Administration, Office of Defense Nuclear Nonproliferation, under Contract DE-AC02-06CH11357. 


\section{References}

[1] K. Sun, L. Hu, E. H. Wilson, A. Bergeron and T. A. Heltemes, "Low Enriched Uranium (LEU) Conversion Preliminary Safety Analysis Report for the MIT Research Reactor (MITR), Revison 2," MIT-NRL-18-01, Massachusetts Institute of Technology, Cambridge, MA, October 2018.

[2] COMSOL Inc., "COMSOL Multiphysics Reference Manual Version 5.3a," COMSOL Inc, Burlington, MA, 2017.

[3] R. Kmak, D. Jaluvka and E. Wilson, "Type F Fuel Plate," R4F-100-003-24, Massachusetts Institute of Technology Reactor (MITR), Cambridge, MA, August 2018.

[4] R. Kmak, D. Jaluvka and E. Wilson, "Type Y Fuel Plate," R4F-100-005-2, Massachusetts Institute of Technology Reactor (MITR), Cambridge, MA, August 2018.

[5] R. Kmak, D. Jaluvka and E. Wilson, "Type T Fuel Plate," R4F-100-006-2, Massachusetts Institute of Technology Reactor (MITR), Cambridge, MA, August 2018.

[6] R. Kmak, D. Jaluvka and E. Wilson, "Side Plate," R4F-100-001-3, Massachusetts Institute of Technology Reactor (MITR), Cambridge, MA, August 2018.

[7] R. Kmak, D. Jaluvka and E. Wilson, "LEU Fuel Element," R4F-100-000-4, Massachusetts Institute of Technology Reactor (MITR), Cambridge, MA, August 2018.

[8] R. Kmak, D. Jaluvka and E. Wilson, "Nozzle End Fitting - Upper," R4F-100-002-3, Massachusetts Institute of Technology Reactor (MITR), Cambridge, MA, August 2018.

[9] R. Kmak, D. Jaluvka and E. Wilson, "Nozzle End Fitting - Lower," R4F-100-004-3, Massachusetts Institute of Technology Reactor (MITR), Cambridge, MA, August 2018.

[10] G. Housley, and et al., "MITR DDE Element Assembly and Details," DWG-606748 Rev. 1, Idaho National Laboratory, Idaho Falls, ID, November 2019.

[11] G. Wang, C. Bojanowski, A. Dave, D. Jaluvka, E. Wilson and L. Hu, "MITR Low-Enriched Uranium Conversion Fluid-Structure Interaction Preliminary Design Verification," ANL/RTR/TM-21/1, Argonne National Laboratory, Lemont, IL, July 2021.

[12] K. Sun, A. Dave, L. Hu, E. Wilson, E. Jaluvka, S. Pham and T. Heltemes, "Transitional Core Planning and Safety Analyses in Support of MITR LEU Fuel Conversion," MITR-NRL-18-02, rev. 1, Massachusetts Institute of Technology Reactor (MITR), Cambridge, MA, June 2020.

[13] K. Sun, A. Dave, L. Hu, D. Jaluvka, S. Pham, J. Stillman and E. Wilson, "Irradiation Demonstration Element Design Parameters for MITR LEU U-Mo Fuel Conversion," MITR-NRL-18-03 Rev. 2, Massachusetts Institute of Technology Reactor (MITR), Cambridge, MA, July 2020.

[14] B. Rabin, M. Meyer, J. Cole, I. Glagolenko, W. Jones, J.-F. Jue, D. Keiser Jr, C. Miller, G. Moore, H. Ozaltun, F. Rice, A. Robinson, J. Smith, D. Wachs, W. Williams, N. Woolstenhulme, G. Hofman and Y. Kim, "Preliminary Report on U-Mo Monolithic Fuel for Research Reactors," INL EXT-17-40975 Revision 3, Idaho National Laboratory, Idaho Falls, ID, March 2020.

[15] L. Jamison, J. Stillman, D. Jaluvka, W. Mohamed, Y. Kim and E. Wilson, "Review of the Technical Basis for Properties and Fuel Performance Data Used in HEU to LEU Conversion Analysis for U10Mo Monolithic Alloy Fuel," ANL/RTR/TM-17/19 Rev. 1, Argonne National Laboratory, Lemont, IL, September 2020.

[16] W. Mohamed, H. Roh, J. Stillman and E. Wilson, "Fuel Swelling and Creep Analysis for a MURR LEU U-10Mo Monolithic Plate," ANL/RTR/TM-18/19, Argonne National Laboratory, Lemont, IL, March 2019. 
[17] H. Roh, W. Mohamend, C. Cetinbas and E. Wilson, "Preliminary Assessment of Structural Behavior of MITR Low-Enriched Uranium Fuel Plates," in Transactions of the American Nuclear Society, 2020 ANS Virtual Winter Meeting, November 16-19, 2020.

[18] W. Frei, "How to Identify and Resolve Singularities in the Model when Meshing," COMSOL Inc., Burlington, MA, 29 October 2013. [Online]. Available: https://www.comsol.com/blogs/howidentify-resolve-singularities-model-meshing/. [Accessed 3 March 2021].

[19] H. Sonnerlind, "Singularities in Finite Element Models: Dealing with Red Spots," COMSOL Inc., Burlington, MA, 3 June 2015. [Online]. Available:

https://www.comsol.com/blogs/singularities-in-finite-element-models-dealing-with-redspots/. [Accessed 3 March 2021]. 


\section{APPENDIX A: MITR LEU without top end fitting versus MITR DDE without top end fitting}

In this section comparison of the results for the case of MITR LEU element without top end fitting and MITR DDE without the top end fitting is performed. MITR LEU element without the top end fitting was not presented in the body of the report as MITR DDE element without the top end fitting was assumed to be a good representation of the case. Here the justification of that assumption is presented. The results presented here for the MITR LEU element without the top end fitting was based on the normal mesh of the MITR LEU element.

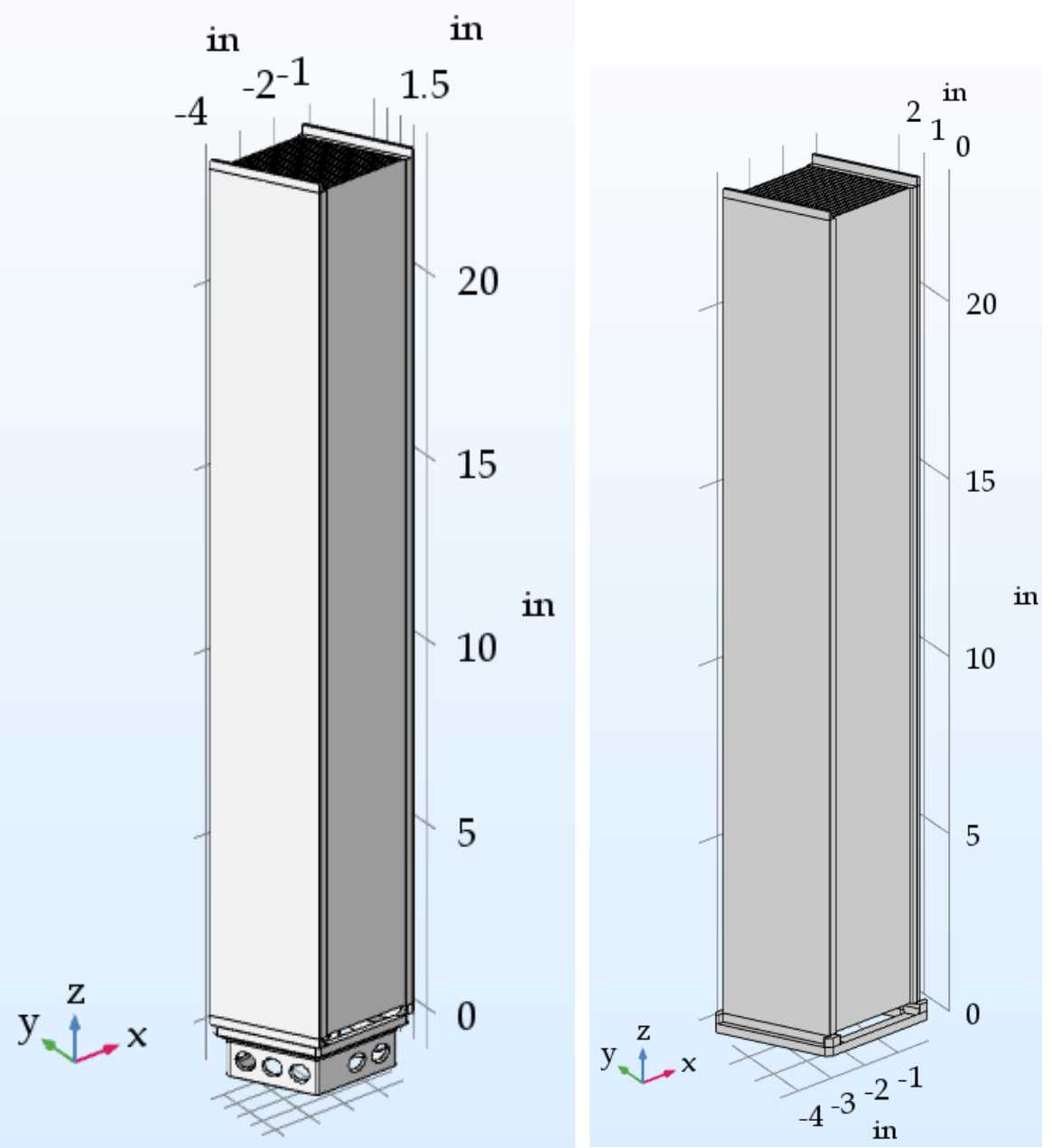

Figure A.1. Geometry of models without the top end fittings (left) MITR LEU (right) MITR DDE. 
Table A.1. Comparison of results for MITR LEU without the top end fitting and MITR DDE without the top end fitting.

\begin{tabular}{|c|c|c|c|c|}
\hline ID & loading cases & $\begin{array}{c}\text { maximum displacement for } \\
\text { MITR LEU fuel element without } \\
\text { the top end fitting (mm) }\end{array}$ & $\begin{array}{c}\text { maximum displacement for } \\
\text { MITR DDE without the top end } \\
\text { fitting (mm) }\end{array}$ & difference (\%) \\
\hline $\mathbf{1}$ & lateral point load & 0.0413 & 0.0416 & 0.7 \\
\hline $\mathbf{2}$ & lateral line load & 0.238 & 0.220 & 8.2 \\
\hline $\mathbf{3}$ & hydraulic load & 0.0622 & 0.0617 & 0.8 \\
\hline $\mathbf{4}$ & thermal & 0.121 & 0.121 & 0.0 \\
\hline
\end{tabular}




\section{APPENDIX B: Average Temperature Distribution in the Plates of MITR LEU Transition Core Element 1 at BOC 1 [12]}

\begin{tabular}{cccccccccc}
$\begin{array}{c}\text { PLATE } \\
01\end{array}$ & $\begin{array}{c}\text { stripe 1 } \\
\text { avg temp } \\
\left({ }^{\circ} \mathrm{C}\right)\end{array}$ & $\begin{array}{c}\text { stripe 2 } \\
\text { avg temp } \\
\left({ }^{\circ} \mathrm{C}\right)\end{array}$ & $\begin{array}{c}\text { stripe 3 } \\
\text { avg temp } \\
\left({ }^{\circ} \mathrm{C}\right)\end{array}$ & $\begin{array}{c}\text { stripe 4 } \\
\text { avg temp } \\
\left({ }^{\circ} \mathrm{C}\right)\end{array}$ & $\begin{array}{c}\text { PLATE } \\
\text { Axial }\end{array}$ & $\begin{array}{c}\text { Axial } \\
\text { stripe 1 } \\
\text { avg temp } \\
\left({ }^{\circ} \mathrm{C}\right)\end{array}$ & $\begin{array}{c}\text { stripe 2 } \\
\text { avg temp } \\
\left({ }^{\circ} \mathrm{C}\right)\end{array}$ & $\begin{array}{c}\text { stripe 3 } \\
\text { avg temp } \\
\left({ }^{\circ} \mathrm{C}\right)\end{array}$ & $\begin{array}{c}\text { stripe 4 } \\
\text { avg temp } \\
\left({ }^{\circ} \mathrm{C}\right)\end{array}$ \\
\hline 1 & 87.84 & 80.61 & 80.45 & 86.53 & 1 & 91.04 & 80.43 & 80.91 & 88.75 \\
2 & 80.54 & 75.24 & 75.28 & 79.38 & 2 & 82.85 & 75.59 & 75.53 & 82.03 \\
3 & 80.93 & 75.51 & 74.64 & 79.05 & 3 & 84.51 & 76.99 & 76.73 & 82.76 \\
4 & 82.11 & 76.33 & 76.42 & 80.17 & 4 & 86.87 & 79.64 & 79.18 & 84.53 \\
\hline 5 & 83.74 & 77.56 & 77.52 & 81.13 & 5 & 88.56 & 81.09 & 80.86 & 86.57 \\
6 & 85.56 & 79.29 & 78.23 & 82.78 & 6 & 91.18 & 82.75 & 82.30 & 88.63 \\
7 & 86.39 & 79.93 & 79.85 & 84.20 & 7 & 92.06 & 84.05 & 83.64 & 90.14 \\
8 & 87.05 & 81.29 & 80.79 & 84.90 & 8 & 93.23 & 85.11 & 84.59 & 90.94 \\
9 & 89.45 & 82.16 & 81.73 & 86.58 & 9 & 95.27 & 85.92 & 85.69 & 92.42 \\
10 & 90.61 & 83.16 & 82.05 & 86.99 & 10 & 96.39 & 86.84 & 85.88 & 92.67 \\
11 & 90.77 & 83.21 & 82.28 & 87.28 & 11 & 96.58 & 86.87 & 85.86 & 92.52 \\
12 & 89.51 & 82.03 & 81.92 & 86.55 & 12 & 95.54 & 85.49 & 85.69 & 91.70 \\
13 & 88.18 & 80.88 & 80.57 & 85.31 & 13 & 93.55 & 84.79 & 84.18 & 91.66 \\
14 & 87.04 & 80.42 & 80.13 & 84.70 & 14 & 92.65 & 84.19 & 82.87 & 89.98 \\
15 & 86.98 & 80.34 & 80.06 & 85.36 & 15 & 92.02 & 83.06 & 82.69 & 90.63 \\
16 & 91.78 & 83.45 & 83.66 & 89.17 & 16 & 96.00 & 86.30 & 86.35 & 94.41
\end{tabular}




\begin{tabular}{ccccc}
$\begin{array}{c}\text { PLATE } \\
03\end{array}$ & $\begin{array}{c}\text { stripe 1 } \\
\text { avg temp } \\
\left({ }^{\circ} \mathrm{C}\right)\end{array}$ & $\begin{array}{c}\text { stripe 2 } \\
\text { avg temp } \\
\left({ }^{\circ} \mathrm{C}\right)\end{array}$ & $\begin{array}{c}\text { stripe 3 } \\
\text { avg temp } \\
\left({ }^{\circ} \mathrm{C}\right)\end{array}$ & $\begin{array}{c}\text { stripe 4 } \\
\text { avg temp } \\
\left({ }^{\circ} \mathrm{C}\right)\end{array}$ \\
\hline 1 & 85.18 & 75.34 & 75.45 & 83.71 \\
2 & 78.97 & 71.82 & 71.23 & 78.69 \\
3 & 81.18 & 73.68 & 73.10 & 80.11 \\
4 & 83.53 & 75.80 & 75.91 & 82.46 \\
\hline 5 & 86.26 & 78.36 & 77.82 & 84.83 \\
6 & 88.37 & 79.98 & 79.62 & 86.73 \\
\hline 7 & 89.71 & 81.47 & 80.78 & 88.00 \\
8 & 91.09 & 82.49 & 81.91 & 89.09 \\
9 & 92.60 & 83.43 & 82.93 & 90.39 \\
10 & 94.38 & 84.34 & 83.50 & 91.57 \\
11 & 94.15 & 84.02 & 83.10 & 91.67 \\
12 & 93.46 & 83.28 & 83.13 & 90.65 \\
13 & 92.12 & 82.35 & 82.19 & 90.25 \\
14 & 91.25 & 81.72 & 81.04 & 89.24 \\
15 & 90.11 & 80.63 & 80.22 & 88.88 \\
16 & 93.78 & 83.47 & 83.24 & 93.12 \\
\hline
\end{tabular}

\begin{tabular}{ccccc}
$\begin{array}{c}\text { PLATE } \\
04\end{array}$ & $\begin{array}{c}\text { stripe 1 } \\
\text { avg temp } \\
\left({ }^{\circ} \mathrm{C}\right)\end{array}$ & $\begin{array}{c}\text { stripe 2 } \\
\text { avg temp } \\
\left({ }^{\circ} \mathrm{C}\right)\end{array}$ & $\begin{array}{c}\text { stripe 3 } \\
\text { avg temp } \\
\left({ }^{\circ} \mathrm{C}\right)\end{array}$ & $\begin{array}{c}\text { stripe 4 } \\
\text { avg temp } \\
\left({ }^{\circ} \mathrm{C}\right)\end{array}$ \\
\hline 1 & 95.75 & 82.22 & 82.35 & 94.82 \\
2 & 88.88 & 77.51 & 77.05 & 87.98 \\
3 & 90.75 & 80.42 & 80.03 & 90.91 \\
4 & 94.17 & 83.61 & 83.53 & 93.81 \\
\hline 5 & 96.94 & 86.68 & 85.79 & 95.82 \\
6 & 99.82 & 87.93 & 87.53 & 97.76 \\
7 & 101.06 & 89.55 & 89.03 & 99.40 \\
8 & 102.42 & 90.43 & 90.33 & 100.59 \\
9 & 103.49 & 91.07 & 91.15 & 101.58 \\
10 & 104.56 & 91.36 & 91.24 & 101.91 \\
11 & 104.67 & 91.16 & 90.10 & 102.13 \\
12 & 102.72 & 89.87 & 89.53 & 100.57 \\
13 & 100.86 & 88.28 & 88.05 & 99.24 \\
14 & 98.57 & 86.61 & 86.19 & 97.61 \\
15 & 96.88 & 84.40 & 84.53 & 97.11 \\
16 & 101.86 & 88.14 & 87.75 & 100.95 \\
\hline
\end{tabular}

\begin{tabular}{ccccc}
$\begin{array}{c}\text { PLATE } \\
05\end{array}$ & $\begin{array}{c}\text { stripe 1 } \\
\text { avg temp } \\
\left({ }^{\circ} \mathrm{C}\right)\end{array}$ & $\begin{array}{c}\text { stripe 2 } \\
\text { avg temp } \\
\left({ }^{\circ} \mathrm{C}\right)\end{array}$ & $\begin{array}{c}\text { stripe 3 } \\
\text { avg temp } \\
\left({ }^{\circ} \mathrm{C}\right)\end{array}$ & $\begin{array}{c}\text { stripe 4 } \\
\text { avg temp } \\
\left({ }^{\circ} \mathrm{C}\right)\end{array}$ \\
\hline 1 & 92.49 & 79.31 & 78.84 & 93.15 \\
2 & 86.00 & 74.83 & 74.19 & 85.61 \\
3 & 87.97 & 78.44 & 77.62 & 88.35 \\
\hline 4 & 91.66 & 81.29 & 80.47 & 92.17 \\
\hline 5 & 94.91 & 83.83 & 83.75 & 94.54 \\
6 & 97.54 & 85.99 & 85.97 & 96.07 \\
\hline 7 & 99.11 & 87.64 & 87.23 & 98.39 \\
8 & 100.13 & 88.44 & 87.93 & 99.21 \\
\hline 9 & 101.09 & 89.10 & 88.38 & 100.62 \\
10 & 103.20 & 89.44 & 89.26 & 101.08 \\
11 & 102.57 & 89.04 & 88.76 & 101.28 \\
12 & 101.00 & 87.99 & 87.12 & 99.67 \\
13 & 98.51 & 86.15 & 86.09 & 98.49 \\
14 & 97.26 & 84.80 & 84.55 & 97.04 \\
15 & 95.75 & 83.07 & 83.12 & 95.87 \\
16 & 100.06 & 86.25 & 86.25 & 100.51 \\
\hline
\end{tabular}

\begin{tabular}{ccccc}
$\begin{array}{c}\text { PLATE } \\
06\end{array}$ & $\begin{array}{c}\text { stripe 1 } \\
\text { avg temp } \\
\left({ }^{\circ} \mathrm{C}\right)\end{array}$ & $\begin{array}{c}\text { stripe 2 } \\
\text { avg temp } \\
\left({ }^{\circ} \mathrm{C}\right)\end{array}$ & $\begin{array}{c}\text { stripe 3 } \\
\text { avg temp } \\
\left({ }^{\circ} \mathrm{C}\right)\end{array}$ & $\begin{array}{c}\text { stripe 4 } \\
\text { avg temp } \\
\left({ }^{\circ} \mathrm{C}\right)\end{array}$ \\
\hline $\begin{array}{c}\text { Axial } \\
1\end{array}$ & 91.51 & 77.67 & 77.19 & 91.50 \\
2 & 83.75 & 72.93 & 72.86 & 84.76 \\
3 & 87.08 & 76.50 & 76.53 & 87.73 \\
4 & 89.87 & 79.47 & 79.51 & 90.58 \\
5 & 92.78 & 82.60 & 82.27 & 93.50 \\
6 & 95.81 & 84.71 & 84.53 & 95.86 \\
7 & 97.22 & 85.77 & 85.86 & 97.66 \\
8 & 98.05 & 86.82 & 86.45 & 98.53 \\
9 & 100.17 & 87.55 & 87.09 & 99.74 \\
10 & 101.33 & 87.57 & 87.38 & 100.08 \\
11 & 100.88 & 86.97 & 87.09 & 100.21 \\
12 & 99.15 & 86.10 & 85.54 & 98.80 \\
13 & 97.65 & 85.00 & 84.81 & 97.33 \\
14 & 95.56 & 83.38 & 82.77 & 95.54 \\
15 & 93.91 & 81.30 & 81.62 & 94.68 \\
16 & 98.41 & 84.44 & 84.46 & 99.36 \\
\hline
\end{tabular}




\begin{tabular}{c|c|c|c|c}
$\begin{array}{c}\text { PLATE } \\
07\end{array}$ & $\begin{array}{c}\text { stripe 1 } \\
\text { avg temp } \\
\left({ }^{\circ} \mathrm{C}\right)\end{array}$ & $\begin{array}{c}\text { stripe 2 } \\
\text { avg temp } \\
\left({ }^{\circ} \mathrm{C}\right)\end{array}$ & $\begin{array}{c}\text { stripe 3 } \\
\text { avg temp } \\
\left({ }^{\circ} \mathrm{C}\right)\end{array}$ & $\begin{array}{c}\text { stripe 4 } \\
\text { avg temp } \\
\left({ }^{\circ} \mathrm{C}\right)\end{array}$ \\
\hline 1 & 89.19 & 76.10 & 76.78 & 90.71 \\
2 & 83.42 & 72.72 & 71.95 & 84.89 \\
\hline 3 & 86.20 & 75.84 & 75.60 & 86.90 \\
\hline 4 & 89.05 & 78.53 & 79.46 & 90.59 \\
\hline 5 & 91.96 & 82.00 & 81.35 & 93.17 \\
6 & 95.54 & 84.09 & 83.60 & 95.34 \\
\hline 7 & 96.54 & 84.93 & 85.04 & 96.51 \\
\hline 8 & 97.62 & 85.91 & 85.70 & 98.32 \\
\hline 9 & 98.97 & 86.27 & 86.26 & 99.16 \\
10 & 100.43 & 86.99 & 86.51 & 99.97 \\
11 & 99.59 & 86.66 & 85.70 & 99.83 \\
12 & 98.31 & 84.75 & 84.43 & 98.27 \\
13 & 95.96 & 83.66 & 83.75 & 96.87 \\
14 & 93.99 & 81.91 & 81.89 & 95.65 \\
15 & 92.81 & 80.40 & 80.06 & 94.22 \\
16 & 97.09 & 83.38 & 83.41 & 98.96 \\
\hline
\end{tabular}

\begin{tabular}{ccccc}
$\begin{array}{c}\text { PLATE } \\
08\end{array}$ & $\begin{array}{c}\text { stripe 1 } \\
\text { avg temp } \\
\left({ }^{\circ} \mathrm{C}\right)\end{array}$ & $\begin{array}{c}\text { stripe 2 } \\
\text { avg temp } \\
\left({ }^{\circ} \mathrm{C}\right)\end{array}$ & $\begin{array}{c}\text { stripe 3 } \\
\text { avg temp } \\
\left({ }^{\circ} \mathrm{C}\right)\end{array}$ & $\begin{array}{c}\text { stripe 4 } \\
\text { avg temp } \\
\left({ }^{\circ} \mathrm{C}\right)\end{array}$ \\
\hline 1 & 89.46 & 76.04 & 75.67 & 90.89 \\
2 & 82.28 & 71.88 & 71.95 & 84.36 \\
3 & 85.58 & 75.64 & 75.50 & 86.65 \\
4 & 88.76 & 78.62 & 79.07 & 90.53 \\
5 & 92.46 & 81.64 & 80.87 & 93.64 \\
6 & 94.50 & 83.63 & 83.09 & 95.05 \\
7 & 95.56 & 84.39 & 84.50 & 97.57 \\
8 & 96.56 & 85.54 & 85.51 & 98.18 \\
9 & 97.58 & 85.56 & 85.77 & 98.95 \\
10 & 99.51 & 86.27 & 86.35 & 99.81 \\
11 & 99.10 & 85.77 & 85.24 & 99.34 \\
12 & 97.37 & 84.53 & 84.14 & 97.61 \\
13 & 95.78 & 83.00 & 83.04 & 96.44 \\
14 & 93.00 & 81.37 & 81.30 & 94.91 \\
15 & 92.09 & 79.67 & 79.56 & 94.38 \\
16 & 95.88 & 82.53 & 82.53 & 98.47 \\
\hline
\end{tabular}

\begin{tabular}{ccccc}
$\begin{array}{c}\text { PLATE } \\
09\end{array}$ & $\begin{array}{c}\text { stripe 1 } \\
\text { avg temp } \\
\left({ }^{\circ} \mathrm{C}\right)\end{array}$ & $\begin{array}{c}\text { stripe 2 } \\
\text { avg temp } \\
\left({ }^{\circ} \mathrm{C}\right)\end{array}$ & $\begin{array}{c}\text { stripe 3 } \\
\text { avg temp } \\
\left({ }^{\circ} \mathrm{C}\right)\end{array}$ & $\begin{array}{c}\text { stripe 4 } \\
\text { avg temp } \\
\left({ }^{\circ} \mathrm{C}\right)\end{array}$ \\
\hline 1 & 88.06 & 75.35 & 75.60 & 90.31 \\
2 & 82.00 & 71.41 & 71.90 & 84.04 \\
3 & 84.82 & 75.30 & 75.29 & 86.83 \\
4 & 88.63 & 78.51 & 78.75 & 90.02 \\
\hline 5 & 91.73 & 81.03 & 81.04 & 92.57 \\
6 & 94.09 & 83.18 & 83.08 & 95.37 \\
\hline 7 & 95.20 & 84.09 & 84.55 & 96.99 \\
8 & 95.62 & 85.05 & 85.12 & 98.15 \\
9 & 97.76 & 85.60 & 85.69 & 99.08 \\
10 & 99.28 & 85.54 & 85.96 & 100.13 \\
11 & 98.15 & 85.38 & 85.12 & 98.56 \\
12 & 96.91 & 83.96 & 83.79 & 98.44 \\
13 & 94.98 & 82.61 & 82.62 & 96.10 \\
14 & 93.17 & 80.61 & 81.11 & 94.78 \\
15 & 91.70 & 79.54 & 79.34 & 94.16 \\
16 & 95.92 & 82.02 & 82.48 & 98.37 \\
\hline & & & & \\
\hline 16 & & & & \\
\hline
\end{tabular}

\begin{tabular}{ccccc}
$\begin{array}{c}\text { PLATE } \\
10\end{array}$ & $\begin{array}{c}\text { stripe 1 } \\
\text { avg temp } \\
\left({ }^{\circ} \mathrm{C}\right)\end{array}$ & $\begin{array}{c}\text { stripe 2 } \\
\text { avg temp } \\
\left({ }^{\circ} \mathrm{C}\right)\end{array}$ & $\begin{array}{c}\text { stripe 3 } \\
\text { avg temp } \\
\left({ }^{\circ} \mathrm{C}\right)\end{array}$ & $\begin{array}{c}\text { stripe 4 } \\
\text { avg temp } \\
\left({ }^{\circ} \mathrm{C}\right)\end{array}$ \\
\hline 1 & 88.31 & 75.74 & 75.43 & 90.09 \\
2 & 82.10 & 71.21 & 71.46 & 84.31 \\
3 & 84.49 & 74.95 & 75.15 & 86.99 \\
4 & 88.15 & 78.48 & 77.99 & 90.15 \\
5 & 90.80 & 80.85 & 81.02 & 92.61 \\
6 & 93.50 & 83.12 & 82.82 & 94.55 \\
7 & 94.66 & 84.18 & 84.66 & 96.82 \\
8 & 96.06 & 84.78 & 84.66 & 97.66 \\
9 & 97.59 & 85.69 & 85.69 & 99.07 \\
10 & 98.72 & 85.61 & 86.04 & 100.33 \\
11 & 98.20 & 85.20 & 85.30 & 99.41 \\
12 & 97.09 & 84.14 & 83.89 & 98.23 \\
13 & 94.43 & 82.40 & 82.91 & 96.76 \\
14 & 92.40 & 80.91 & 81.08 & 94.83 \\
15 & 91.35 & 79.19 & 79.62 & 94.30 \\
16 & 94.72 & 82.00 & 82.32 & 98.20 \\
\hline
\end{tabular}




\begin{tabular}{c|c|c|c|c}
$\begin{array}{c}\text { PLATE } \\
11\end{array}$ & $\begin{array}{c}\text { stripe 1 } \\
\text { avg temp } \\
\left({ }^{\circ} \mathrm{C}\right)\end{array}$ & $\begin{array}{c}\text { stripe 2 } \\
\text { avg temp } \\
\left({ }^{\circ} \mathrm{C}\right)\end{array}$ & $\begin{array}{c}\text { stripe 3 } \\
\text { avg temp } \\
\left({ }^{\circ} \mathrm{C}\right)\end{array}$ & $\begin{array}{c}\text { stripe 4 } \\
\text { avg temp } \\
\left({ }^{\circ} \mathrm{C}\right)\end{array}$ \\
\hline 1 & 88.45 & 75.23 & 75.51 & 90.78 \\
2 & 81.73 & 70.99 & 71.68 & 84.76 \\
3 & 84.95 & 74.94 & 75.52 & 86.71 \\
4 & 88.77 & 78.72 & 78.40 & 90.20 \\
\hline 5 & 90.91 & 80.52 & 81.29 & 93.45 \\
6 & 93.64 & 82.86 & 83.19 & 95.02 \\
\hline 7 & 94.84 & 84.21 & 84.57 & 96.79 \\
8 & 95.11 & 84.54 & 84.82 & 98.39 \\
9 & 97.52 & 85.20 & 85.91 & 99.75 \\
10 & 98.72 & 85.65 & 85.70 & 100.76 \\
\hline 11 & 97.51 & 85.10 & 85.73 & 99.86 \\
12 & 96.42 & 84.47 & 84.44 & 98.26 \\
13 & 94.69 & 82.85 & 82.83 & 96.89 \\
14 & 92.62 & 80.90 & 81.50 & 95.02 \\
15 & 91.09 & 79.04 & 79.88 & 94.00 \\
16 & 94.51 & 81.71 & 82.37 & 98.23 \\
\hline
\end{tabular}

\begin{tabular}{ccccc}
$\begin{array}{c}\text { PLATE } \\
12\end{array}$ & $\begin{array}{c}\text { stripe 1 } \\
\text { avg temp } \\
\left({ }^{\circ} \mathrm{C}\right)\end{array}$ & $\begin{array}{c}\text { stripe 2 } \\
\text { avg temp } \\
\left({ }^{\circ} \mathrm{C}\right)\end{array}$ & $\begin{array}{c}\text { stripe 3 } \\
\text { avg temp } \\
\left({ }^{\circ} \mathrm{C}\right)\end{array}$ & $\begin{array}{c}\text { stripe 4 } \\
\text { avg temp } \\
\left({ }^{\circ} \mathrm{C}\right)\end{array}$ \\
\hline 1 & 88.13 & 75.30 & 75.45 & 90.71 \\
2 & 81.57 & 71.47 & 71.82 & 84.08 \\
3 & 84.69 & 75.53 & 75.53 & 86.27 \\
4 & 88.45 & 78.66 & 78.77 & 90.19 \\
\hline 5 & 90.81 & 81.06 & 81.69 & 93.43 \\
6 & 93.41 & 82.95 & 83.33 & 95.23 \\
7 & 95.06 & 84.27 & 84.72 & 97.09 \\
8 & 95.29 & 84.65 & 85.60 & 98.76 \\
9 & 96.81 & 85.62 & 86.19 & 99.92 \\
10 & 98.56 & 85.78 & 86.39 & 101.00 \\
\hline 11 & 98.12 & 85.29 & 85.87 & 100.04 \\
12 & 96.17 & 83.90 & 84.76 & 99.00 \\
13 & 94.62 & 82.69 & 83.43 & 97.76 \\
\hline 14 & 92.29 & 81.15 & 81.45 & 95.22 \\
15 & 90.86 & 79.24 & 80.11 & 94.09 \\
16 & 94.54 & 81.83 & 82.61 & 98.76 \\
\hline
\end{tabular}

\begin{tabular}{c|c|c|c|c}
$\begin{array}{c}\text { PLATE } \\
13\end{array}$ & $\begin{array}{c}\text { stripe 1 } \\
\text { avg temp } \\
\left({ }^{\circ} \mathrm{C}\right)\end{array}$ & $\begin{array}{c}\text { stripe 2 } \\
\text { avg temp } \\
\left({ }^{\circ} \mathrm{C}\right)\end{array}$ & $\begin{array}{c}\text { stripe 3 } \\
\text { avg temp } \\
\left({ }^{\circ} \mathrm{C}\right)\end{array}$ & $\begin{array}{c}\text { stripe 4 } \\
\text { avg temp } \\
\left({ }^{\circ} \mathrm{C}\right)\end{array}$ \\
\hline 1 & 87.45 & 75.41 & 76.01 & 91.60 \\
2 & 82.21 & 71.77 & 72.17 & 84.43 \\
3 & 84.69 & 75.41 & 75.66 & 87.41 \\
4 & 88.39 & 78.63 & 79.20 & 90.41 \\
\hline 5 & 91.79 & 81.89 & 82.10 & 93.60 \\
6 & 93.76 & 83.29 & 83.72 & 95.78 \\
7 & 95.31 & 84.47 & 85.27 & 97.93 \\
8 & 95.68 & 85.48 & 86.17 & 99.22 \\
\hline 9 & 97.29 & 85.74 & 86.89 & 100.57 \\
10 & 98.35 & 86.41 & 86.99 & 100.73 \\
11 & 97.02 & 86.03 & 86.54 & 101.07 \\
12 & 96.00 & 84.38 & 85.56 & 99.71 \\
13 & 94.39 & 83.11 & 83.97 & 97.57 \\
14 & 92.21 & 81.28 & 82.28 & 96.23 \\
15 & 90.89 & 79.66 & 80.58 & 94.88 \\
16 & 94.14 & 82.36 & 83.33 & 99.66 \\
\hline
\end{tabular}

\begin{tabular}{ccccc}
$\begin{array}{c}\text { PLATE } \\
14\end{array}$ & $\begin{array}{c}\text { stripe 1 } \\
\text { avg temp } \\
\left({ }^{\circ} \mathrm{C}\right)\end{array}$ & $\begin{array}{c}\text { stripe 2 } \\
\text { avg temp } \\
\left({ }^{\circ} \mathrm{C}\right)\end{array}$ & $\begin{array}{c}\text { stripe 3 } \\
\text { avg temp } \\
\left({ }^{\circ} \mathrm{C}\right)\end{array}$ & $\begin{array}{c}\text { stripe 4 } \\
\text { avg temp } \\
\left({ }^{\circ} \mathrm{C}\right)\end{array}$ \\
\hline $\begin{array}{c}\text { Axial } \\
1\end{array}$ & 88.15 & 75.64 & 77.16 & 91.96 \\
2 & 82.34 & 72.32 & 72.60 & 85.69 \\
3 & 85.93 & 76.13 & 77.18 & 88.05 \\
4 & 89.02 & 79.63 & 79.94 & 91.51 \\
5 & 91.05 & 82.04 & 82.74 & 94.73 \\
6 & 93.44 & 83.92 & 84.71 & 97.16 \\
7 & 95.50 & 85.30 & 85.79 & 98.80 \\
8 & 96.01 & 85.88 & 86.87 & 100.35 \\
9 & 97.30 & 86.37 & 87.56 & 101.22 \\
10 & 99.29 & 87.23 & 88.22 & 102.28 \\
11 & 97.77 & 86.61 & 87.51 & 101.97 \\
12 & 96.45 & 85.18 & 86.24 & 100.88 \\
13 & 94.68 & 83.80 & 85.00 & 98.83 \\
14 & 92.61 & 82.13 & 83.19 & 97.27 \\
15 & 91.03 & 80.44 & 81.64 & 95.68 \\
16 & 94.53 & 83.20 & 84.05 & 100.01 \\
\hline
\end{tabular}


ANL/RTR/TM-21/3

\begin{tabular}{c|c|c|c|c}
$\begin{array}{c}\text { PLATE } \\
15\end{array}$ & $\begin{array}{c}\text { stripe 1 } \\
\text { avg temp } \\
\left({ }^{\circ} \mathrm{C}\right)\end{array}$ & $\begin{array}{c}\text { stripe 2 } \\
\text { avg temp } \\
\left({ }^{\circ} \mathrm{C}\right)\end{array}$ & $\begin{array}{c}\text { stripe 3 } \\
\text { avg temp } \\
\left({ }^{\circ} \mathrm{C}\right)\end{array}$ & $\begin{array}{c}\text { stripe 4 } \\
\text { avg temp } \\
\left({ }^{\circ} \mathrm{C}\right)\end{array}$ \\
\hline 1 & 89.91 & 76.78 & 77.92 & 93.33 \\
2 & 83.46 & 73.22 & 73.49 & 86.33 \\
\hline 3 & 87.08 & 77.14 & 77.32 & 89.32 \\
\hline 4 & 89.74 & 80.57 & 80.99 & 92.88 \\
\hline 5 & 92.28 & 83.26 & 83.84 & 96.36 \\
6 & 93.72 & 85.39 & 86.05 & 98.50 \\
\hline 7 & 96.36 & 86.16 & 87.39 & 100.14 \\
8 & 96.52 & 87.33 & 88.65 & 102.01 \\
\hline 9 & 98.17 & 87.76 & 89.20 & 103.31 \\
10 & 99.04 & 88.57 & 89.74 & 103.57 \\
11 & 98.73 & 88.17 & 89.14 & 103.74 \\
12 & 97.48 & 86.80 & 87.95 & 102.21 \\
13 & 95.69 & 85.43 & 86.63 & 101.24 \\
\hline 14 & 93.33 & 83.58 & 84.85 & 99.30 \\
15 & 91.35 & 81.63 & 83.13 & 97.10 \\
16 & 94.95 & 84.35 & 85.64 & 101.56 \\
\hline
\end{tabular}

\begin{tabular}{ccccc}
$\begin{array}{c}\text { PLATE } \\
16\end{array}$ & $\begin{array}{c}\text { stripe 1 } \\
\text { avg temp } \\
\left({ }^{\circ} \mathrm{C}\right)\end{array}$ & $\begin{array}{c}\text { stripe 2 } \\
\text { avg temp } \\
\left({ }^{\circ} \mathrm{C}\right)\end{array}$ & $\begin{array}{c}\text { stripe 3 } \\
\text { avg temp } \\
\left({ }^{\circ} \mathrm{C}\right)\end{array}$ & $\begin{array}{c}\text { stripe 4 } \\
\text { avg temp } \\
\left({ }^{\circ} \mathrm{C}\right)\end{array}$ \\
\hline 1 & 91.23 & 79.12 & 80.09 & 95.60 \\
2 & 84.02 & 74.75 & 75.16 & 88.05 \\
3 & 87.38 & 78.64 & 78.95 & 91.66 \\
4 & 90.25 & 82.16 & 82.98 & 95.62 \\
5 & 93.91 & 84.72 & 85.39 & 98.10 \\
6 & 94.98 & 86.35 & 87.76 & 100.65 \\
7 & 97.50 & 88.17 & 89.09 & 101.48 \\
8 & 97.26 & 88.55 & 89.63 & 103.42 \\
9 & 98.95 & 89.57 & 91.26 & 104.95 \\
10 & 100.75 & 90.46 & 91.62 & 105.55 \\
11 & 99.51 & 89.77 & 90.75 & 105.09 \\
12 & 97.55 & 88.26 & 89.62 & 103.87 \\
13 & 95.72 & 86.55 & 87.87 & 102.20 \\
14 & 93.50 & 84.65 & 85.62 & 99.97 \\
15 & 91.43 & 82.31 & 83.96 & 98.08 \\
16 & 94.74 & 85.31 & 86.61 & 102.22 \\
\hline & & & & \\
\hline
\end{tabular}

\begin{tabular}{ccccc}
$\begin{array}{c}\text { PLATE } \\
17\end{array}$ & $\begin{array}{c}\text { stripe 1 } \\
\text { avg temp } \\
\left({ }^{\circ} \mathrm{C}\right)\end{array}$ & $\begin{array}{c}\text { stripe 2 } \\
\text { avg temp } \\
\left({ }^{\circ} \mathrm{C}\right)\end{array}$ & $\begin{array}{c}\text { stripe 3 } \\
\text { avg temp } \\
\left({ }^{\circ} \mathrm{C}\right)\end{array}$ & $\begin{array}{c}\text { stripe 4 } \\
\text { avg temp } \\
\left({ }^{\circ} \mathrm{C}\right)\end{array}$ \\
\hline 1 & 79.86 & 71.94 & 73.02 & 84.37 \\
2 & 74.74 & 68.51 & 68.86 & 77.96 \\
3 & 77.01 & 70.90 & 71.91 & 80.74 \\
4 & 79.72 & 74.33 & 74.66 & 83.96 \\
\hline 5 & 82.15 & 76.22 & 77.35 & 86.53 \\
6 & 83.74 & 78.17 & 79.20 & 88.33 \\
\hline 7 & 85.35 & 79.28 & 80.62 & 90.36 \\
8 & 86.36 & 79.99 & 81.31 & 91.08 \\
9 & 87.87 & 81.72 & 82.89 & 92.93 \\
10 & 89.30 & 82.88 & 83.74 & 94.96 \\
\hline 11 & 88.75 & 82.51 & 83.46 & 94.48 \\
12 & 87.88 & 81.59 & 82.78 & 93.90 \\
13 & 86.55 & 79.81 & 81.16 & 92.51 \\
14 & 85.36 & 79.02 & 80.25 & 91.64 \\
15 & 83.94 & 77.72 & 78.55 & 90.42 \\
16 & 87.21 & 80.12 & 81.41 & 94.21 \\
\hline & & & & \\
\hline 16 & & & & \\
\hline
\end{tabular}

\begin{tabular}{ccccc}
$\begin{array}{c}\text { PLATE } \\
18\end{array}$ & $\begin{array}{c}\text { stripe 1 } \\
\text { avg temp } \\
\left({ }^{\circ} \mathrm{C}\right)\end{array}$ & $\begin{array}{c}\text { stripe 2 } \\
\text { avg temp } \\
\left({ }^{\circ} \mathrm{C}\right)\end{array}$ & $\begin{array}{c}\text { stripe 3 } \\
\text { avg temp } \\
\left({ }^{\circ} \mathrm{C}\right)\end{array}$ & $\begin{array}{c}\text { stripe } 4 \\
\text { avg temp } \\
\left({ }^{\circ} \mathrm{C}\right)\end{array}$ \\
\hline 1 & 83.10 & 75.37 & 76.24 & 87.49 \\
2 & 76.09 & 70.30 & 70.83 & 80.51 \\
3 & 78.51 & 73.21 & 74.15 & 82.79 \\
4 & 81.66 & 75.84 & 76.87 & 85.48 \\
5 & 83.31 & 78.31 & 79.28 & 88.91 \\
6 & 84.82 & 79.94 & 80.87 & 91.14 \\
7 & 86.57 & 81.36 & 82.32 & 92.06 \\
8 & 86.93 & 81.74 & 83.33 & 92.74 \\
9 & 89.43 & 83.42 & 84.94 & 95.19 \\
10 & 90.65 & 85.39 & 86.16 & 97.74 \\
11 & 89.94 & 84.64 & 85.60 & 97.34 \\
12 & 89.01 & 83.56 & 84.95 & 95.74 \\
13 & 86.96 & 81.71 & 82.89 & 93.90 \\
14 & 85.31 & 80.39 & 81.48 & 92.22 \\
15 & 83.44 & 78.56 & 79.84 & 90.78 \\
16 & 87.27 & 81.34 & 82.78 & 95.28 \\
\hline
\end{tabular}




\begin{tabular}{|c|c|c|c|c|}
\hline $\begin{array}{c}\text { PLATE } \\
19\end{array}$ & $\begin{array}{l}\text { stripe } 1 \\
\text { avg temp } \\
\text { (C) }\end{array}$ & $\begin{array}{l}\text { stripe } 2 \\
\text { avg temp } \\
\text { (C) }\end{array}$ & $\begin{array}{l}\text { stripe } 3 \\
\text { avg temp } \\
\text { (C) }\end{array}$ & $\begin{array}{c}\text { stripe } 4 \\
\text { avg temp } \\
\text { (C) }\end{array}$ \\
\hline 1 & 78.91 & 73.49 & 74.63 & 83.37 \\
\hline 2 & 72.30 & 68.00 & 68.44 & 75.98 \\
\hline 3 & 73.76 & 70.20 & 70.90 & 77.58 \\
\hline 4 & 76.34 & 72.17 & 73.09 & 79.94 \\
\hline 5 & 77.76 & 74.37 & 75.14 & 82.76 \\
\hline 6 & 79.12 & 75.52 & 77.10 & 84.66 \\
\hline 7 & 80.09 & 76.74 & 77.82 & 85.36 \\
\hline 8 & 80.32 & 77.36 & 77.94 & 86.16 \\
\hline 9 & 82.62 & 79.17 & 80.18 & 89.00 \\
\hline 10 & 85.25 & 81.26 & 82.52 & 91.21 \\
\hline 11 & 84.51 & 80.83 & 81.89 & 90.55 \\
\hline 12 & 83.02 & 79.20 & 80.49 & 89.32 \\
\hline 13 & 81.01 & 77.72 & 78.80 & 87.41 \\
\hline 14 & 79.58 & 76.27 & 77.79 & 86.00 \\
\hline 15 & 77.65 & 74.47 & 75.74 & 84.53 \\
\hline 16 & 81.14 & 77.50 & 79.21 & 88.91 \\
\hline
\end{tabular}




\section{APPENDIX C: Additional Mesh Sensitivity Study}

Figure C.1 shows the dependency of the maximum displacements on the number of DOFs in the model for line load cases with various end fitting geometries: MITR LEU, MITR DDE, and no top end fitting. The difference between the maximum displacement for the normal mesh (white data points on the plot) and the coarse mesh is at or below $0.7 \%$ for all three models. The difference in the results for the fine mesh and the normal mesh is around $0.2 \%$ which indicates that the results are well converged.
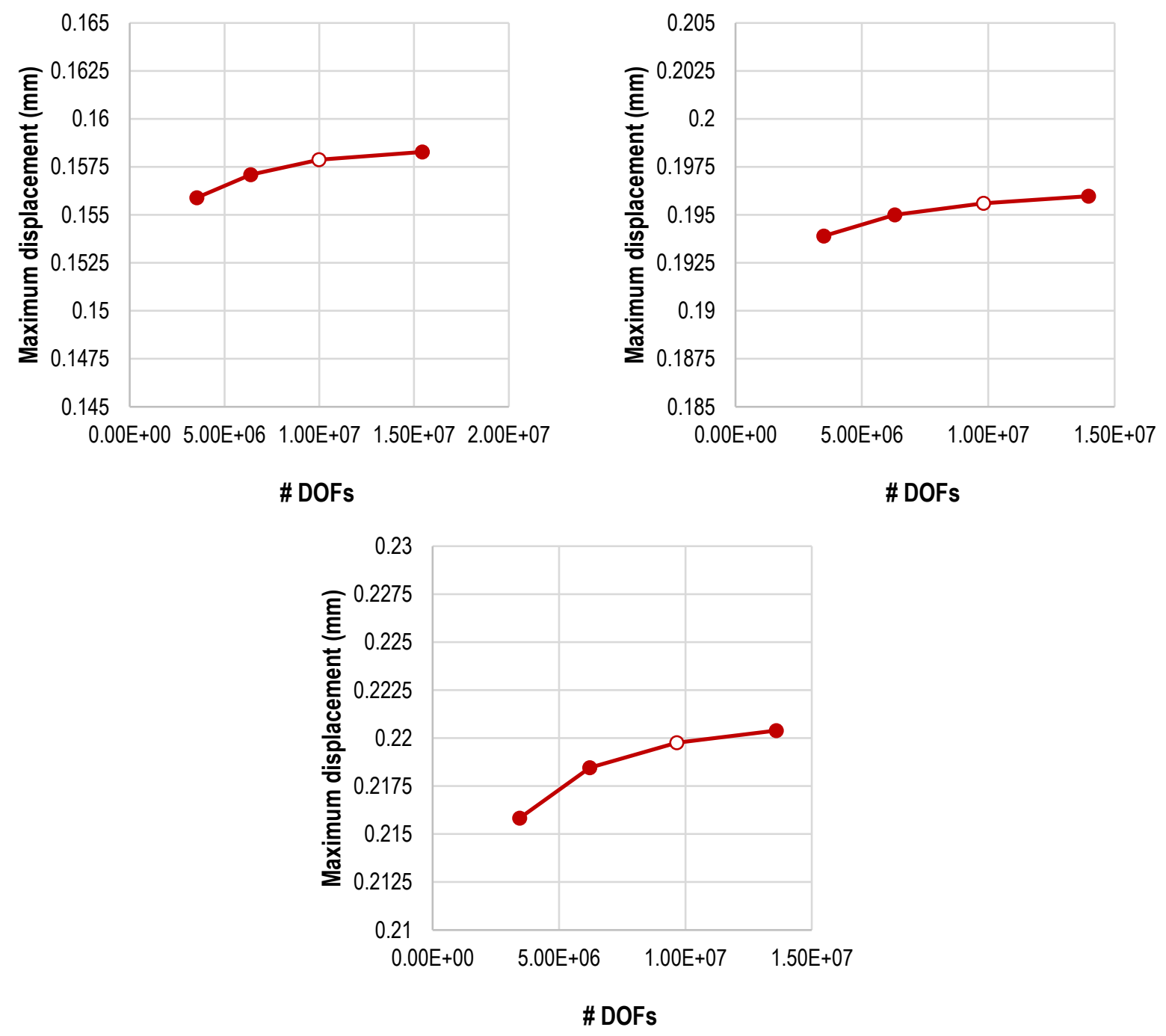

Figure C.1. Dependency of maximum displacements on number of DOFs in the model for line load cases with the following geometries: MITR LEU end fittings (top left), MITR DDE end fittings (top right), and element without top end fitting (bottom). 
Figure C.2 shows the dependency of the maximum displacements on the number of DOFs in the model for hydraulic load cases with various end fitting geometries: MITR LEU, MITR DDE, and no top end fitting. The difference between the maximum displacement for the normal mesh (white data points on the plot) and the coarse mesh is around $1.6 \%$ for all three models. The difference in the results for the fine mesh and the normal mesh is around $0.7 \%$ which indicates that the results are converged.
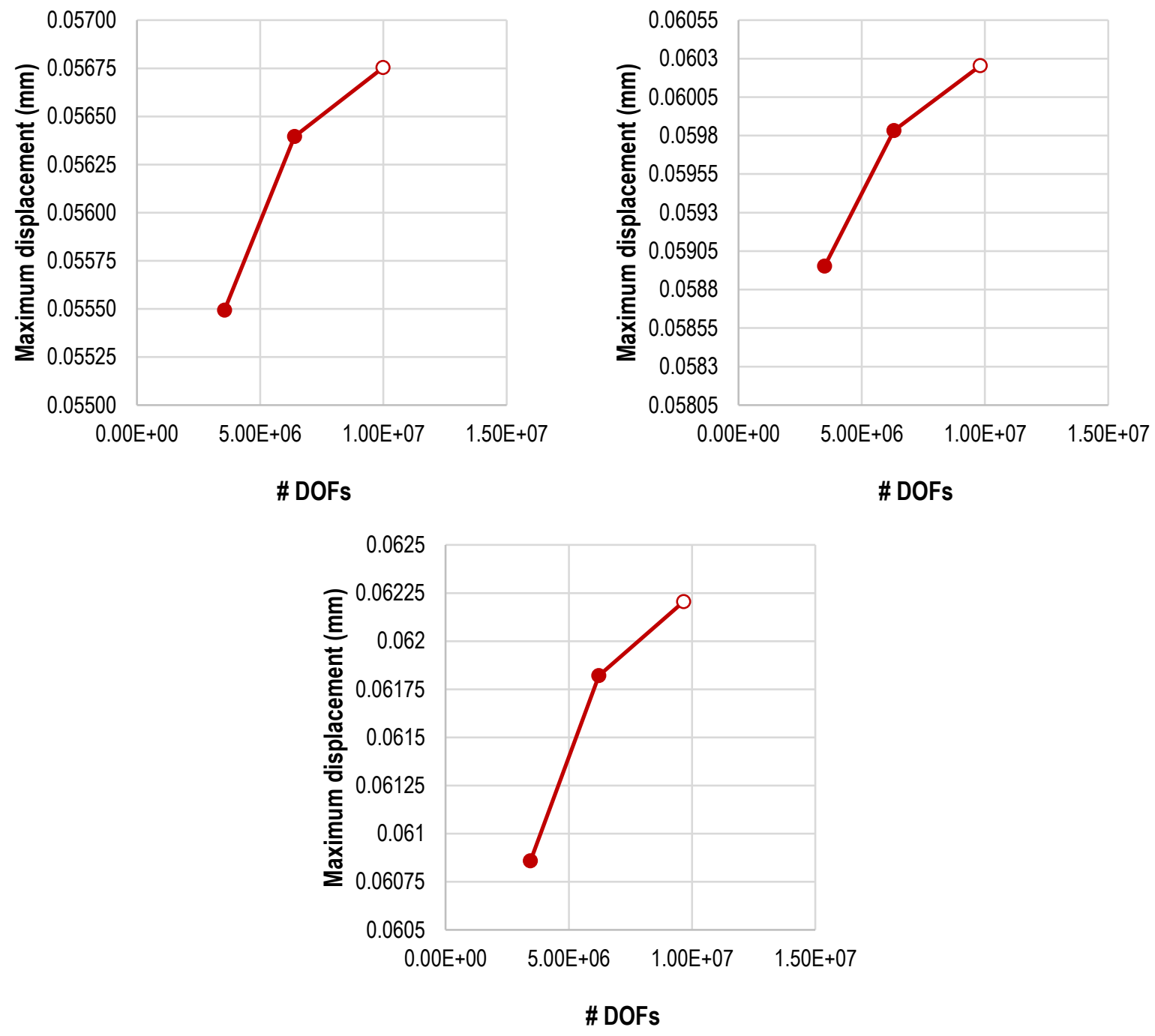

Figure C.2. Dependency of maximum displacements on number of DOFs in the model for hydraulic load cases with the following geometries: MITR LEU end fittings (top left), MITR DDE end fittings (top right), and element without top end fitting (bottom). 
Figure C.3 shows the dependency of the maximum displacements on the number of DOFs in the model for thermal load cases with various end fitting geometries: MITR LEU, MITR DDE, and no top end fitting. The difference between the maximum displacement for the normal mesh (white data points on the plot) and the coarser meshes is lower than $0.01 \%$ which indicates that the results are converged.
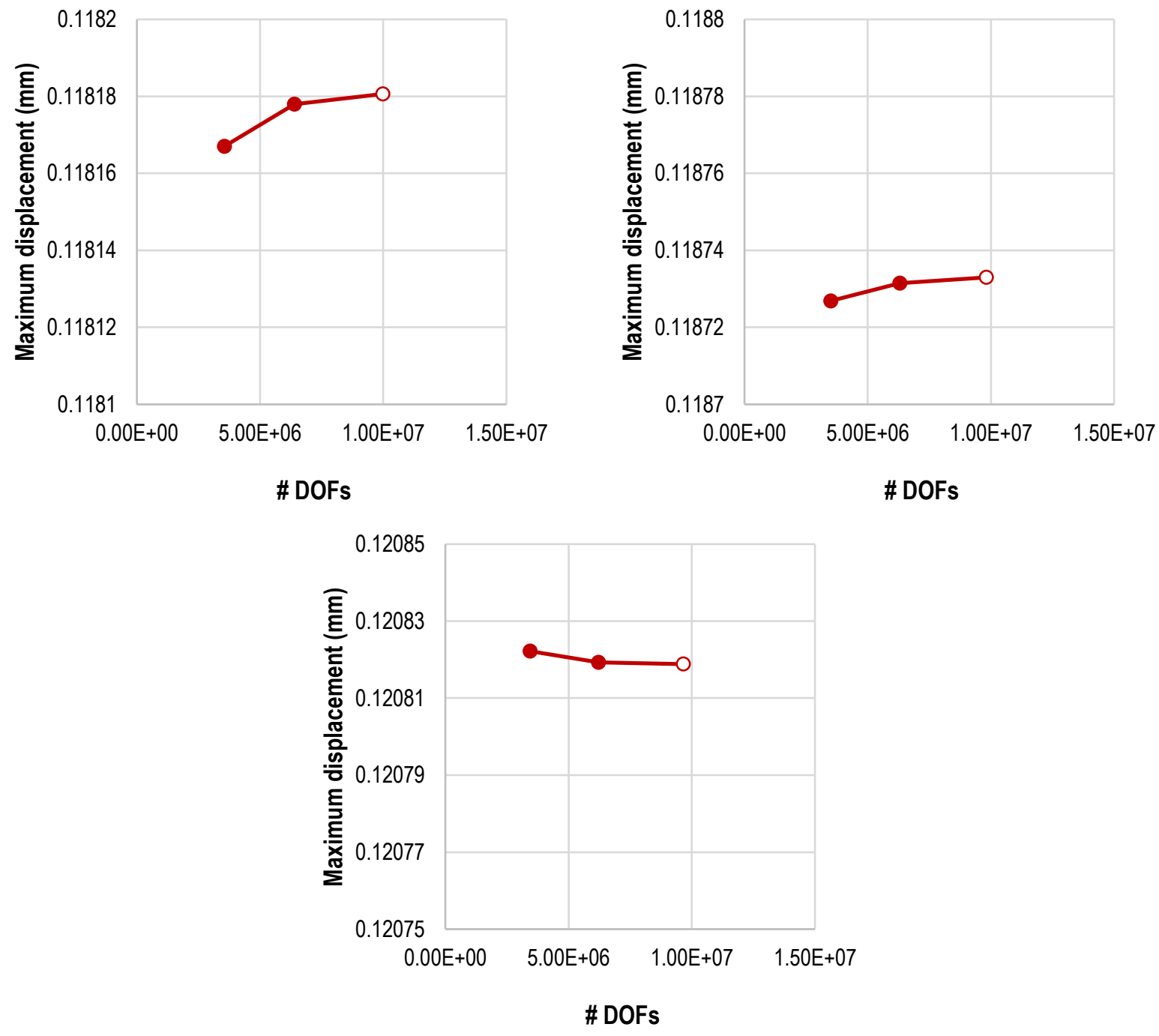

Figure C.3. Dependency of maximum displacements on number of DOFs in the model for thermal load cases with the following geometries: MITR LEU end fittings (top left), MITR DDE end fittings (top right), and element without top end fitting (bottom). 


\section{Argonne}

Nuclear Science \& Engineering Division

Argonne National Laboratory

9700 South Cass Avenue, Bldg. 208

Lemont, IL 60439

www.anl.gov 